\title{
Investment is style and strategy
}

Citation for published version (APA):

Ramezanifar, E. (2018). Investment is style and strategy. [Doctoral Thesis, Maastricht University]. Maastricht University. https://doi.org/10.26481/dis.20180228er

Document status and date:

Published: 01/01/2018

DOI:

10.26481/dis.20180228er

Document Version:

Publisher's PDF, also known as Version of record

\section{Please check the document version of this publication:}

- A submitted manuscript is the version of the article upon submission and before peer-review. There can be important differences between the submitted version and the official published version of record.

People interested in the research are advised to contact the author for the final version of the publication, or visit the DOI to the publisher's website.

- The final author version and the galley proof are versions of the publication after peer review.

- The final published version features the final layout of the paper including the volume, issue and page numbers.

Link to publication

\footnotetext{
General rights rights.

- You may freely distribute the URL identifying the publication in the public portal. please follow below link for the End User Agreement:

www.umlib.nl/taverne-license

Take down policy

If you believe that this document breaches copyright please contact us at:

repository@maastrichtuniversity.nl

providing details and we will investigate your claim.
}

Copyright and moral rights for the publications made accessible in the public portal are retained by the authors and/or other copyright owners and it is a condition of accessing publications that users recognise and abide by the legal requirements associated with these

- Users may download and print one copy of any publication from the public portal for the purpose of private study or research.

- You may not further distribute the material or use it for any profit-making activity or commercial gain

If the publication is distributed under the terms of Article $25 \mathrm{fa}$ of the Dutch Copyright Act, indicated by the "Taverne" license above, 




\section{Investment is style and strategy}

\section{DISSERTATION}

to obtain the degree of Doctor at the Maastricht University, on the authority of the Rector Magnificus, Prof. Dr. Rianne M. Letschert, in accordance with the decision of the Board of Deans, to be defended in public on Wednesday, February 28, 2018 at 16:00

by

Ehsan Ramezanifar 
Supervisor:

Prof. Dr. Dennis Bams

\section{Co-supervisor:}

Dr. Roger Otten

\section{Assessment Committee:}

Prof. Dr. Rob Bauer (chair)

Prof. Dr. Roger Meuwissen

Prof. Dr. Thorsten Lehnert, University of Luxembourg, Luxembourg Dr. Laurens Swinkels, Erasmus University of Rotterdam 
Acknowledgement 
When I was 15 years old, my mother told me that she bought some stocks of a mineral company. However, at that time she had no idea (and still does not have any idea!) about the price, risk and return of the stock she bought! Therefore, she decided to make the following deal with me: I should check and report the stock price to her every month and if the stock price goes beyond a specific threshold, she would pay me $20 \%$ of that return!! I was excited and started to check stock prices every day. Although my mother's stock never even got close to the threshold up until today, this deal introduced me to the stock exchange market and triggered my financial interests! I was especially fascinated by stock price movements, news and technical analysis, yet I had no idea about the market's behaviour. Later, during my undergraduate program, I took a course of "Financial management" that just lit the fire in me and gave me lots of insights about how the financial markets work. This was a beginning of my journey in finance!

During this journey, last year, I had the tremendous opportunity to become a colleague of Prof. Harry Markowitz, the father of modern portfolio theory, a 90-year old professor, who still teaches, does research and writes a book (and surprisingly, he still drives!). Harry gave me a very important lesson that I never forget: "the only way to do a great job is to follow your passion".

Many other great people also contributed to and supported me on my journey and I am deeply thankful to everyone who crossed my path the last three years. My first words of thanks go to my promoter, Dennis Bams. Dennis, I am greatly indebted to you and you know that words cannot describe what I owe you. You are an amazing coach, motivator and never-ending supporter. Whenever you made a promise, you did your best to make it happen. You taught me countless lessons. The combination of you and Roger Otten perfectly suited my passion for research. Roger, your great knowledge and experience from industry always inspired my ideas and research. Thank you for always encouraging me to take on new challenges. 
In fall 2016, I had the chance to visit the University of California, San-Diego, I am deeply grateful towards Allan Timmerman, who shaped me as a researcher. Allan, your knowledge and enthusiasm were an incredible source of inspiration and I would like to thank you for all your support. Also I want to thank Mark Kamstra, from the York University, and Lisa Kramer, from the University of Toronto, who are the kindest academics I got to know. Your supports and our brainstorming were simply amazing.

I would like to thank all members of my reading committee for taking the time to evaluate my dissertation: Prof. Dr. Rob Bauer, Prof. Dr. Roger Meuwissen, Prof. Dr. Torsten Lehnert, Dr. Laurens Swinkels. I am grateful for your timely and helpful assessment of the dissertation.

I can say that I am lucky and I also feel very honored to have been member of the finance department at Maastricht University. First, I would like to thank Paul Smeets. Paul, without any exaggeration you are the coolest academic researcher that I have ever met. Our trips in Orlando and Miami were among the highlights during my Ph.D. It is always great to talk to you about research and life. Further, I want to especially thank Rob Bauer for being my career role model. Rob, you showed me how it is possible to combine academia with industry. Also thanks to Paulo Rodrigues, who is truly a superhero for $\mathrm{PhD}$ candidates. Paulo, your feedback and comments on my research were always very helpful. I would like to thank Jaap Bos for all his great advice and support. I thank Piet Eichholtz for his contributions and positive energy that he always brought to the finance department. Thanks to Jeroen Derwall for his support so far and going forward. I also like to thank Peter Schotman, Stefan Straetmans, Stefanie Kleimeier, Thomas Post and Arvid Hoffmann for the great brainstorming sessions and conversations we had.

Very special thanks to Iman Honarvar. Iman, you have been my friend for more than 12 years and there is nothing better than hanging out with you. You were 
unofficially my third supervisor in my Ph.D. research and one of the most influential people in my life. I owe you a lot for the great lessons that I learned from you.

Many special thanks go to Els van Aernsbergen, Cecile Luijten, Francien, Schijlen, and Carina Wijnands. You are the heart of the finance department and you have always assisted me kindly and efficiently in any matter. I deeply appreciate all your help.

I like to thank all Ph.D. students at Maastricht University, in particular my constant office mate, Tobias Ruof. Tobias, for anyone who knows us, it is clear that it is a big mistake to put us together in one room. However, we shared the same office during my entire Ph.D. life in Maastricht! We had so much fun and thank you for your great company as a colleague and friend. I deeply thank Clarissa Hauptmann, who was the best officemate, the kindest colleague and of course an amazing Salsa dancer. Clarissa, I learned many wonderful lessons from your personality. I also thank Alessandro Pollastri and Inka Eberhardt for a great time during the first ASSA trip in New York, Boston and beyond. I also thank Nora Pankratz for being a great office mate and a mediator between me and Tobias. I thank Mike Langen, my German "dadash" for all the wonderful and interesting non-academic conversations we had. Further, I thank Juan Palacios Temprano, for the many incredible memories we have (especially "Stayokay").

Special thanks also go to Judith Künneke, the member of De All rescue team! We have had a lot of nice chats and laughs at SBE and particularly at your favorite place, "Basilica". I am looking forward to meeting you more often in Utrecht.

I thank all the doctoral students at the finance department of the University of California, San-Diego, especially Youngjae Choi and Ritong Qu for organizing my $\mathrm{PhD}$ colloquium and seminar. I like to thank Jan Feiling, who became a very good friend in San-Diego. Jan, maybe you do not know, but I learned a lot from your German discipline and the way you live and appreciate life. 
Acknowledgment

Thanks to all my colleagues at Open University, Faculty of Management, Science and Technology: Pieter Kamminga, Jorunn Irene Andersen and Dieter Smeulders. I am especially grateful to the great Head of the Finance Department, Willem Buijink, who is the sunshine of the department and always has lots of positive energy.

I further thank all my colleagues at Utrecht University, Faculty of Law, Economic and Governance: Utz Weitzel, Dirk Gerristen, Rients Galma, Philip Fliers, Sarah Rezaei and Diogo Geraldes.

Many thanks go to my wonderful Iranian community in Maastricht. You are the warmest people that I have met in my life. I want to thank Iman Rajabzadeh, Ahmad Salahnejhad, Naser Davarzani, Shuan SadreGhazi, Saba Mehrafza, Mehrdad Seifari, Maryam Madantjiand and Pouyan Savoli.

I am grateful for sharing my Ph.D journey with: Lidwien Sol, Luuk Perik, Rogier Holtermans, Michael Kurz, Erdal Aydin, Runliang Li, Matteo Bonetti, Marina Gertsberg, Hang Sun, Judy Chalabi, Rogier Quaedvlieg, Shusen Qi, Adarajew Tamirat, Nagihan Mimiroglu, and many more. I also thank Sanne Jongen, Sjoke Merk, Pomme Theunissen.

I further thank Sandra Schafhäutle for proof-reading, smart conversation and great company we have. I also thank Angie Mounir and Garret McLean for all their great support.

I cannot express in words how grateful I am towards my paranymphs for their friendship and all time support: Sofya Isaakyan and Mattijs Korevaar. Sofya, everyone who knows you, believes that you are the kindest person (at least!) in the Netherlands and I think no words can describe your great personality. I met you for the first time in September 2014 at the Ph.D. academy boat party in Maastricht, and kept on meeting you in Basilica and Café Cliniq by coincidence!! You helped me prepare my visit at UC San-Diego, job interviews and many other things. I can 
only say thank you so much for all you have done for me. I am really looking forward to seeing you more often in Rotterdam and Utrecht.

Matthijs, my professor bubble! Your great coffee machine at the Persian castle always made my days wonderful. You are indeed the sunshine of the castle. I learned a lot from you and I always enjoy listening to your amazing travel experiences and stories. Your patience, broad knowledge and great attitude make you a very special office mate and friend for me. Our ASSA trips in Chicago and ski trip in Austria became unforgettable memories and I hope that I can welcome you more often in Utrecht.

Last yet, most importantly, I thank my family, my parents, the kindest and most generous people in the world, my wonderful sister Nazanin and my great brother Amir. There are really no words that could describe how grateful I am for everything that you have done for me during these past years and throughout my life.

Ehsan $:$ 


\section{Contents}

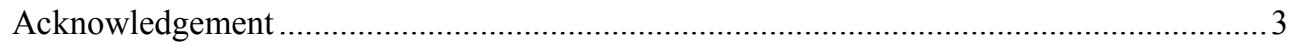

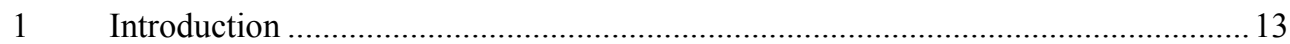

1.1 The US financial market and the market players .................................... 14

1.2 Investment style analysis in US mutual funds ........................................... 16

1.3 Algorithmic trading and Reinforcement Learning ...................................... 19

2 Investment Style Misclassification and Mutual Fund Performance ..........................23

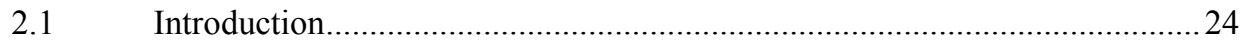

2.2 A Measure of Misclassification Level ...................................................... 30

2.2.1 Asymptotic distribution of the style estimates ................................. 30

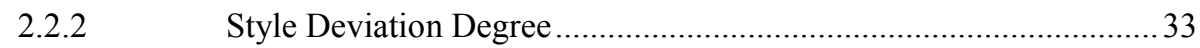

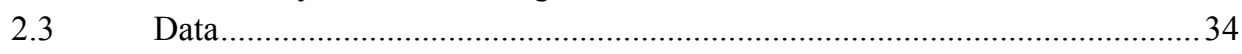

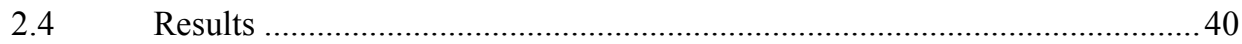

2.4.1 Investment Style Misclassification ................................................... 40

2.4.2 Style Deviation Degree and Fund Characteristics ............................43

2.4.3 Style Deviation Degree and Fund Performance.................................46

2.4.4 Persistence of Style deviation ...................................................... 49

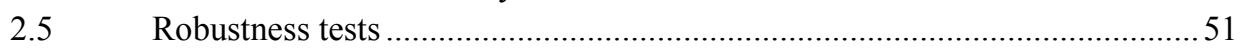

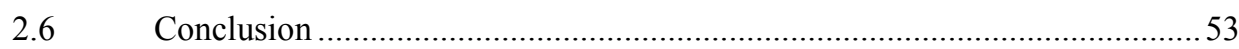

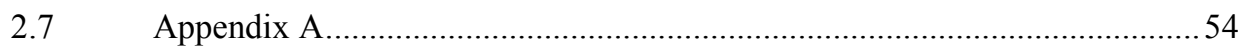

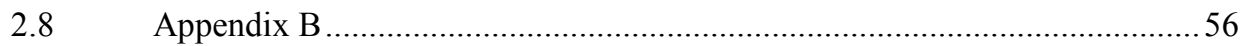

3 Investor Clientele and Style Changing Behavior in Mutual Funds ..........................61

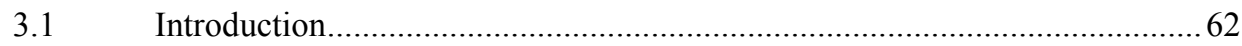

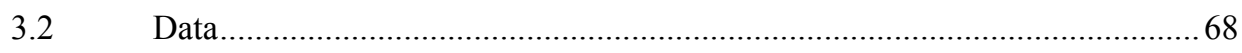

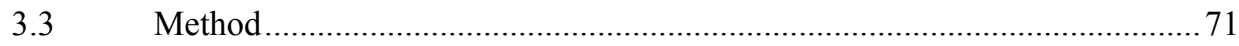

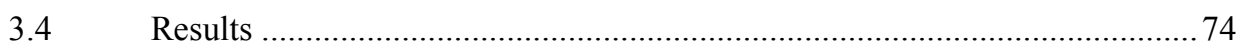

3.4.1 Institutional investors versus retail investors ................................... 74

3.4.2 Broker-sold funds versus direct-sold funds .................................... 77

3.5 Fund performance and Style deviation/ Style drift .................................. 80

3.6 Shareholder composition and fund manager incentive ................................ 82

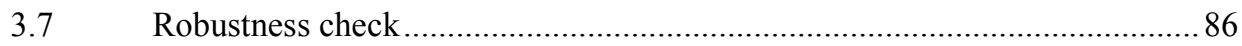

3.7.1 Convex relationship between fund flow and fund performance ........86

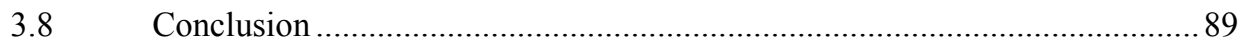

4 Pairs Trading Strategy Optimization using the Reinforcement Learning Method: A

Cointegration Approach ........................................................................................... 91

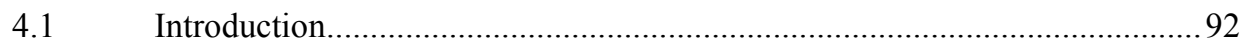

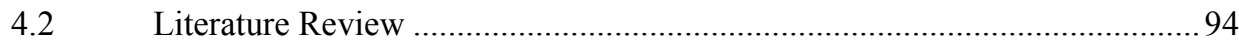

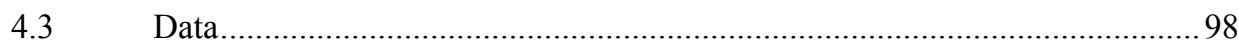

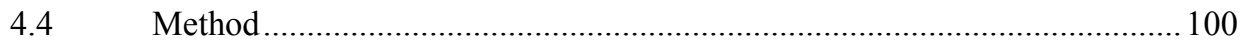




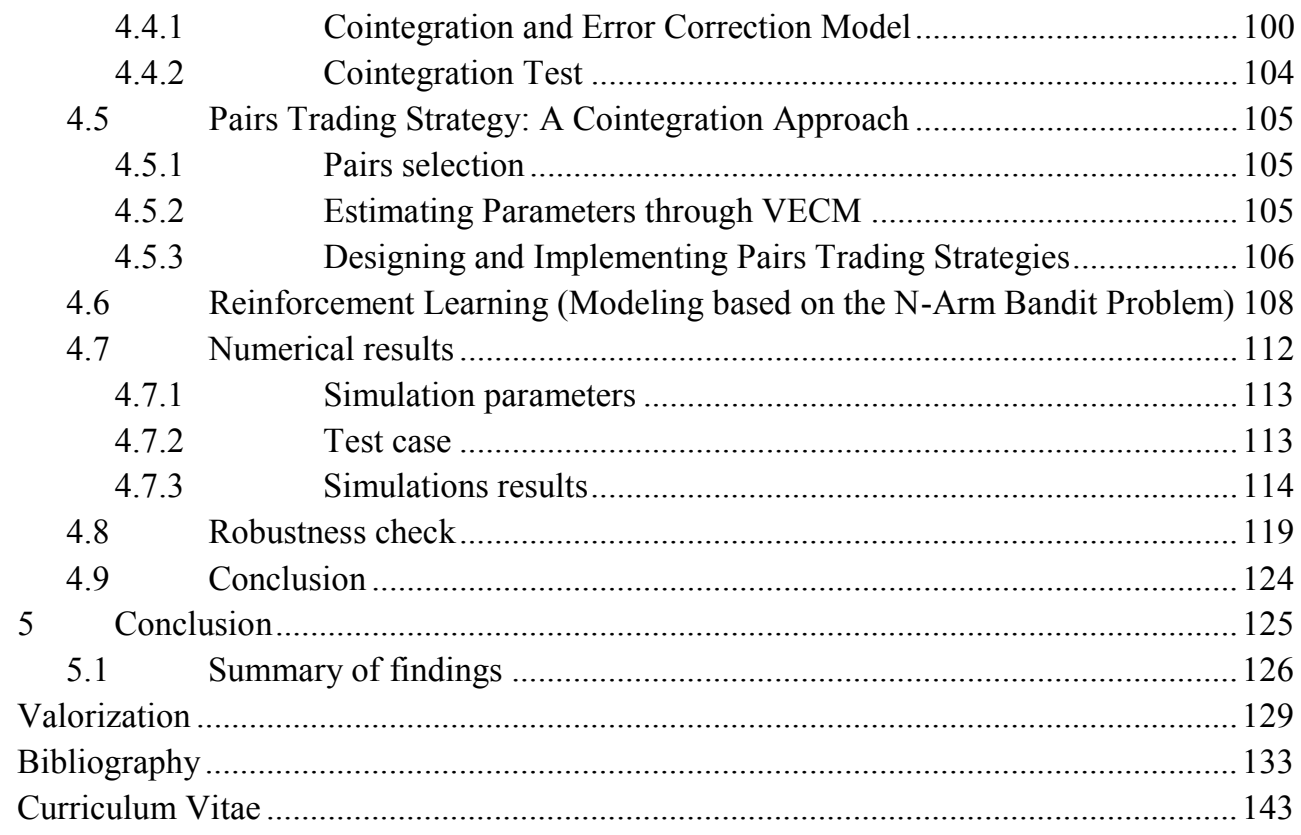




\section{List of Figures}

Figure 1-1 - Market capitalization of US listed domestic companies and US mutual funds asset over the 1990- 2016

Figure 1-2- Reinforcement learning framework for the pairs trading.................................20

Figure 2-1 - Example of different Style Deviation Degrees ................................................ 34

Figure 4-1 - Intraday prices of Amazon and Google ......................................................... 114

Figure 4-2- indicator and positions on the in-sample data of Amazon-Google pair which is

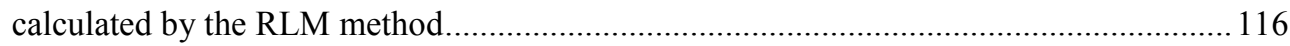

Figure 4-3- indicator and positions on the in sample data of Amazon-Google pair which is calculated by the static parameters method (SPM) 116

Figure 4-4- indicator and positions on the out of sample data of Amazon-Google pair which has been calculated by the static parameters method (SPM)

Figure 4-5- indicator and positions on the out of sample data of Amazon-Google pair which has been calculated by the proposed method (RLM) 


\section{List of Tables}

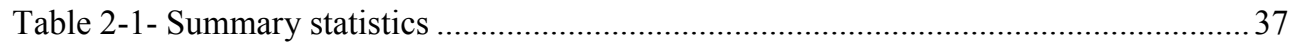

Table 2-2- Summary statistics of mutual fund characteristics .......................................... 39

Table 2-3- Equally-weighted average portfolio of funds ................................................ 40

Table 2-4- Mutual fund misclassifications based on individual fund returns ..................... 42

Table 2-5- Relationship between Style Deviation Degree and Fund Characteristics ......... 44

Table 2-6- Relation between Style Deviation Degree (SDD) and Fund Characteristics in

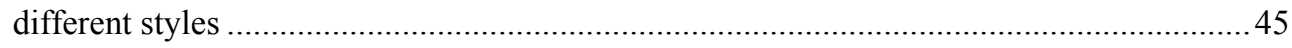

Table 2-7- Relationship between Style Deviation Degree and Fund Performance with Net

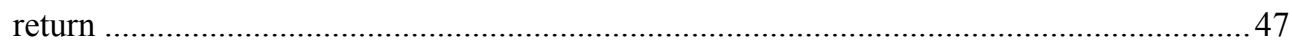

Table 2-8- Relationship between Style Deviation Degree and Fund Performance with Gross

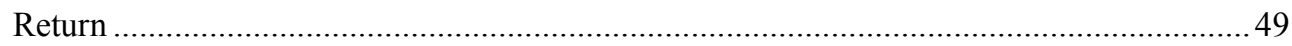

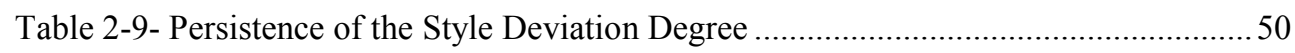

Table 2-10- Results Robustness Test RBSA model - Alternative style benchmarks- Russell

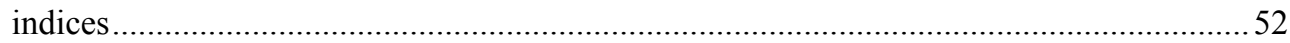

Table 2-11- Results Robustness Test RBSA model - sub-sample analysis 2003- 2009 ......57

Table 2-12- Results Robustness Test RBSA model - sub-sample analysis 2009- 2016 ......58

Table 2-13- Relationship between Style Deviation Degree and Fund Performance by using

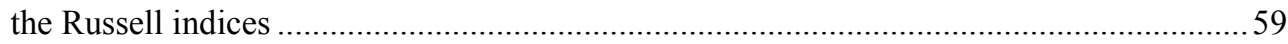

Table 2-14- Relationship between Style Deviation Degree and Fund Characteristics by

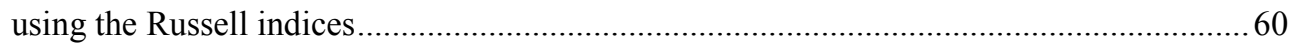

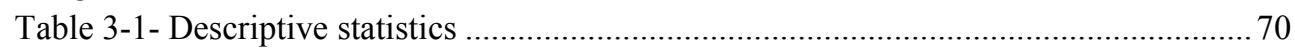

Table 3-2- Style Deviation Degree (SDD) and Style Drift Score (SDS) ............................. 73

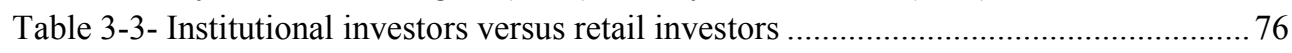

Table 3-4- Broker-sold versus direct-sold mutual funds .................................................... 79

Table 3-5- Fund performance and style deviation/drift ..................................................... 81

Table 3-6- Shareholder composition and fund manager incentive ....................................... 85

Table 3-7- Convexity of the future fund flow and fund performance ................................. 88

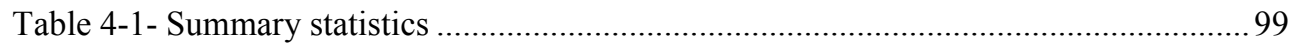

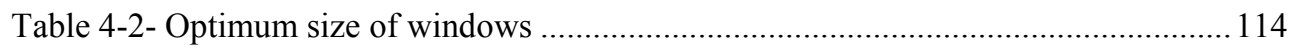

Table 4-3- simulation results on Amazon-Google pair in the in sample and out of sample

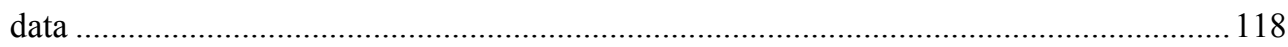

Table 4-4- The results of the RLM and the static parameters method (SPM) on the different

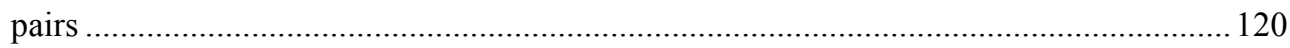

Table 4-5- The results of the RLM method (RLM) and the static parameters method (SPM)

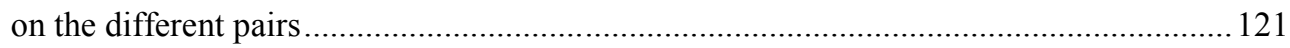

Table 4-6- The results of the RLM method and the static parameters method (SPM) on the

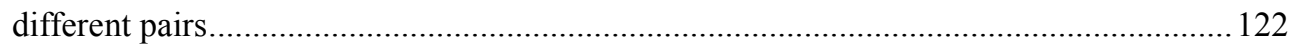

Table 4-7- Copmaring the results of five-pair stocks from two methods ........................ 123 


\section{Chapter 1}

\section{Introduction}




\subsection{The US financial market and the market players}

In the 1990s, the US financial market boomed and the market capitalization of listed domestic companies rose from a level of \$3 trillion to more than $\$ 27$ trillion in 2016. An increase in the number of financial intermediaries and the exploitation of developments in information technology among other factors had a tremendous effect on the flourishing of the US financial market over the last two decades. Financial intermediaries like mutual fund industry managed more than $\$ 16$ trillion in assets at year-end 2016, largely on behalf of more than 95 million US retail investors and many institutional investors (2017 Investment Company Fact book). On the other hand, the bloom of the US financial market is also due to the rapid development of information technology that removes geographical barriers and brings more efficiency and liquidity to the financial market. This dissertation highlights these two subjects, more specifically in the field of the US mutual fund industry and in algorithmic trading.

The growth rate of mutual funds asset has been even higher than the growth rate of US financial market assets; assets under management of mutual funds rose from $\$ 1$ trillion in 1990 to more than $\$ 16$ trillion in $2016 .{ }^{1}$ As an illustration of these trends, Figure 1-1 depicts the market capitalization of US listed domestic companies and US mutual funds asset, over the 1990- 2016 period. Over the years, as assets under management in the mutual fund industry have grown, the importance of this industry among researchers, policy makers and practitioners have also increased. In particular, the focus is on the better understanding of the functioning of this industry to make sure that mutual fund managers act in the best interest of their investors.

\footnotetext{
${ }^{1}$ Although there are other types of funds play an important role in this industry, the size of assets under management of mutual funds in comparison with other types of funds is substantially larger. For example, in 2016 ETFs hold only 13\% of total assets under management of the US-registered investment companies, in which Mutual funds hold $85 \%$ of total assets (2017 Investment Company Fact book).
} 
One of the most controversial issues in the mutual fund industry that can lead to a potential conflict of interest between fund managers and investors is when funds deviate from the stated investment objectives. This behaviour can cause investors to be exposed to different types and levels of risks. For example, someone could have purchased a value mutual fund, but might have ended up with growth stocks in the fund. We refer to this as an investment style deviation.

The second and third chapters of this dissertation address the investment style deviation issue and carry out an investment style analysis in the mutual fund industry. More specifically, the second chapter introduces a novel measure to capture the gap between the stated investment style and the actual investment style of mutual funds and explores the consequences of style deviation on long-term fund performance. The third chapter shows how investors with different sophistication level react to a change in investment style.

In addition, over the last decade, the nature of market participants has changed from absolute traditional investors to more sophisticated robots. In the early $21^{\text {st }}$ century, the merger of electronic trading mechanisms with information technology resulted in Algorithmic-Trading which delegates trading decisions to computer programs. Algorithmic trading by increasing number of trades and exploiting market frictions improves liquidity and the in formativeness of quotes in the market and eventually contributes to the welfare of market participants (Hendershott and Menkveld 2011). Although algorithmic trading is one of the hottest areas of capital expenditure for Wall Street firms, surprisingly it has not received a lot of attention from academia (Glantz and Kissell 2013). The last chapter of this dissertation focuses on algorithmic trading and attempts to find an optimal solution for a pairs trading platform through machine learning methods. 
Chapter 1

Figure 1-1- Market capitalization of US listed domestic companies and US mutual funds asset over the 1990- 2016

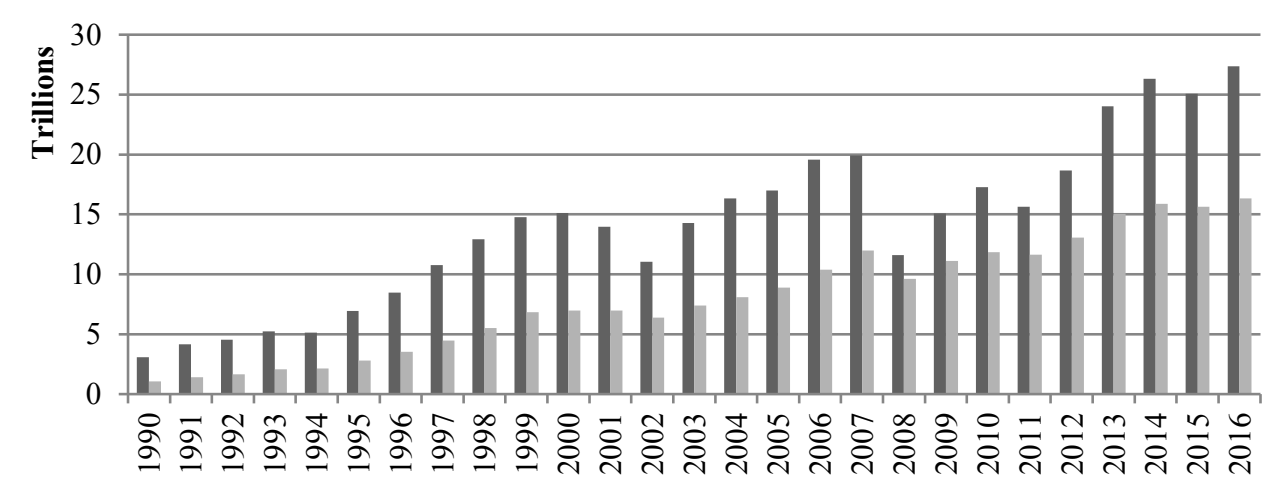

- Market capitalization of listed domestic companies

Total asset of US Mutual funds

\subsection{Investment style analysis in US mutual funds}

Investors decide to participate in a mutual fund that meets their desired risk and return profile. A mutual fund summarizes its investment strategy and investment policy including an expectation regarding future risk and return in the investment objective statement. To improve the transparency of fund investment, in 2002, the US Security and Exchange Commission (SEC) mandated all mutual fund managers to maintain a minimum of 80 percent of the value of the portfolio in securities that are consistent with the fund's stated investment style. Moreover, in 2004, SEC mandated mutual funds to increase the frequency of portfolio discourse from a semiannually basis to a quarterly basis. Despite the 80 percent rule of SEC and the high frequent portfolio disclosure policy, many previous studies have shown a deviation between the stated investment objective in the prospectus and the actual investment style of the mutual fund.

The investment style deviation behaviour has potentially serious consequences for investors because it may result in an overall risk and return profile of an investor's 
investment portfolio that does not meet the desired profile, e.g. bearing an unforeseen risk or insufficiently diversification in the portfolio. For instance, an institutional investor (such as a pension plan sponsor) may select a few actively managed mutual funds with different investment styles. Therefore, if all mutual funds follow similar styles, the overall risk of the portfolio is highly undiversified. Such style deviation may only be the tip of the iceberg. Hence it is natural to ask how we can measure the extent of style deviation with a certain confidence level.

On one hand, the quarterly portfolio holding report only represents the positions of underlying assets at the reported dates, while the exact holding of portfolio over three-month is unknown. ${ }^{2}$ Moreover, some funds use a window-dressing technique to hide the real investment strategy from the competitors. On the other hand, more frequent fund holding data like a monthly basis is unlikely. For example, Wermers (2001) and Parida and Teo (2016) show that due to existing of copy-caters, free riders and front-runners in the mutual fund industry, more frequent disclosure of portfolio holdings can have a negative effect on the performance of the fund. Thus, investment style analysis based on the fund portfolio holding data might be subject to significant measurement error. For this reason, investors and regulators need a reliable measure of investment style analysis without using mutual funds portfolio holding data to capture investment style deviations accounting for the abovementioned uncertainty. Yet, the growing literature on mutual funds investment style analysis has not focused on providing a single statistic that takes into account the level of style deviation with confidence level.

Chapter 2 of this dissertation addresses mutual fund style deviation using a novel and more granular measure, which summarizes the gap between actual investment style and stated investment style in a single statistic with a certain confidence level. While previous work drew upon results from a binary approach by comparing well- versus misclassified funds we define a continuous measure that allows for a

\footnotetext{
${ }^{2}$ Mutual funds have even 60 days after end of the fiscal quarter to disclose their portfolio holdings.
} 


\section{Chapter 1}

more granular investigation of the level of style misclassification and the impact of this on long-term fund performance. Moreover, in contrast to previous studies that use Morningstar investment style classification, we extract the stated investment style of funds from their prospectuses directly. We ended up with a sample of 1,866 US equity mutual funds with monthly returns over the period 2003-2016. We next examine the relation between the level of style deviation and fund performance on a long-term basis and we also address what kind of mutual funds are more likely to be misclassified. Overall, we find that: (1) mutual funds differ substantially in their commitments to the stated investment style, (2) using our more granular approach we find that the most misclassified funds significantly underperform well-classified funds by $1.73 \%$ per year based on Carhart alpha of gross return, and (3) misclassified funds appear to be younger, smaller in size and charge higher expense ratios. In addition to these findings, misclassification seems to be a persistent phenomenon instead of short-term negligence.

While we learn in chapter 2 that the investment style of many US mutual funds drift or even change over time, in chapter 3 we examine different clienteles' reactions to this behaviour. More specifically, we test how investors with different levels of sophistication respond to the style changing behaviour of mutual fund managers. Previous studies have shown that investors with different sophistication levels have different abilities and tools to monitor changes in a fund's investment style. Therefore, we expect that investors have a different understanding about fund style deviation and they react differently to this behaviour.

Although some of the style deviations might have occurred unintentionally, Cooper, Gulen and Rau (2005) and Sensoy (2009) show that funds likely deliberately change styles to attract new fund flows. While prior studies on fund investors' sensitivity to style deviation treat all investors as a homogeneous group, we extend this literature by considering the heterogeneity of fund flows with respect to the heterogeneity in their clientele. Hence, by using the fine granularity 
of daily mutual fund data, we show that less sophisticated investors reward stylechanging behaviour by an increase in fund flow, while more sophisticated investors punish this behaviour by redemption.

We then examine potential explanations of the heterogeneity in fund flow with respect to style deviation. First, we test whether a result of style changing behaviour may relate to the different impact of style deviation/drift on different fund performance measures. Second, we investigate the possibility that the presence of less informed investors in mutual funds may be an incentive for fund managers to deviate from the stated investment style. Hence, a strong relationship between the presence of unsophisticated investors and the subsequent change in a fund's investment style may partially explain the heterogeneity in fund flows and style-changes with respect to the sophistication level of investors.

It turns out that style changing behaviour has different impact on various types of fund performance measures. More specifically, style deviation has a strong positive impact on 'simple' fund performance measures, which are more often used by lesssophisticated investors, while it has no or a negative impact on more advanced fund performance measures. Overall, our findings suggest that taking into account the investor's sophistication level, allows for a more complete picture of an investor's response to changes in mutual funds' investment style behaviour.

\subsection{Algorithmic trading and Reinforcement Learning}

Algorithmic trading became popular in the early 2000s. With an emerging popularity of electronic trading platforms, algorithmic trading of securities has become a chief of modern approaches to financial investment. Although some market participants believe that markets are efficient, some others assume that it is still possible to make extraordinary profits. The industry experienced an acceleration of algorithmic trading and by 2005, algorithmic trading accounted for about $25 \%$ of the total trading volume (Glantz and Kissell, 2013). 
Chapter 1

Pairs trading is one of the well-known algorithmic trading strategies, which is the market neutral strategy in its basic form. Recent studies show that the growing popularity of the pairs trading strategy may pose a problem as the opportunities to trade become much smaller. Therefore, the optimization of pairs trading features has gained widespread attention among high-frequency traders specifically using new machine learning methods. In the last chapter of this dissertation, we employ Reinforcement Learning (RL), which is a branch of machine learning, in a platform of pairs trading strategy.

Reinforcement learning is the leading theory of heuristic updating. It is based on repeating actions that have produced favourable results in the past. We employ Reinforcement Learning, to optimize the level of pairs trading specifications using a cointegration approach. Figure 1-2 shows the function of the reinforcement learning for the pairs trading strategy.

Figure 1-2- Reinforcement learning framework for the pairs trading

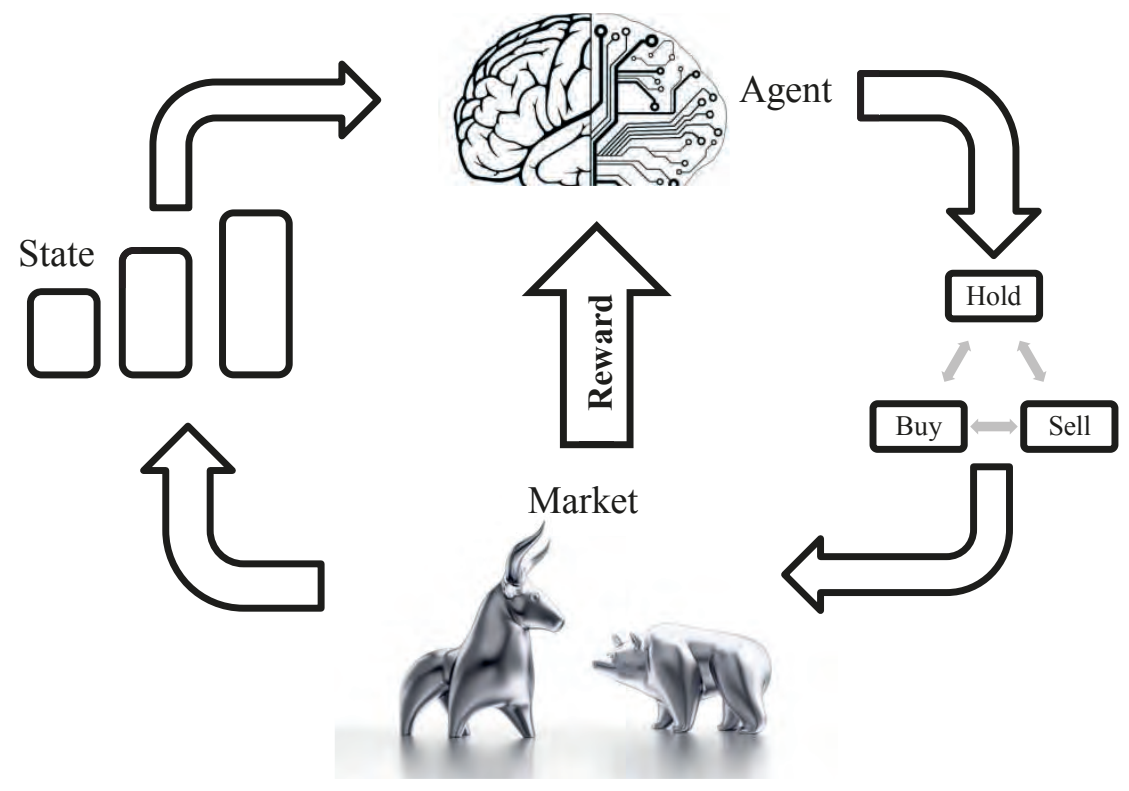


Introduction

We find that boosting pairs trading specifications by using the proposed approach significantly over-performs existing methods based on static parameters. Empirical results, based on comprehensive intraday data for some S\&P500 constituent stocks, confirm the efficiency of our proposed method. 


\section{Chapter 2}

\section{Investment Style Misclassification and Mutual Fund Performance*}

* This chapter is co-authored with Dennis Bams (Maastricht University) and Roger Otten (Maastricht University) 


\subsection{Introduction}

By year-end 2016, US mutual funds managed more than $\$ 16$ trillion in assets and many of them invest on behalf of long-term savers, taxpayers, and investors. For instance, at year-end 2015, 60 percent of household 401(k) plan assets were mainly invested in equity mutual funds. ${ }^{3}$ In addition, both search costs and tax motivation encourage investors to stay longer in mutual funds and subsequently reduce switching costs and delay payment of taxes. ${ }^{4}$

On the other hand, the longer the investor's holding period, the greater the possibility to bear more risk. One of the risks associated with the long-term holding period, concerns the deviation of a fund gradually from the promised investment style which means altering the fund's risk profile and causing investors to be exposed to different types and levels of risk. Such style deviation may only be the tip of the iceberg. Hence investors should be aware of the amount of style deviation with confidence level to consider whether this deviation means they are still meeting their long-term investment objectives. ${ }^{5}$ Although the US Security and Exchange Commission (SEC) mandates all fund managers to adhere to the selfclaimed investment style, previous studies document that a significant number of mutual funds deviate from their stated investment objective. ${ }^{6}$ In this study, to complete the literature, we exploit this feature of mutual fund industry on a longterm basis using a novel statistical measure to indicate that (1) how far mutual funds are from the stated investment objective with a certain confidence level (2)

\footnotetext{
${ }^{3}$ Source: Ten important facts about 401(k) plans, Investment Company Institute report 2016 and Factbook of Investment company Institute 2017

${ }^{4}$ Capital gains are taxed on realization basis in the U.S. (for the Search-costs in mutual funds see Sirri and Tufano (1998) among others)

${ }^{5}$ According to a survey by the Investment Company Institute (ICI), 40\% of retail investors indeed use the fund prospectus to learn about a fund's investment objective

${ }^{6}$ See diBartolomeo \& Wikowski (1997), Brown \& Goetzmann (1997), Kim, Shukla \& Tomas (2000), Kim, White \& Stone (2005), Cremers and Petajisto (2007), Mason et al. (2012) and Cao, Iliev \& Velthuis (2017) among others.
} 
Investment Style Misclassification and Mutual Fund Performance how investment style deviation matters for the performance of long-run fund investors.

Because the characteristics of the underlying stocks, like value-growth and market cap, may change over time, some deviation from the stated investment style on a long-term basis is unavoidable, especially if a fund manager holds the same stocks over time. For example, a small-cap stock may grow up and become a large-cap stock. However, too much style deviation of the entire portfolio may be a strong indication that fund managers have changed the investment strategy and have veered away from a fund's stated objective (Financial Post, February 14, 2013). ${ }^{7}$ Hence, it is relevant to quantify the extent of style deviation and to classify a mutual fund in terms of investment style deviation. Some studies address this by classifying funds in two groups only, either to be following the correct style (wellclassified group) or deviating (misclassified group) (see Brown and Goetzman (1997), Dibartolomeo and Witkowski (1997) and Kim, Shukla, and Tomas (2000), among others).

Some other studies define measures to detect style drift in mutual funds (see Idzorek and Bertsch (2004) and Brown, Harlow \& Zhang (2015) among others). A style drift measure shows the volatility of a fund's style change over time but does not address how far mutual funds are away from the stated investment objective. For example, imagine a fund manager of a growth mutual fund that consistently pursues a value investment style over a long-time period. In this particular case, the style drift measure would be almost zero over time. Our measure builds upon the well-known Return Based Style Analysis (henceforth RBSA) framework of Sharpe (1988, 1992) and is a refinement of the asymptotic confidence interval of the investment style estimates approach of Lobosco and DiBartolomeo (1997) and

\footnotetext{
${ }^{7}$ Beware of style drift in mutual funds, National Post's Financial Post \& FP Investing (Canada), February 14, 2013, David Pett
} 


\section{Chapter 2}

Kim, White \& Stone (2005). ${ }^{8}$ We determine the asymptotic multivariate distribution of a fund's investment style exposures.

We re-examine investment style deviation of mutual funds by using more granular econometric techniques and cleaner data. Inspired by the concept of Value at Risk (VaR), we introduce the Style Deviation Degree (henceforth $S D D$ ) that is a measure of a portfolio's return deviation from the relevant investment style benchmark return with a certain confidence level. Hence, style deviation greater than the $S D D$ can occur only with a specified small probability. This measure is suitable for a cross-sectional comparison and can be used by regulator and investors to quantify the amount of style deviation with confidence level.

Froot and Teo (2008) also document that institutional investors make decisions at the style level. Hence, the granularity of our measure is helpful to institutional investors when setting their optimal asset allocation based on a different class of investment style and allows them to set their exposures to different types of investment style risks with a certain confidence level.

In our measure, the distribution of a fund's investment style exposures allows for a rich set of statistical inference, such as the pair-wise comparison of the stated investment style with all other investment styles to detect any statistically significant deviation. The ability to carry out statistical inference distincts our approach from other measures in the literature such as Tracking Error (Grinold and Kahn 1999), Active Share Measure (Cremers and Petajisto 2009) and Mutual fund's $\mathrm{R}^{2}$ (Amihud and Goyenko 2013). From the cross-sectional analysis in our

\footnotetext{
${ }^{8}$ Sharpe (1992) introduces his method by regressing a fund's return on returns to cash, bond and a variety of equity classes. Sharpe model allows for separate effects from each of the underlying equity asset classes and Chan, Chen, and Lakonishok (2002) show that Sharpe's method in comparison with Fama-French three-factor and Brown and Goetzmann (1997) provides a more accurate customized style benchmark.
} 
Investment Style Misclassification and Mutual Fund Performance sample, it follows that $14 \%$ of US equity mutual funds are significantly misclassified.

Another important feature separating our approach from many others in the literature is the data. In contrast to previous studies, we retrieve the stated investment styles of mutual funds by reviewing all the funds' prospectuses and then matching them with the Lipper Objective codes. ${ }^{9}$ For instance Brown, Harlow \& Zhang (2015) use investment styles from the Morningstar Style Box which is based on the actual fund's portfolio holding and can change every quarter; hence this investment style does not necessarily represent the stated investment style. Cremers and Petajisto (2009) introduce the active management measure by employing the benchmark which best fits the portfolio composition regardless of the fund's stated investment style. Our measure only requires the return data on funds and benchmark indexes, which avoids us from the pitfalls associated with holding data. ${ }^{10}$

Using a sample of 1,866 US equity mutual funds including monthly returns, over the period 2003-2016, our empirical analysis leads to two main contributions. ${ }^{11} \mathrm{We}$ first examine the impact of a fund's style deviation on long-term fund performance; then we show what type of mutual funds is more likely to deviate from the stated investment style.

\footnotetext{
${ }^{9}$ Lipper's objective codes are assigned based on the language that the fund uses in its prospectus to describe how it intends to invest. Morningstar is a widely-used source for style analysis but the classification method is not based on the fund's prospectus.

10 For example, Kacperczyk et al. (2008) show that disclosed mutual fund holdings are not representative of the actual investment activity.

${ }^{11}$ Kim et al. (2005) use 2 U.S. mutual funds from 1979 through 1997. Horst et al. (2004) use 18 U.S. based internationally mutual funds with international MSCI growth and value indices, from 1989 through 1999. Swinkels and Van der Sluis (2006) use 12 international funds and 87 asset allocation funds and finally, Kim et al. (2000) assess U.S. funds in 7 objective groups over the period from 1993 through 1996.
} 


\section{Chapter 2}

Previous studies are inconclusive on whether deviation from the stated investment style delivers superior risk-adjusted returns on a short-term basis (see Chan, Chen, and Lakonishok (2002), Swinkels and Tjong-A-Tjoe (2007), Budiono and Martens (2009), Wermers (2012), Brown, Harlow and Zhang (2015), Cao, Iliev \& Velthuis (2017) among others).

Contrary to previous studies, we focus on the relationship between style deviation and fund performance on a long-term basis (10+ years), whereas previous work focused on short-term style deviation. To examine this relationship, we sort all mutual funds into buckets based on their style deviation level. We find that misclassified funds on the long run significantly underperform well-classified funds by $0.92 \%$ annually on a style-adjusted return basis. Moreover, funds that are in the highest misclassification bucket exhibit an abnormal return of $-2.01 \%$ per year using the Carhart model, whereas funds that adhere to the stated investment levels exhibit an abnormal return of $-1.09 \%$ per year.

Furthermore, we test one of the assumptions of a model by Berk and Green (2004), who suggest that in the equilibrium, all active funds have positive expected riskadjusted return before costs and zero expected risk-adjusted return after costs. Looking at the returns before expenses enables us to better evaluate the investment ability of mutual fund managers. Hence, we examine the performance of funds by returns before deducting the cost. The results show that alpha of funds increase monotonically from the highest misclassified mutual funds to the lowest misclassified funds. This finding suggests that most investment style disciplined funds have informational advantages about their specific investment style stocks and the advantage may reflect in their stock selection or the market timing abilities. ${ }^{12}$ Our results are also in line with the contemporaneous findings of Pastor, Stambaugh \& Taylor (2015) and Kempf, Manconi \& Spalt (2017), who find that

\footnotetext{
${ }^{12}$ Kasperczyk, Sialm and Zheng (2005) show that concentrated funds have both better stock selection and market timing ability.
} 
Investment Style Misclassification and Mutual Fund Performance mutual fund managers perform better on their investments where they have more experience.

In addition, we find that for some mutual funds the tendency to style deviation is persistent over a long time-period, suggesting that certain types of mutual funds actively employ this strategy. Therefore, by taking advantage of our measure, we investigate the relationship between the level of style misclassification on a longterm basis and fund characteristics like size, age, turnover, and expense ratio. Prior studies suggest that several fund characteristics are related to incentives for fund managers to alter their investment style and the associated risk levels. For example, diBartolomeo and Witkowski (1997) show that young mutual funds may be especially prone to misclassification. Frijns et al. (2016) report that funds that switch more aggressively, have on average higher expense ratios and are younger. Huang, Sialm \& Zhang (2011) point out that fund with higher expense ratios experience more severe performance consequences when they alter risk. Unlike most of the previous literature in which this relationship is shown based on style drift, we investigate the relationship based on long-term style deviation. We divide funds into several buckets using fund characteristics and sort them by their level of misclassification. We find that higher misclassified funds appear to be younger, smaller in size and more expensive.

The remainder of the paper is organized as follows. In section 2 , we introduce the methodology to measure the misclassification level. In section 3 , we describe the data that are used in the empirical application. Section 4 contains empirical results while in section 5 we address the robustness of these results. Finally, section 6 concludes the paper. 


\subsection{A Measure of Misclassification Level}

\subsubsection{Asymptotic distribution of the style estimates}

Typically, in the RBSA approach, the fund return is related to the returns on a number of selected passive style indices. The indices represent distinct investment styles within particular asset classes (e.g. value, growth, small caps). The style of the fund is represented by the loadings on the indices. RBSA explains the return for a given fund $i$ with the following model:

$$
\begin{aligned}
& R_{i t}=\sum_{k=1}^{N} \beta_{i k} I_{k t}+u_{i t} \quad t=1, \ldots, T \\
& \text { s.t: } \quad \sum_{k=1}^{N} \beta_{i k}=1 \\
& \beta_{i k} \geq 0 \quad k=1, \ldots, N
\end{aligned}
$$

where $R_{i t}$ denotes the return of mutual fund $i$ at time $t, N$ is the number of style classes, $\beta_{i k}$ is a style estimate that expresses the sensitivity of the fund return to the factor-mimicking portfolio return of index $k, I_{k t}$ denotes the return of index $\mathrm{k}$ at time $\mathrm{t}$ and $u_{i t}$ reflects idiosyncratic noise, orthogonal to the style indices, i.e. $E\left(I_{k t} u_{i t}\right)=0 .{ }^{13}$ There are two main constraints. First, as equation 2 shows, style estimates are restricted to add-up to one, in order to give them the interpretation of portfolio weights. Second, as equation 3 shows, positivity constraints are imposed

\footnotetext{
13 A few prerequisites should be met before any reliable results are to be obtained. First, the benchmarks should be mutually exclusive which means they may not include any securities that already form part of any other basic asset classes considered in the model. Second, indices should be exhaustive benchmarks, meaning as many securities as possible should be included in the chosen asset classes. Thirdly, the correlation between returns on the basic asset groups considered in the proposed model should be low.
} 
Investment Style Misclassification and Mutual Fund Performance on the style estimates to meet the short-selling constraint that fund managers are mostly subject to. ${ }^{14}$

Almazan, Brown, Carlson, and Chapman (2004) report that about 70\% of mutual funds are not allowed to pursue any short selling activities and only $2 \%$ actually do sell short. The positive weight interpretation of the parameter estimates turns out to be useful for two reasons. First, it provides parameter estimates that are more efficient, and second this standardization towards portfolio weights is an attractive feature in the formulation of a standardized measure for the misclassification level. However, because of the computing difficulties for obtaining estimated style regression with restrictions, many previous studies relax the constraints in the RBSA method (see for example Annaert and Van Campenhout (2007) and Swinkels and Van der Sluis (2006) among others).

Using quadratic programming, we estimate the style weights by considering two main constraints. In addition, one shortcoming of Sharpe's RBSA is the fact that it only focuses on point estimates for the factor loadings. Lobosco and DiBartolomeo (1997) address the lack of a precision measure by proposing a method to approximate confidence interval for style estimates based on a Taylor expansion. However, the method is only valid in the special case in which none of the style estimates are zero or one, which prevents us to obtain the asymptotic distribution of the style regression coefficients. In this study, by combining quadratic programming and a standard bootstrapping algorithm, we build up the asymptotic multivariate distribution of the investment style estimates. The asymptotic distribution plays an important role in testing the significance of style estimates.

One statistical test focuses on the ability to identify whether a fund invests in a particular type of security. Another relevant test is to check whether a fund is more

\footnotetext{
${ }^{14}$ Ter Horst et al. (2004) investigated the effect of the portfolio and short-selling constraints in style analysis. They argue that although there is no straightforward analytical expression to define the benefit of imposing constraints, if both constraints are the case in reality, this results in more efficient parameter estimates.
} 


\section{Chapter 2}

invested in one type of style than in another one, also requiring the asymptotic distribution. The asymptotic distribution allows for a rich set of statistical inferences, such as pair-wise comparisons of the stated investment style with four other investment styles to detect any statistical significant deviation. Let $\beta_{\text {s style }}$ be the exposure to the stated investment style of a given mutual fund and $\beta_{j}$ be the other investment styles exposures of the fund, the difference between $\beta_{s}$ style and other $\beta_{j}$ is then

$$
d_{s j}=\beta_{\text {style }}-\beta_{j} \quad j \neq s
$$

Defining $\mu_{s j}=E\left[d_{s j}\right]$ as the expected difference between the exposure to the stated investment style of $s$ and the exposure to the investment style of $j$, we define a fund to be well-classified if $\mu_{s j}>0$. Therefore, the null hypothesis for this pairwise comparison is:

$$
H_{0}: \mu_{s j}>0 \quad j \neq s
$$

Against the alternative hypothesis that the expected difference for at least one investment style less than zero.

$$
H_{1}: \mu_{s j}<0 \quad j \neq s
$$

As Kim, White \& Stone (2005) document, when the beta is close to the boundary the beta distribution is not normal, and the bootstrap approximation can be better than a normal approximation for the investment style exposures distribution. Using a p-test, we test the null hypothesis whether the stated investment style is significantly different from all other investment style estimates. In Appendix A, we show the procedure to arrive at the asymptotic distribution of the investment style estimates. Our measure also takes into account the Family-Wise Error rate (FWE) for the dependence structure of all individual comparisons of p-values. The FWE is 
Investment Style Misclassification and Mutual Fund Performance defined as the probability of incorrectly identifying that at least one style exposure is higher than the stated investment style. Following Holm (1979), we order the pvalues from the smallest to the largest, $P_{(1)}, P_{(2)}, \ldots, P_{(s)}$ with their corresponding null hypotheses, $H_{(1)}, H_{(2)}, \ldots, H_{(s)}$. Then we reject the $H_{(s)}$ at level $\alpha$ if $P_{(s)} \leq$ $\alpha /(S-j+1)$ for all $\mathrm{j}=1, \ldots, \mathrm{s}$.

\subsubsection{Style Deviation Degree}

We define our measure of misclassification level, the Style Deviation Degree, in the context of the RBSA approach. Previous studies divide mutual funds into two groups only in which funds are either considered to be completely well-classified or completely misclassified. Our measure provides a more granular specification of the style misclassification level. This continuous measure is further fine-tuned by also incorporating the statistical significance level of the measure. More specifically, we assign each fund a number between zero and one, which represents the distance between the actual investment style of a fund and the stated investment style. Low numbers represent a low amount of misclassification and high numbers represent a high amount of misclassification.

The Style Deviation Degree is defined based on a two-step procedure. First, as mentioned in section 2.1, we obtain the asymptotic distribution of a fund's stated investment style estimate. Second, the Style Deviation Degree (SDD) is defined as one minues the $(1-\alpha)$ quantile of the asymptotic distribution of the exposure to the stated investment style:

$$
\begin{aligned}
& S D D=1-\beta_{\text {stated style }(1-\alpha, P)} \\
& =1-\inf \left\{x: \operatorname{Prob}_{P}\{\beta \leq x\} \geq 1-\alpha\right\}
\end{aligned}
$$

For example, let's assume a fund that claims in the prospectus to pursue the growth investment style. We first obtain the asymptotic distribution of the $\beta_{\text {Growth }}$, which denotes the fund's stated investment style estimate. Second, we define the Style 
Chapter 2

Deviation Degree (SDD) of the fund as one minus the value of $\beta_{\text {Growth }}$ at the (1 $\alpha) \%$ probability level of its distribution.

We use bootstrapping to estimate the asymptotic distribution function $\mathrm{P}$, and given $\mathrm{P}$, we take the 1- $\alpha$ quantile. The asymptotic distribution of style estimates is always between zero and one, allowing the measure to be interpreted as a standardized degree. As the SDD gets close to zero, it shows that the fund is highly likely to be a well-classified fund and obviously, as the SDD gets close to one, it shows that the fund is highly likely to be a misclassified fund.

Figure 2-1 shows an example of three different mutual funds that have three different Style Deviation Degrees.

Figure 2-1- Example of different Style Deviation Degrees

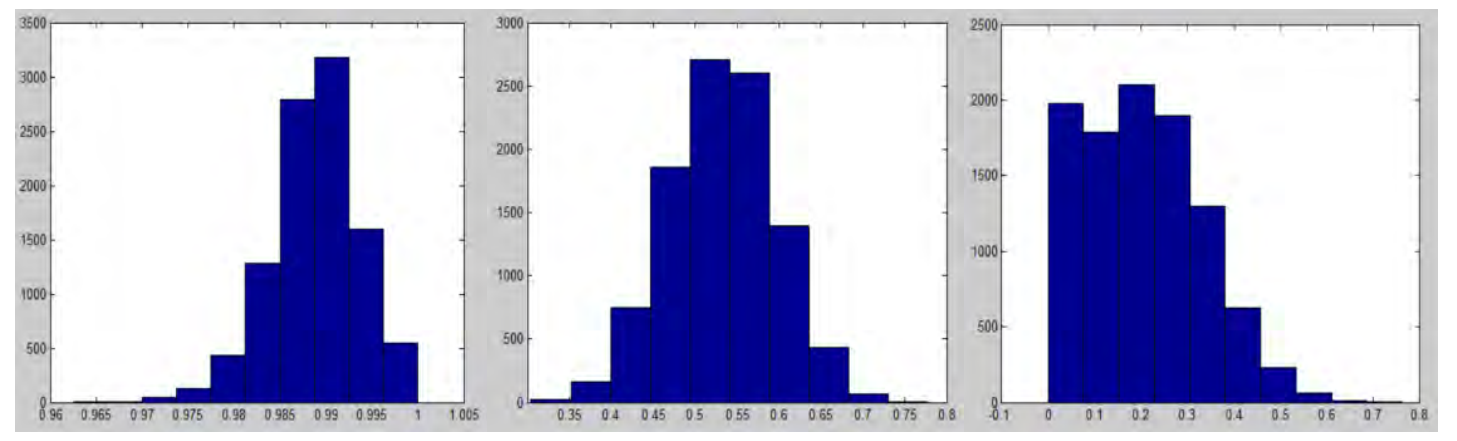

This figure represents an example of three mutual funds with three different investment styles. The Bar graphs show the asymptotic distribution of the stated investment style for each fund which varies between zero and one. From left to the right, the first Bar graph is an example of the stated style distribution with negative skewness and it shows a high well- classified fund whose five-percentile distribution is 0.98 . The second Bar graph shows a symmetric distribution of the stated style where the $S D D$ is 0.58 . The last Bar graph is an example of a fund with positive skewness and it represents a highly misclassified fund whose $S D D$ is 0.99 .

\subsection{Data}

Our study sets out to investigate long term style deviation where most previous studies have investigated short term deviation. For this reason, we only consider mutual funds which have a static stated investment style over the entire sample period based on their prospectus and the Lipper Objective codes. An explicit 
Investment Style Misclassification and Mutual Fund Performance change of the stated investment objective requires approval from the shareholders and it also may force some existing investors to close their accounts. ${ }^{15} \mathrm{Kim}$, Shukla, and Tomas (2000) find that more than $92 \%$ of mutual funds did not change their stated objective over the sample period.

In addition to investigating long term style deviation we utilize a much larger database both in terms of number of funds $(1,866)$ and sample period covered (2003-2016). We retrieve mutual fund data from the Center for Research in Security Prices (CRSP). The CRSP mutual fund database includes information on monthly total returns, total net assets (TNA), expense ratio, fund age, turnover ratio, and other mutual fund characteristics. ${ }^{16}$ Total returns are provided by CRSP and are after management fees, expenses and brokerage commissions, but before front-end or back-end loads. Dead funds are included in order to mitigate potential survivorship bias. Following previous studies such as Berk and Binsbergen (2013), Mason et al. (2012), Nanda, Wang, and Zheng (2009), Kacperczyk et al. (2008), Chen et al. (2004) and Elton, Gruber and Blake (2001), we consider six selection criteria to narrow down our dataset.

First, to facilitate comparison with the previous literature, we restrict our analysis to domestic U.S. equity mutual funds, so we drop all balanced, bond, international and sector funds.

Second, because some mutual funds which have different share classes may enter into the database multiple times at the same period, we aggregate all share classes into a single fund to eliminate such redundant observations.

\footnotetext{
${ }^{15}$ Section 13 (a), item (3), of investment Company Act of 1940, version January 3, 2012, states that "deviation from its policy in respect of concentration of investments in any particular industry or group of industries as recited in its registration statement, deviation from any investment policy which is changeable only if authorized by shareholder vote."

${ }^{16}$ Monthly total returns values are calculated as a change in NAV including reinvested dividends from one period to the next. NAVs are net of all management expenses and $12 \mathrm{~b}-1$ fees. Front and back-end load fees are excluded.
} 
Chapter 2

Third, we drop all fund observations where the size of the fund in the previous quarter does not exceed $\$ 1.5$ million.

Fourth, we check the mutual funds' asset composition and remove all funds from the database which have negative weights, in order to exclude funds that engage in short-selling.

Fifth, since we only focus on actively managed mutual funds, we remove all index funds from our sample. We also exclude all funds which have a zero turnover ratio in one year to make sure that our sample includes actively managed funds, only.

Sixth, we only include funds that exist for at least 30 months during the estimation period.

The number of distinct U.S. mutual funds that meet our selection criteria over the sample period from July 2003 through January 2016 is 1,866 funds. These funds are classified into four main investment style classes, based on the Lipper Prospectus Objective codes, which are provided by CRSP as well. ${ }^{17}$ We only focus on mutual funds that have an invariant stated investment objective during the sample period.

Initially, we form six equally-weighted portfolios, which will be analysed in more depth. We construct an equally-weighted portfolio containing all individual funds, an equally-weighted portfolio of funds that did not survive the whole sample period (referred to as dead funds), and equally-weighted portfolios of mutual funds with the following particular investment objectives: growth, income, growth/income and small cap.

As we only consider U.S. equity funds, the relevant style benchmarks are all U.S. indices. We include the U.S. value index (S\&P500 Value index), the U.S. growth

${ }^{17} \mathrm{http}: / /$ www.crsp.com/products/documentation/lipper-objective-and-classification-codes 
Investment Style Misclassification and Mutual Fund Performance index (S\&P500 Growth index), the U.S. small cap index (S\&P600 index) and two fixed income classes, cash (30-day Treasury bill rate) and bonds (30-years bonds). We retrieve the data on equity indices from FactSet Research System Inc., and obtain fixed income data from CRSP. This leads to a 5-factor RBSA model, to infer a fund's investment style. Table 2-1 provides summary statistics on the different equally weighted portfolios (panel A) and benchmarks (panel B). In particular panel A shows that a substantial part of the sample, i.e. more than $36 \%$ of all funds in our sample, did not survive during the entire sample period. These funds also register a significantly lower return which would introduce survivorship bias if not included in our analysis. Therefore dead funds are included.

Table 2-1- Summary statistics

Panel A: Mutual fund returns

\begin{tabular}{lccc}
\hline Investment Objective & $\begin{array}{c}\text { Mean } \\
\text { Return }\end{array}$ & $\begin{array}{c}\text { Standard } \\
\text { Deviation }\end{array}$ & Number of funds \\
\hline Growth & 8.02 & 16.27 & 848 \\
Income & 7.80 & 13.94 & 191 \\
Small caps & 9.72 & 19.22 & 350 \\
Growth/Income & 7.39 & 15.00 & 477 \\
\hline All funds & 8.15 & 16.26 & 1866 \\
Dead funds & 6.03 & 16.91 & 681 \\
\hline
\end{tabular}


Chapter 2

Table 2-1

Panel B: Benchmark returns

Cross correlations

\begin{tabular}{lrrrrrrr}
\cline { 3 - 7 } Benchmark & $\begin{array}{r}\text { Mean } \\
\text { Return }\end{array}$ & $\begin{array}{r}\text { Standard Value } \\
\text { deviation }\end{array}$ & & & $\begin{array}{r}\text { Small } \\
\text { cap }\end{array}$ & Cash & Bond \\
\hline S\&P 500 Value & 6.06 & 15.07 & 1.00 & 0.90 & 0.90 & -0.02 & -0.32 \\
S\&P 500 Growth & 7.76 & 13.47 & & 1.00 & 0.86 & -0.07 & -0.31 \\
S\&P 600 Small & 10.58 & 18.12 & & & 1.00 & -0.05 & -0.34 \\
cap & & & & & & & \\
30 Day treasury B 1 & 1.25 & 0.50 & & & & 1.00 & 0.00 \\
30 Years Bonds & 6.90 & 14.86 & & & & & 1.00 \\
\hline
\end{tabular}

Panel C: Variance inflation factors in the proposed benchmarks

\begin{tabular}{|c|c|c|c|c|c|}
\hline & $\begin{array}{l}\text { S\&P } 500 \\
\text { Value }\end{array}$ & $\begin{array}{l}\text { S\&P 500 } \\
\text { Growth }\end{array}$ & $\begin{array}{l}\text { S\&P 600 } \\
\text { Small cap }\end{array}$ & $\begin{array}{c}30 \text { Day } \\
\text { Treasury Bill }\end{array}$ & $\begin{array}{l}30 \text { Years } \\
\text { Bonds }\end{array}$ \\
\hline$R^{2}$ & 0.88 & 0.85 & 0.81 & 0.02 & 0.12 \\
\hline VIF & 4.43 & 3.60 & 2.91 & 1.00 & 1.01 \\
\hline \multicolumn{6}{|c|}{$\begin{array}{l}\text { These tables provide summary statistics on the U.S. mutual funds (Panel A) and benchmarks (Panel B) } \\
\text { that are used in the empirical analysis. Panel A reports annualized total returns with corresponding } \\
\text { standard deviations for six equally weighted portfolios of funds. Panel B reports returns and standard } \\
\text { deviations on the style benchmarks. Cross correlations between the benchmarks are given in Panel B } \\
\text { columns } 4 \text { through 8. Panel C reports the Variance Inflation Factors (VIFs) for the style benchmarks and } \\
R^{2} \text { is the determinant coefficient for the linear regression of a style index } i \text { in relation to the other four } \\
\text { style indices. }\end{array}$} \\
\hline
\end{tabular}

A potential concern in a RBSA analysis is the impact of multicollinearity between different benchmarks. As Horst et al. (2004) discuss, the difference between actual portfolio holdings in mutual funds and estimated exposures to style indices, is more likely related to multicollinearity problems, caused by the correlations between the different indices. Hence, to assess the impact of multicollinearity 
Investment Style Misclassification and Mutual Fund Performance among benchmarks, we determine Variance Inflation Factors (VIF). The VIF associated with style index $i$ is given by

$$
V I F_{i}=\frac{1}{1-R_{i}^{2}}
$$

Where $R_{i}^{2}$ is the coefficient of variation of the linear regression of style index $i$ on the other style indices. Table 2-2, Panel C shows that all VIFs are less than 10, which is the relevant threshold that is applied as a common rule of thumb in multicollineary analysis. Hence, despite the high correlations between the style indices, we do not expect any issues arising from multicollinearity problems. As a robustness check, we will employ Russell indices in section 5 in order to investigate the sensitivity of our results to the choice of benchmarks.

Table 2-2 reports summary statistics on fund's Total Net Assets (TNA), 52- week low Net Asset Value (NAV), 52- week high Net Asset Value (NAV), age, expense ratio and turnover ratio.

Table 2-2- Summary statistics of mutual fund characteristics

\begin{tabular}{lcc}
\hline Variable & Mean & Std. Dev. \\
\hline Total Net Assets (TNA) (\$ Million) & 1062 & 248 \\
52- week low Net Asset Value (NAV) (\$ Million) & 16.20 & 13.21 \\
52- week high Net Asset Value (NAV) (\$ & 19.98 & 17.52 \\
Million) & & \\
Age (in Years) & 13.78 & 6.50 \\
Expense Ratio (in Percent) & 1.23 & 1.20 \\
Turnover Ratio & 0.76 & 0.62 \\
Total Number of Funds & 1,866 & \\
Total Number of Observations & 188,155 & \\
\hline
\end{tabular}

This table provides summary statistics of characteristics of the mutual funds in our sample between July 2003 and January 2016. The Turnover Ratio is defined as the minimum (of aggregated sales or aggregated purchases of securities of a fund divided by the average 12-month Total Net Asset value of the fund. The Expense ratio is the ratio of total investment that shareholders pay for the fund's operating expenses, which include $12 \mathrm{~b}-1$ fees. 


\subsection{Results}

In this section, we examine the empirical evidence of misclassification. We first determine mutual funds as either significantly well-classified or significantly misclassified. By using SDD, we rank all mutual funds from the highest misclassified funds to the lowest misclassified funds. This ranking allows us to investigate a potential relationship between the level of style deviation, fund performance and fund characteristics.

\subsubsection{Investment Style Misclassification}

In Table 2-3, we report the parameter estimates of the RBSA model for the four style-related equally-weighted portfolios of funds. Panel A shows the estimated style weights including all funds within the particular style category.

Table 2-3- Equally-weighted average portfolio of funds

Panel A: Estimated style weights

\begin{tabular}{lllllll}
\hline Objective & Value & Growth & Small cap & Cash & Bond & $\mathrm{R}^{2}$ \\
\hline Growth & $0.14^{* * *}$ & $0.63^{* * *}$ & $0.22^{* * *}$ & 0.00 & 0.00 & 0.97 \\
Income & $0.54 * * *$ & $0.33^{* * *}$ & $0.04 * * *$ & $0.04 * * *$ & $0.03 * * *$ & 0.98 \\
Small cap & $0.01 * * *$ & $0.11^{* * *}$ & $0.87^{* * *}$ & $0.00^{* * *}$ & 0.00 & 0.96 \\
Growth/Income & $0.39 * * *$ & $0.45^{* * *}$ & $0.10^{* * *}$ & $0.05^{* * *}$ & 0.00 & 0.97 \\
\hline
\end{tabular}

Panel B: 95\% Confidence intervals for style weights

\begin{tabular}{llllll}
\hline Objective & Value & Growth & Small cap & Cash & Bond \\
\hline Growth & {$[0.09-0.20]$} & {$[0.57-0.68]$} & {$[0.19-0.26]$} & {$[0.00-0.02]$} & {$[0.00-0.01]$} \\
Income & {$[0.49-0.58]$} & {$[0.29-0.37]$} & {$[0.02-0.07]$} & {$[0.02-0.07]$} & {$[0.02-0.04]$} \\
Small cap & {$[0.00-0.07]$} & {$[0.06-0.16]$} & {$[0.83-0.91]$} & {$[0.00-0.02]$} & {$[0.00-0.01]$} \\
Growth/Income & {$[0.35-0.44]$} & {$[0.41-0.49]$} & {$[0.07-0.13]$} & {$[0.03-0.07]$} & {$[0.00-0.02]$} \\
\hline
\end{tabular}

This table presents the parameter estimates of the RBSA model for four equally weighted portfolios of funds. Each row deals with one particular investment objective, where the elements in columns 2 to 6 report the estimated style weights. Panel B reports the $95 \%$ confidence intervals for all estimated style weights for the portfolios. Because of the constraints on the parameters these have been constructed by a combination of quadratic optimization and a standard bootstrapping algorithm. We indicate significance at the $10 \%, 5 \%$ and $1 \%$ level, by $*, * *$, and $* * *$, respectively. 
Investment Style Misclassification and Mutual Fund Performance We find that for both panels the income fund is mainly exposed to the value benchmark, the growth fund to the growth benchmark, growth/income fund to the growth and value benchmarks and finally the small cap fund is up to $87 \%$ exposed to the smaller companies benchmark. These results, based on point estimates only, suggest that mutual funds indeed invest in line with their stated investment style. In panel B, 95\% confidence intervals are provided per style category. The confidence intervals show that the point estimates are relatively precise reflections of the portfolio weights.

Table 2-3 does not produce evidence of serious style deviations by mutual fund managers on average. It may be the case that the construction of equally-weighted portfolios averages out misclassification effects that are present in individual funds. DiBartolomeo \& Witkowski (1997), Indro et al (1998) and Kim, Shukla \& Tomas (2000) find that more than $50 \%$ of U.S. mutual funds differ from their benchmarks, and over $30 \%$ of the funds are significantly misclassified. We next fine-tune our analysis by investigating the misclassification phenomenon at the individual mutual fund level. 
Chapter 2

Table 2-4- Mutual fund misclassifications based on individual fund returns

\begin{tabular}{|c|c|c|c|}
\hline \multicolumn{4}{|c|}{ Mutual fund misclassifications based on individual funds } \\
\hline Objective & $\begin{array}{c}\% \\
\text { Misclassifications }\end{array}$ & $\frac{\% \text { Significant }}{\text { Misclassifications }}$ & $\begin{array}{l}\text { \%Significant } \\
\text { Well- } \\
\text { classification }\end{array}$ \\
\hline Growth & $29 \%$ & $23 \%$ & $61 \%$ \\
\hline Income & $26 \%$ & $26 \%$ & $47 \%$ \\
\hline Small Cap & $1.5 \%$ & $0.8 \%$ & $98 \%$ \\
\hline Growth/Income & $5 \%$ & $3.8 \%$ & $90 \%$ \\
\hline All mutual funds & $17 \%$ & $14 \%$ & $75 \%$ \\
\hline
\end{tabular}

This table provides evidence of fund misclassification using individual fund returns. We assume that a growth/income fund should predominantly be exposed to the growth or value benchmark, income finds to the value benchmark, growth funds to the growth benchmark and finally small cap funds to the small cap benchmark. If a fund exhibits a higher weight on any other benchmark, we consider it to be misclassified. Column 2 reports the percentage of misclassified funds per investment objective, solely based on the point estimates for style weights. In column 3 and 4 , we take account of the significance of the estimated style weights and report the percentage of significantly misclassified funds and significant well-classified funds per investment objective respectively.

In Table 2-4, for each mutual fund, we compare the distribution of stated investment style estimate with the other investment style estimates distributions. In our particular setting that leads to 4 different comparisons per style. For example, if the stated investment objective of a mutual fund is Value, there are 4 comparisons including Value with Growth, Value with Small cap, Value with Cash and value with Bond. When the point estimate of the stated style estimate is lower than one or more point estimates of the other style indices, we consider it to be misclassified. Based on the asymptotic confidence interval of the style estimates, we identify a fund as significantly misclassified if its stated style estimate is significantly lower than one or more other style weights. Subsequently, if the stated style estimate is greater than all other style weights, we put the fund into the wellclassified funds group.

The results based on individual funds in Table 2-4 suggest that especially growth $(29 \%)$ and income (26\%) funds are significantly misclassified while small cap $(1.5 \%)$ and growth/income (5\%) funds mostly seem to adhere to their stated 
Investment Style Misclassification and Mutual Fund Performance investment style. Taking into account the information in the asymptotic distribution function, leads to slightly lower overall levels of misclassification; $14 \%$ compared to $17 \%$ based on point estimates alone. Interestingly, for growth and income funds, respectively $61 \%$ and $47 \%$ of funds are significantly well classified. From this, we infer that style deviation is indeed a serious issue, especially for growth and income oriented funds.

\subsubsection{Style Deviation Degree and Fund Characteristics}

In this section, we discuss how style deviation is related to fund characteristics. In line with our previous analysis, we use a decile analysis to rank order funds with respect to their Style Deviation Degree and compute the average fund characteristics in each decile. 
Chapter 2

Table 2-5- Relationship between Style Deviation Degree and Fund Characteristics

\begin{tabular}{lccccc}
\hline & SDD & $\begin{array}{c}\text { Turnover } \\
\text { ratio }\end{array}$ & $\begin{array}{c}\text { \% Expense } \\
\text { ratio }\end{array}$ & $\begin{array}{c}\text { Log } \\
\text { (TNA) }\end{array}$ & Age \\
\hline $\begin{array}{l}\text { Decile 1 (Highest } \\
\text { misclassified funds) }\end{array}$ & 0.95 & 0.83 & 1.46 & 2.71 & 19.11 \\
Decile 2 & 0.75 & 0.67 & 1.33 & 2.97 & 17.75 \\
Decile 3 & 0.63 & 0.78 & 1.26 & 2.83 & 15.84 \\
Decile 4 & 0.53 & 0.54 & 1.21 & 2.85 & 15.04 \\
Decile 5 & 0.45 & 0.85 & 1.26 & 2.95 & 14.42 \\
Decile 6 & 0.37 & 0.68 & 1.19 & 3.24 & 13.75 \\
Decile 7 & 0.30 & 0.77 & 1.19 & 3.22 & 13.44 \\
Decile 8 & 0.24 & 0.72 & 1.19 & 2.95 & 12.96 \\
Decile 9 & 0.18 & 0.70 & 1.19 & 3.02 & 11.15 \\
$\begin{array}{l}\text { Decile 10 (Lowest } \\
\text { misclassified funds) }\end{array}$ & 0.09 & 0.78 & 1.02 & 3.22 & 9.90 \\
\hline $\begin{array}{l}\text { Top - Bottom } \\
\text { Decile }\end{array}$ & & 0.05 & $0.44^{* * *}$ & $-0.51 * *$ & $-9.21 * * *$ \\
\end{tabular}

This table presents the relationship between the Style Deviation Degree (SDD) and several fund characteristics. We sort funds into deciles and calculate fund performance within the portfolios. Top Bottom decile represents the test of equal means between the top and bottom decile; we report t-stats in parentheses. We indicate significance at the $10 \%, 5 \%$ and $1 \%$ level, by *, **, and ***, respectively.

We report the results of the relationship between the Style Deviation Degree and fund characteristics in Table 2-5. The results show expense ratios exhibit a significant positive relationship with the Style Deviation Degree, which indicates that funds in misclassified categories are substantially more likely to have a higher 
Investment Style Misclassification and Mutual Fund Performance expense ratio than others. Moreover, columns 5 and 6 show that funds which deviate from their stated investment style are likely to be smaller and younger than funds with more stability in their stated investment style.

The results are confirmed by a regression of the Style Deviation Degree on the several fund characteristics.

$$
\begin{gathered}
\operatorname{SDD}_{i}=b_{1} . \text { Turnover }_{i}+b_{2} \cdot \text { Expense }_{i}+b_{3} \cdot \log \left(\text { Size }_{i}\right) \\
+b_{4} \cdot \log \left(\text { Age }_{i}\right)+\varepsilon_{i}
\end{gathered}
$$

where $S D D_{i}$ is the Style Deviation Degree of mutual fund $i$, Turnover $_{i}$ is the average turnover of the fund, Expense $e_{i}$ is the annual expense ratio, $\log \left(\operatorname{Size}_{i}\right)$ is the logarithm of TNA and $\log \left(A g e_{i}\right)$ is the logarithm of the age of the fund.

Table 2-6- Relation between Style Deviation Degree (SDD) and Fund Characteristics in different styles

\begin{tabular}{ccccc}
\hline & Turnover ratio & Expense Ratio & Log (TNA) & Log (Age) \\
\hline All mutual & $-0.02 * *$ & $12.44 * * *$ & $-0.01 * *$ & $-0.12 * * *$ \\
funds & $(-2.04)$ & $(8.41)$ & $(-1.96)$ & $(-7.18)$ \\
& & & & $-0.11 * * *$ \\
Dead mutual & $0.02 * *$ & $10.28 * * *$ & $-0.04 * * *$ & $(-8.12)$ \\
funds & $(2.03)$ & $(4.83)$ & $(-2.78)$ &
\end{tabular}

The table reports the regression results for Equation (9). SDD is the Style Deviation Degree coefficient, $\log \left(\right.$ Size $\left._{f}\right)$ is the logarithm of TNA, Expense $e_{f}$ is the annualized expense ratio and Log $\left(\mathrm{Age}_{f}\right)$ is the logarithm of the age of mutual fund. We report t-statistics within parentheses. We indicate significance at the $10 \%, 5 \%$ and $1 \%$ level, by $*, * *$ and $* * *$, respectively.

Table 2-6 reports the results of the regression analysis. We find that the turnover ratio, log (TNA), and log (Age) are significantly negatively related to the Style Deviation Degree. A significant positive relationship exists between the Style Deviation Degree and the expense ratio, suggesting that funds which deviate more and hence charge higher expense ratios are more likely to be misclassified. 
Chapter 2

\subsubsection{Style Deviation Degree and Fund Performance}

After establishing the level of misclassification, we now turn to the effect of the level of misclassification on fund performance. Some studies report that deviation from investment style for mutual funds over time can generate significant outperformance while some other studies show that there is an inverse relationship between fund performance and misclassification behavior. Recently, Brown, Harlow and Zhang (2015) study the effect of style volatility on future fund performance on a short-term basis (3,6 and 12-month) and infer that for fund managers having less style volatility is one way that they can show their superior skill to potential investors. They argue that managers with stable investment styles are easier for investors to be accurately evaluated.

To examine the effect of different misclassification levels on fund performance, specifically on a long-term basis, we employ a decile analysis. In Table 2-7 we rank order funds with respect to their Style Deviation Degree into deciles and following Khorana (2001), Del Guercio and Tkac (2002), Lynch and Musto (2003), Nanda, Wang, and Zheng (2004), Keswani and Stolin (2008), Gil-Bazo and Ruiz-Verdu (2009), we compute the style- adjusted return and risk-adjusted return of the funds in each decile.

The top decile, i.e. decile 1, contains the highest misclassified mutual funds, where the average value of their SDD is 0.95 . The bottom decile, decile 10, contains the lowest misclassified mutual funds, where the average value of their SDD is 0.09. 
Investment Style Misclassification and Mutual Fund Performance

Table 2-7- Relationship between Style Deviation Degree and Fund

Performance with Net return

\begin{tabular}{|c|c|c|c|c|c|}
\hline & SDD & $\begin{array}{l}\text { Alpha- } \\
\text { CAPM }\end{array}$ & $\begin{array}{l}\text { Alpha- } \\
3 \mathrm{~F}\end{array}$ & $\begin{array}{l}\text { Alpha- } \\
\text { Carhart }\end{array}$ & Alpha- 5F \\
\hline Top 5\% highest & 0.99 & -2.59 & -2.62 & -2.64 & -2.23 \\
\hline \multicolumn{6}{|l|}{ Misclassified funds } \\
\hline Decile 1 & 0.95 & -2.00 & -1.95 & -2.01 & -1.83 \\
\hline Decile 2 & 0.75 & -1.40 & -1.41 & -1.44 & -1.37 \\
\hline Decile 3 & 0.63 & -1.18 & -1.23 & -1.20 & -1.18 \\
\hline Decile 4 & 0.53 & -0.98 & -1.13 & -1.16 & -1.22 \\
\hline Decile 5 & 0.45 & -0.97 & -1.18 & -1.26 & -0.97 \\
\hline Decile 6 & 0.37 & -1.16 & -1.25 & -1.28 & -1.00 \\
\hline Decile 7 & 0.30 & -1.10 & -1.30 & -1.41 & -1.00 \\
\hline Decile 8 & 0.24 & -1.20 & -1.46 & -1.57 & -1.42 \\
\hline Decile 9 & 0.18 & -1.02 & -1.30 & -1.35 & -1.31 \\
\hline Decile 10 & 0.09 & -1.29 & -1.11 & -1.09 & -1.15 \\
\hline $\begin{array}{l}\text { Bottom 5\% lowest } \\
\text { Misclassified funds }\end{array}$ & 0.06 & -1.30 & -1.03 & -1.00 & -1.04 \\
\hline Top - Bottom Decile & & $\begin{array}{l}-0.71^{*} \\
(-1.88)\end{array}$ & $\begin{array}{l}-0.84 * * \\
(-2.38)\end{array}$ & $\begin{array}{c}-0.92 * * * \\
(-2.72)\end{array}$ & $\begin{array}{c}-0.69 * * * \\
(-2.63)\end{array}$ \\
\hline Top -Bottom 5\% & & $\begin{array}{l}-1.29 * \\
(-1.93)\end{array}$ & $\begin{array}{l}-1.59 * * \\
(-2.45)\end{array}$ & $\begin{array}{c}-1.64 * * * \\
(-2.68)\end{array}$ & $\begin{array}{c}-1.19 * * * \\
(-3.03)\end{array}$ \\
\hline
\end{tabular}

This table presents the relationship between the Style Deviation Degree (SDD) and several fund characteristics. We sorted funds into decile and calculated fund performance within the portfolios. Top - Bottom Decile- represents the test of equal means between the top and bottom decile; we report $\mathrm{t}$ - stat in parentheses. We indicate significance at the $10 \%, 5 \%$ and $1 \%$ level, by $*, * *$, and ***, respectively. 
Chapter 2

Our results indicate that the level of misclassification has a significantly negative relation with fund performance. The highest misclassified funds (decile 1) underperform the lowest misclassified classified funds (decile 10) significantly by $1.07 \%$ (style-adjusted return), 0.71\% (CAPM alpha), 0.84\% (three-factor alpha) and $0.92 \%$ (Carhart alpha) per year. The magnitude of the performance difference decreases further if we compare the top and the bottom 5\% of funds. From this we infer that long-term deviation from the stated investment style has a significantly negative influence on fund performance. This calls for close style monitoring by investors, specifically for those investors who have a buy and hold investment strategy.

Berk and Green (2004) provide a prominent theoretical model that shows an active manager has ability to generate a positive alpha before cost but after consideration the cost the alpha reduces to zero. For this reason, we examine the factor-adjusted returns before subtracting fund expense ratios. The results show the highest misclassified funds have significantly lower alpha than lowest misclassified funds. For example, the 5 -factor alpha of the first decile equals $-0.23 \%$ annually. In contrast the last decile shows an alpha of $1.21 \%$ per year. The difference of 5factor alpha between the most misclassified funds and the least misclassified funds is significantly different from zero at the $1 \%$ significant level. 
Investment Style Misclassification and Mutual Fund Performance

Table 2-8- Relationship between Style Deviation Degree and Fund Performance with Gross Return

\begin{tabular}{lccccc}
\hline & SDD & $\begin{array}{c}\text { Alpha- } \\
\text { CAPM }\end{array}$ & Alpha-3F & Alpha-Carhart & Alpha- 5F \\
\hline Decile 1 & 0.95 & -0.50 & -0.55 & -0.48 & -0.23 \\
Decile 2 & 0.75 & -0.35 & -0.25 & -0.27 & 0.00 \\
Decile 3 & 0.63 & 0.08 & 0.02 & 0.10 & 0.17 \\
Decile 4 & 0.53 & -0.05 & -0.06 & 0.06 & 0.07 \\
Decile 5 & 0.45 & 0.31 & 0.23 & 0.35 & 0.63 \\
Decile 6 & 0.37 & 0.42 & 0.21 & 0.34 & 0.53 \\
Decile 7 & 0.30 & 0.61 & 0.44 & 0.44 & 0.73 \\
Decile 8 & 0.24 & 0.73 & 0.31 & 0.28 & 0.49 \\
Decile 9 & 0.18 & 1.36 & 1.03 & 1.01 & 1.11 \\
Decile 10 & 0.09 & 1.34 & 1.32 & 1.25 & 1.21 \\
\hline $\begin{array}{l}\text { Top - Bottom } \\
\text { Decile }\end{array}$ & & $-1.84 * * *$ & $-1.88^{* * *}$ & $-1.73^{* * *}$ & $-1.45^{* * *}$ \\
\hline
\end{tabular}

This table presents the relationship between the Style Deviation Degree (SDD) and several fund characteristics. We sorted funds into decile and calculated fund performance within the portfolios. Top - Bottom Decile- represents the test of equal means between the top and bottom decile; we report t- stat in parentheses. We indicate significance at the $10 \%, 5 \%$ and $1 \%$ level, by $*, * *$, and ***, respectively.

\subsubsection{Persistence of Style deviation}

Style deviation can be due to short-term negligence or might persist for a longer time period. To test whether style deviation is persistent on a long-term basis, we sort all mutual funds in our sample into deciles according to their lagged Style Deviation Degree during the previous 3-, 5- and 7- year intervals and show the average Style Deviation Degree during the subsequent year. The result shows that 
Chapter 2

the style-concentration ranking of the decile portfolios in the year after the formation period remains identical to that in the formation period.

Table 2-9- Persistence of the Style Deviation Degree

\begin{tabular}{lccc}
\hline & 3 Years & 5 Years & 7 Years \\
\hline Decile 1 (Highest misclassified funds) & 0.58 & 0.75 & 0.80 \\
Decile 2 & 0.60 & 0.73 & 0.72 \\
Decile 3 & 0.58 & 0.70 & 0.71 \\
Decile 4 & 0.56 & 0.66 & 0.67 \\
Decile 5 & 0.50 & 0.57 & 0.67 \\
Decile 6 & 0.34 & 0.47 & 0.66 \\
Decile 7 & 0.40 & 0.41 & 0.49 \\
Decile 8 & 0.28 & 0.36 & 0.42 \\
Decile 9 & 0.28 & 0.26 & 0.33 \\
Decile 10 (Lowest misclassified funds) & 0.25 & 0.17 & 0.19 \\
\hline (1)-(10) & $\begin{array}{l}0.33^{* * *} \\
(4.20)\end{array}$ & $0.58^{* * *}$ & $(5.18)$ \\
\hline
\end{tabular}

This table reports the means of the 3-year, 5-year and 7-year Style Deviation Degree (SDD) for decile portfolios of mutual funds sorted by their average lagged SDD during the previous 3, 5, and 7 years over the period July-2003 to Jan-2016. The table also calculates the differences in the SDD between the top and the bottom deciles, along with the corresponding t-stats in parentheses. The significance levels are denoted by $*, * *$, and $* * *$ and indicate whether the results are statistically different from zero at the 10-, 5-, and 1-percent significance levels.

Deciles are formed according to the average $S D D$ during the previous 3-, 5-, and 7year intervals. The first column shows that funds in the highest misclassified decile, based on the previous 3 years, show an average $S D D$ of 0.58 in the subsequent 3 years. On the other hand, funds in the lowest misclassified decile show a $S D D$ of 0.25 . The difference in the $S D D$ between the two extreme deciles is 
Investment Style Misclassification and Mutual Fund Performance statistically significant, as is the difference between the top five and the bottom five deciles. Furthermore, the average $S D D$ decreases monotonically.

To indicate evidence on the long-term persistency of the misclassification pattern, we also track the SDD over the subsequent 5 and 7 years. The second and third columns in Table 2-9 show the persistence pattern is also remarkably persistent over a longer time period if we sort funds according to their average $S D D$ during the prior 5 and 7 years.

\subsection{Robustness tests}

In this section we test whether our previous results are sensitive to benchmark choice or to sample period. Index selection is an important issue in RBSA. Hence, we pay close attention to the benchmark choice in setting up an RBSA model especially when the correlation coefficients between benchmarks are high. As Sensoy (2009) discussed, over $90 \%$ of U.S. equity mutual funds use the S\&P or Russell benchmark index. According to Table 2-1, the correlations between benchmarks are high and this may cause problems. To assess the impact of this choice on our results we replace both the S\&P500 value and growth benchmark by the Russell 1000 value and Russell 1000 growth and we consider Russell 2000 as small cap benchmark. ${ }^{18}$ The results in Table 2-10 lead us to believe that our results remain unchanged when using alternative benchmarks. Appendix B includes two more robustness tests.

\footnotetext{
${ }^{18}$ We also employ the S\&P500 pure value and S\&P500 pure growth indices. They do not have any impact on our previous results.
} 
Chapter 2

Table 2-10- Results Robustness Test RBSA model - Alternative style benchmarks- Russell indices

Panel A: Estimated style weights for Alive Portfolio

\begin{tabular}{lllllll}
\hline Objective & Value & Growth & Small cap & Cash & Bond & $\mathrm{R}^{2}$ \\
\hline Growth & $0.19^{* * *}$ & $0.66^{* * *}$ & $0.14^{* * *}$ & 0.00 & 0.00 & 0.97 \\
Income & $0.65^{* * *}$ & $0.26^{* * *}$ & $0.06^{* * *}$ & $0.06^{* * *}$ & $0.02^{* * *}$ & 0.98 \\
Small cap & $0.00^{* * *}$ & $0.15^{* * *}$ & $0.84^{* * *}$ & $0.00^{* * *}$ & 0.00 & 0.96 \\
Growth/Income & $0.46^{* * *}$ & $0.42^{* * *}$ & $0.05^{* * *}$ & $0.06^{* * *}$ & 0.00 & 0.97 \\
\hline
\end{tabular}

Panel B: 95\% Confidence intervals for style weights

\begin{tabular}{llllll}
\hline Objective & Value & Growth & Small cap & Cash & Bond \\
\hline Growth & {$[0.15-0.23]$} & {$[0.62-0.70]$} & {$[0.12-0.17]$} & {$[0.00-0.01]$} & {$[0.00-0.01]$} \\
Income & {$[0.62-0.69]$} & {$[0.22-0.29]$} & {$[0.00-0.03]$} & {$[0.04-0.08]$} & {$[0.01-0.03]$} \\
Small cap & {$[0.00-0.04]$} & {$[0.11-0.18]$} & {$[0.81-0.87]$} & {$[0.00-0.01]$} & {$[0.00-0.01]$} \\
Growth/Income & {$[0.42-0.49]$} & {$[0.39-0.46]$} & {$[0.02-0.07]$} & {$[0.04-0 . .07]$} & {$[0.00-0.01]$} \\
\hline
\end{tabular}

Notes This table presents the parameter estimates of the RBSA model for six equally weighted portfolios of funds. In panel A estimated style weights are given. Each row deals with one particular investment objective, where the elements in columns 2 to 6 report the estimated style weights. Panel B reports the $95 \%$ confidence intervals for all estimated style weights. We indicate significance at the $10 \%, 5 \%$ and $1 \%$ level, by $* * *$ and ${ }^{* * *}$, respectively. 


\subsection{Conclusion}

Mutual fund investors, when selecting funds, rely on the information provided in a mutual fund's investment prospectus. In addition to that the SEC mandates funds to stick to their stated investment styles. However, previous research has shown that funds frequently deviate from their stated investment style. We extend the previous literature in 3 distinct ways; 1) by developing a novel continuous measure of style deviation we provide a more granular investigation of the impact on the level of deviation on fund performance, 2) we focus on long-term deviation where previous studies focus on short-term, and 3) we examine the link between the level of style deviation and fund characteristics.

Using a sample of 1,866 US equity funds over the 2003-2016 period and by taking advantage of the new measure we document 3 main results: 1) mutual funds differ substantially in their commitment to follow the stated investment style. 2) by using our more granular classification, based on the level of misclassification, we find that the most misclassified funds significantly underperform well classified funds by $1.73 \%$ per year based on Carhart alpha of gross return, and 3) misclassified funds appear to be younger, smaller in size and charge higher expense ratios. The results are robust using alternative performance measures and alternative style benchmarks. From this we infer that monitoring long term style deviation is critically important for investors. Maintaining a consistent style is a crucial ingredient for achieving solid long-term risk-adjusted performance. We believe that the Style Deviation Degree offers a meaningful benefit to investors trying to investigate the style deviation level of mutual funds. 
Chapter 2

\subsection{Appendix A}

Sharpe's model as described in section 2 is compactly rewritten in matrix algebra terms as follows:

$Y=X \beta+u_{y}$

$j^{\prime} \beta=1$

$\beta \geq 0 \quad k=2, \ldots, N+1$

Where $Y$ is a $(T \times 1)$ vector of fund returns, $\mathrm{X}$ denotes a $T \times(N \times 1)$ matrix where the elements in the first column are all one, and the other columns consist of $\mathrm{N}$ style index returns, $\mathrm{u}$ is a $(T \times 1)$ vector of error terms. The $(N+1) \times 1$ vector $\beta$ has as first element the intercept $\alpha$ and the other elements are the style index sensitivities denoted by $\beta_{k}(k=1, \ldots, N)$. We are interested in the parameter estimates together with the associated asymptotic distribution for the vector. Because of the inequality constraints, we employ the estimation algorithm introduced by Kuhn-Tucker. We show that in the case of a linear regression model this Kuhn-Tucker estimator, denoted as $b_{K T}$, can be written in terms of a so-called Lagrange estimator, $b_{L}$. A Lagrange estimator finds optimal parameter estimates subject to equality constraints. Next, the Lagrange estimator can be expressed in terms of the ordinary least squares (OLS) unconstrained estimator, $b_{U}$.

The principle behind the Kuhn-Tucker algorithm lies in the treatment of the inequality constraints on the factor sensitivities. When a particular constraint is non-binding then its estimator for the associated factor loading is equal to the OLS estimator. When the particular constraint is binding then its estimator is equal to the Lagrange estimator. Beforehand it is not known which constraints will be binding and which will be non-binding. Therefore, we consider the estimators for all possible combinations of binding and non-binding restrictions. The combination 
Investment Style Misclassification and Mutual Fund Performance that leads to the lowest residual sum of squares and that meets all constraints then leads to the optimal parameter estimates. We show that the Kuhn-Tucker solution is expressed in terms of the unconstrained least squares estimator as follows:

$b_{K T}=\min \left\{\left(Y-X b_{s}\right)^{\prime}\left(Y-X b_{s}\right) \mid j^{\prime b_{S}}=1 ; S b_{s}=0\right\}$

Where

$b_{S}=\left[I_{N+1}-V S\left(S V S^{\prime}\right)^{-1} S\right] P+\left[I_{N+1}-V S\left(S V S^{\prime}\right)^{-1} S\right]\left[I_{N+1}-P\right] b_{U}$

$P=\left(X^{\prime} X\right)^{-1} j\left[j^{\prime\left(X^{\prime} X\right)^{-1}} j\right]^{-1}$

$V=\left(I_{N+1}-P j^{\prime}\right)\left(X^{\prime} X\right)^{-1}$

and $I_{N+1}$ is the $(N+1) \times(N+1)$ identity matrix. Let $S$ be the matrix that represents the binding inequality constraints, i.e. the associated equality constraint reads

$$
S \beta=0
$$

For example, the following $2 \times(N+1)$ matrix represents the sub-problem where the second and the third parameter are binding:

$$
S=\left(\begin{array}{llllll}
0 & 1 & 0 & 0 & \cdots & 0 \\
0 & 0 & 1 & 0 & \cdots & 0
\end{array}\right)
$$

The set of all possible matrices $\mathrm{S}$ representing combinations of binding and nonbinding constraints is given by $\Omega$. The expressions above show that the KuhnTucker solution is identical to the Lagrange estimator $\left(b_{s}\right)$ for one of the possible sub-problems $(S \in \Omega)$, i.e. combination of binding and non-binding constraints. In equation (7A) we show that this estimator is related to the unconstrained estimator and some deterministic matrices. The unconstrained least squares estimator reads 
Chapter 2

$$
b_{u}=\left(X^{\prime} X\right)^{-1} X^{\prime} Y
$$

And the associated variance covariance matrix is given by

$$
V\left(b_{u}\right)=\hat{\sigma}^{2}\left(X^{\prime} X\right)^{-1}
$$

Where $\hat{\sigma}^{2}$ is the variance of the residuals. The asymptotic distribution of the KuhnTucker estimate follows by employing the standard bootstrapping technique. To arrive at this distribution we proceed as follows:

1. Draw a sample for the error term, denoted with $u^{i} \sim N\left(0, \hat{\sigma}^{2} I_{T}\right)$

2. Construct a vector of dependent variables $y^{i}=X b_{K T}+u^{(i)}$

3. Estimate the model $y^{(i)}=X \beta+u^{(i)}$ subject to the constraints in (7) and (8)

4. This leads to an estimate $b_{K T}^{(i)}$

5. Repeat steps (1)-(4) 10,000 times. This gives a set $b_{K T}^{(i)} i=1, \ldots, 10,000$

These 10.000 values represent the asymptotic distribution of the Kuhn-Tucker estimator.

Finally, we obtain the asymptotic confidence interval by using the percentiles of the bootstrapped distribution. When bootstrapped samples are completed, we sort the results and then the 5th and 95th largest values show the confidence interval.

\subsection{Appendix B}

As a second robustness check we divide our sample period into two equal subperiods. The first sub-period runs from July 2003 - September 2009 and the second sub-period from October 2009 - January 2016. The results for both sub-periods are fairly identical and confirm our prior results. 
Investment Style Misclassification and Mutual Fund Performance

Table 2-11- Results Robustness Test RBSA model - sub-sample analysis 20032009

Panel A: Estimated style weights for Alive Portfolio

\begin{tabular}{lllllll}
\hline Objective & Value & Growth & Small cap & Cash & Bond & $\mathrm{R}^{2}$ \\
\hline Growth & $0.19^{* * *}$ & $0.67^{* * *}$ & $0.14^{* * *}$ & 0.00 & 0.00 & 0.98 \\
Income & $0.54^{* * *}$ & $0.30^{* * *}$ & $0.06^{* * *}$ & $0.07 * * *$ & $0.03^{* * *}$ & 0.96 \\
Small cap & $0.01^{* * *}$ & $0.16^{* * *}$ & $0.83^{* * *}$ & $0.00^{* * *}$ & 0.00 & 0.96 \\
Growth/Income & $0.46^{* * *}$ & $0.44^{* * *}$ & $0.05^{* * *}$ & $0.04^{* * *}$ & 0.01 & 0.97 \\
\hline
\end{tabular}

Panel B: 95\% Confidence intervals for style weights

\begin{tabular}{llllll}
\hline Objective & Value & Growth & Small cap & Cash & Bond \\
\hline Growth & {$[0.13-0.24]$} & {$[0.61-0.72]$} & {$[0.10-0.18]$} & {$[0.00-0.02]$} & {$[0.00-0.02]$} \\
Income & {$[0.48-0.59]$} & {$[0.24-0.36]$} & {$[0.02-0.10]$} & {$[0.03-0.11]$} & {$[0.00-0.05]$} \\
Small cap & {$[0.00-0.05]$} & {$[0.10-0.21]$} & {$[0.78-0.87]$} & {$[0.00-0.03]$} & {$[0.00-0.02]$} \\
Growth/Income & {$[0.42-0.50]$} & {$[0.39-0.48]$} & {$[0.02-0.09]$} & {$[0.02-0.07]$} & {$[0.00-0.02]$} \\
\hline
\end{tabular}

This table presents the parameter estimates of the RBSA model for six equally weighted portfolios of funds. In panel A estimated style weights are given. Each row deals with one particular investment objective, where the elements in columns 2 to 6 report the estimated style weights. Panel B reports the $95 \%$ confidence intervals for all estimated style weights. We indicate significance at the $10 \%, 5 \%$ and $1 \%$ level, by $*, * *$ and $* * *$, respectively. 
Chapter 2

Table 2-12- Results Robustness Test RBSA model - sub-sample analysis 20092016

Panel A: Estimated style weights for Alive Portfolio

\begin{tabular}{lllllll}
\hline Objective & Value & Growth & Small cap & Cash & Bond & $\mathrm{R}^{2}$ \\
\hline Growth & $0.19^{* * *}$ & $0.64^{* * *}$ & $0.16^{* * *}$ & 0.01 & 0.00 & 0.97 \\
Income & $0.57 * * *$ & $0.33^{* * *}$ & $0.04 * * *$ & $0.02 * * *$ & $0.04 * * *$ & 0.96 \\
Small cap & $0.02^{* * *}$ & $0.10^{* * *}$ & $0.87^{* * * *}$ & $0.01 * * *$ & 0.01 & 0.98 \\
Growth/Income & $0.45^{* * *}$ & $0.41^{* * *}$ & $0.05^{* * *}$ & $0.08^{* * *}$ & 0.00 & 0.97 \\
\hline
\end{tabular}

Panel B: 95\% Confidence intervals for style weights

\begin{tabular}{llllll}
\hline Objective & Value & Growth & Small cap & Cash & Bond \\
\hline Growth & {$[0.14-0.25]$} & {$[0.59-0.69]$} & {$[0.13-0.19]$} & {$[0.00-0.02]$} & {$[0.00-0.01]$} \\
Income & {$[0.51-0.63]$} & {$[0.27-0.39]$} & {$[0.00-0.07]$} & {$[0.00-0.06]$} & {$[0.01-0.05]$} \\
Small cap & {$[0.00-0.07]$} & {$[0.05-0.15]$} & {$[0.83-0.90]$} & {$[0.00-0.03]$} & {$[0.00-0.02]$} \\
Growth/Income & {$[0.39-0.51]$} & {$[0.36-0.46]$} & {$[0.02-0.08]$} & {$[0.06-0.10]$} & {$[0.00-0.02]$} \\
\hline
\end{tabular}

This table presents the parameter estimates of the RBSA model for six equally weighted portfolios of funds. In panel A estimated style weights are given. Each row deals with one particular investment objective, where the elements in columns 2 to 6 report the estimated style weights. Panel B reports the $95 \%$ confidence intervals for all estimated style weights. We indicate significance at the $10 \%, 5 \%$ and $1 \%$ level, by $* * *$ and $* * *$, respectively.

As a final robustness check we investigate the relationship between the Style Deviation Degree and fund performance, as in Table 2-7, and the relationship between the Style Deviation Degree and fund characteristics, as in Table 2-6. Table 2-13 and Table 2-14 provide the results when applying Russell indices. The results are comparable to the findings in Table 2-7 and Table 2-8 respectively. 
Investment Style Misclassification and Mutual Fund Performance

Table 2-13- Relationship between Style Deviation Degree and Fund Performance by using the Russell indices

\begin{tabular}{lccccc}
\hline & SDD & $\begin{array}{c}\text { Annual style- } \\
\text { adjusted return }\end{array}$ & $\begin{array}{c}\text { Alpha- } \\
\text { CAPM }\end{array}$ & $\begin{array}{c}\text { Alpha- } \\
3 \mathrm{~F}\end{array}$ & $\begin{array}{c}\text { Alpha- } \\
\text { Carhart }\end{array}$ \\
\hline $\begin{array}{l}\text { Decile 1 (Highest } \\
\text { misclassified funds) } \\
\text { Decile 2 }\end{array}$ & 0.94 & -3.46 & -2.05 & -2.18 & -2.26 \\
Decile 3 & 0.74 & -3.50 & -1.28 & -1.38 & -1.41 \\
Decile 4 & 0.60 & -3.16 & -1.19 & -1.24 & -1.23 \\
Decile 5 & 0.51 & -2.47 & -1.02 & -1.05 & -1.09 \\
Decile 6 & 0.41 & -2.27 & -0.98 & -1.06 & -1.14 \\
Decile 7 & 0.33 & -2.88 & -1.49 & -1.34 & -1.41 \\
Decile 8 & 0.26 & -2.83 & -1.09 & -1.44 & -1.45 \\
Decile 9 & 0.21 & -2.76 & -1.15 & -1.34 & -1.33 \\
Decile 10 (Highest & 0.08 & -1.99 & -1.00 & -1.04 & -1.05 \\
well-classified funds) & & $-1.46 * * *$ & $-1.04 * * *$ & $-1.14 * * *$ & $-1.21 * * *$ \\
\hline (1)-(10) & & $-4.45)$ & $(-2.89)$ & $(-3.20)$ & $(-3.47)$ \\
\hline
\end{tabular}

This table presents the relationship between the Style Deviation Degree (SDD) and several fund performance basis. We sorted funds into decile and calculated fund performance within the portfolios. (1)-(10) represents the test of equal means between the top and bottom decile; we report t- stats in parentheses. We indicate significance at the $10 \%, 5 \%$ and $1 \%$ level, by $* * *$, and ${ }^{* * *}$, respectively. 
Chapter 2

Table 2-14- Relationship between Style Deviation Degree and Fund Characteristics by using the Russell indices

\begin{tabular}{|c|c|c|c|c|c|}
\hline & SDD & $\begin{array}{c}\text { Turnove } \\
\text { r ratio }\end{array}$ & $\begin{array}{c}\text { \% Expense } \\
\text { ratio }\end{array}$ & $\begin{array}{c}\text { Log } \\
\text { (TNA) }\end{array}$ & $\begin{array}{c}\text { Log } \\
(\mathrm{Age})\end{array}$ \\
\hline $\begin{array}{l}\text { Decile } 1 \text { (Highest } \\
\text { misclassified funds) }\end{array}$ & 0.94 & 0.85 & 1.43 & 2.66 & 5.14 \\
\hline Decile 2 & 0.74 & 0.70 & 1.35 & 2.94 & 5.14 \\
\hline Decile 3 & 0.60 & 0.68 & 1.21 & 2.85 & 5.16 \\
\hline Decile 4 & 0.51 & 0.74 & 1.23 & 2.81 & 5.14 \\
\hline Decile 5 & 0.41 & 0.67 & 1.26 & 2.80 & 5.21 \\
\hline Decile 6 & 0.33 & 0.76 & 1.25 & 3.20 & 5.21 \\
\hline Decile 7 & 0.26 & 0.74 & 1.20 & 3.00 & 5.20 \\
\hline Decile 8 & 0.21 & 0.61 & 1.16 & 3.14 & 5.21 \\
\hline Decile 9 & 0.15 & 0.88 & 1.20 & 2.68 & 5.24 \\
\hline $\begin{array}{l}\text { Decile } 10 \text { (Highest } \\
\text { well-classified funds) }\end{array}$ & 0.08 & 0.71 & 0.99 & 3.27 & 5.20 \\
\hline (1)-(10) & & $\begin{array}{c}0.13 \\
(1.14)\end{array}$ & $\begin{array}{c}0.44 * * * \\
(7.32)\end{array}$ & $\begin{array}{c}-0.61 * * * \\
(-3.56)\end{array}$ & $\begin{array}{c}-0.12 * * * \\
(-5.59)\end{array}$ \\
\hline
\end{tabular}

This table presents the relationship between the Style Deviation Degree (SDD) and several fund characteristics. We sorted funds into deciles and calculated fund characteristics within the portfolios. (10)-(1) represents the test of equal means between the top and bottom decile; we report t- stats in parentheses. We indicate significance at the $10 \%, 5 \%$ and $1 \%$ level, by $*, * *$, and ${ }^{* *}$, respectively. 


\section{Chapter 3}

\section{Investor Clientele and Style Changing Behavior in Mutual Funds*}

* This chapter is co-authored with Dennis Bams (Maastricht University) and Roger Otten (Maastricht University) 
Chapter 3

\subsection{Introduction}

Prior studies show that the investment style of many mutual funds drift or even change over time and suggest that fund investors need to be aware of investment style changing behavior, because it can cause investors to be exposed to unexpected risk. ${ }^{19}$ On the other hand, some other studies show that investors vary with regards to sophistication level, and better-informed investors use more sophisticated tools to monitor fund managers. ${ }^{20}$ Hence, the assumption that all mutual fund investors are equally aware of investment style changes and likely to react equally to this behavior is deeply skeptical. Therefore, the central question of interest in this paper is whether the sensitivity of investors to fund managerial decisions that result in style changes can be different due to a difference in the investors' sophistication level. In addition, we will propose some potential explanations along these observations. For example, one potential explanation of heterogeneity in fund flow because of style changing behavior relates to the different impact of style deviation/drift on different fund performance measures. If style changes have a positive impact on a specific fund performance measure, which is used by an investor, it is possible that not only the investor does not penalize this behavior but may even reward it. Hence, it is relevant to understand how style-changing behavior affects different fund performance measures. Another possibility is that informed investors may play the role of "shareholder activism" in mutual funds to discipline fund managers with respect to style changing behavior. Hence, a strong relationship between the presence of sophisticated investors and the subsequent fund's investment style-changing behavior may partially explain the heterogeneity of fund flow.

19 See diBartolomeo \& Wikowski (1997), Brown \& Goetzmann (1997), Kim, Shukla \& Tomas (2000), Kim, White \& Stone (2005), Cremers and Petajisto (2007), Sensoy (2009), Mason et al. (2012), Bams, Otten \& Ramezanifar (2016) and Cao, Iliev and Velthuis (2017) among others.

${ }^{20}$ See Barber, Huang and Odean (2016) and Berk and Van Binsbergen (2016) among others. 
Investor Clientele and Style Changing Behavior in Mutual Funds Although a large body of literature has identified the sensitivity of fund investors to fund performance, a topic that has attracted much less attention is the sensitivity of fund investors to investment style-changing behavior. ${ }^{21}$ Previous findings are mixed; for example, Cooper, Huseyin and Rau (2005) find that a change in a mutual fund's stated investment objective, on average, causes a strong positive abnormal fund flow. They show that a simple timed name change can trick fund participants. Sensoy (2009) shows that deviation from the stated benchmarks matters to fund investors and causes an increase in fund flows. ${ }^{22}$ Barber, Huang and Odean (2016) find that investors, on average, are strongly sensitive to the factor-related returns associated with the Morningstar-style categories. In contrast, Barberis and Shleifer (2003) infer that investors categorize assets with respect to style category and they do not distinguish between assets within a style. Del Guercio and Tkac (2002) show that the money market pension fund sponsors punish high deviation from the benchmark as is measured by tracking error. ${ }^{23}$ However they do not find the same relationship in mutual funds. Holmes and Faff (2007) show that for Australian mutual funds the level of style drift is not related to fund flows.

Our study contributes to the literature in three distinct ways. First, while prior studies on fund investors' reactions to style deviation/drift treat all different types of investors equally, we extend this literature by highlighting and considering the heterogeneity of investors' flows with respect to their sophistication level. We believe that taking the average of fund flows means treating all investors as a homogenous group, which may ignore investor class-specific effects. Hence,

\footnotetext{
${ }^{21}$ For the relationship between fund flow and fund performance, see Ippolito (1992); Chevalier and Ellison (1997); Sirri and Tufano (1998); Brown, Harlow \& Starks (1996) and Clifford (2013) among others.

${ }^{22}$ Sensoy (2009) mentions that the mismatched self-designed benchmarks are not typically a result of style drift or a change in fund styles and so do not appear incidental.

${ }^{23}$ Tracking error is the standard deviation of the return difference between the fund and its benchmark.
} 
Chapter 3

previous findings could lead to undesirable conclusions. We address this concern by comparing how investors with different levels of sophistication respond to style deviation/drift of funds.

Second, less sophisticated investors with a lack of financial literacy are less equipped to evaluate fund managers in a proper way and they may simply rely on benchmark-adjusted returns to rank mutual funds. More sophisticated investors such as banks, hedge funds, pension fund sponsors and insurance companies are usually better equipped to evaluate fund performance with more precise measures like a multi-factor model. Berk and Van Binsbergen (2016) and Barber, Huang and Odean (2016) find that the average investor assesses fund performance with simple tools like the market-adjusted return. This simplicity may lead investors to interpret the style-changing behavior as a skill of fund managers, which is not the case if one considers size, value versus growth and momentum factors for fund performance evaluation. Thus, it is relevant to understand how style-changing behavior affects different performance metrics. By dividing fund performance measures in simple and advanced, we test whether style-changing behavior has an equal impact on different fund performance measures.

Third, we investigate the relationship between investment style discipline of fund managers and the fund participant's sophistication level. For example, Egan, Matvos and Seru (2016) show that misconduct of financial advisers in the US is concentrated in firms with retail customers and suggest that misconduct maybe targeted at customers who are less financially sophisticated. Therefore, when highsophisticated investors represent a larger proportion of fund investors, the fund manager may be restricted to engage in more strategic behavior such as style drift or style deviation. To test whether informed investors can effectively discipline fund managers with respect to style changing behavior, we examine the relationship between the sophistication level of fund participants and the subsequent fund investment style deviation/drift. 
Investor Clientele and Style Changing Behavior in Mutual Funds Using U.S. equity mutual funds data, we employ two different proxies to identify an investor's sophistication level. The first proxy distinguishes between retail funds and institutional funds at the share-class level. Since institutional investors have more "skin in the game" than retail investors, we would expect them to be better equipped to monitor managers than their smaller counterparts. Evans and Fahlenbrach (2012) use this proxy and show that institutional investors are more sensitive to high fees and poor risk-adjusted performance. Del Guercio and Tkac (2002) and Goyal and Waha (2008) show that institutional investors severely punish funds that perform poorly by redeeming their shares. James and Karceski (2006) report that institutional fund flows are significantly less sensitive to past fund raw returns and more sensitive to risk-adjusted measures of performance than retail fund flows. Moreover, for money market mutual funds, Christoffersen and Musto (2002) show that the performance sensitivity of institutional investors is strongly opposite to retail funds. They argue that funds with a worse performance history will have a clientele that is less performance-sensitive. Schmidt, Timmermann and Wermers (2016) find that prime institutional holdings in money market mutual funds, over the financial crisis, exhibit much larger persistence in run-like behavior than retail share classes. Therefore, we divide our sample into two parts: (i) institutional funds, representing sophisticated investors and (ii) retail funds, representing unsophisticated investors.

The second proxy of investor sophistication level distinguishes between a directsold versus broker-sold distribution channel. Buying mutual funds through a broker or an investment company usually means choosing among different mutual fund share-classes. Chalmers and Reuter (2013) show that investors who purchase mutual funds through a broker tend to be less well educated than investors who buy funds directly sold from fund companies. Del Guercio and Reuter (2013) find that flows are more sensitive to alpha for direct-sold funds than for broker-sold funds, while broker-sold funds respond more to market-adjusted returns. Barber, Huang 


\section{Chapter 3}

and Odean (2016) find that direct-sold fund investors use more sophisticated models to assess fund manager skill rather than broker-sold fund investors. They infer that direct-sold fund investors take into account a fund's exposure to factors such as size and value rather than attributing the excess returns to manager skill. For this reason, following Barber, Huang and Odean (2016) and Evans and Fahlenbrach (2012), we split our sample into: (i) broker-sold, representing unsophisticated investors and (ii) direct-sold funds, representing sophisticated investors.

To measure the style changing behavior of fund managers, we employ two different approaches to capture both sides of this behavior including: (i) style deviation and (ii) style drift. Style deviation is defined as the difference between the actual investment style and the stated investment style of a fund which is reported in the fund's prospectus. Style drift of mutual funds is defined as the volatility of a fund's investment style exposures over time which represents the fund's investment style consistency. To quantify style deviation and style drift in mutual funds, prior studies propose several quantitative methods. Using the return of mutual funds data, Bams, Otten \& Ramezanifar (2016) introduce the Style Deviation Degree (SDD) as a continuous investment style deviation measure. We adopt the SDD to rank all funds in our sample in terms of investment style deviation. Idzorek and Bertsch (2004) use fund return data and develop the Style Drift Score (SDS) as a single quantitative measure of style consistency of a fund over time. In our analysis, we also employ this measure as a style drift index.

Our empirical analysis that we apply to the fine granularity of hand-inspected US equity mutual funds data at the share class-level brings new insights into the existing literature. We first find that on average, investors are more sensitive to absolute deviation of fund from the stated investment style than to the volatility of fund's investment style exposures over time. In addition, we show that there is a significant positive relationship between fund flows and fund's style deviation 
Investor Clientele and Style Changing Behavior in Mutual Funds which is in line with Cooper, Huseyin and Rau (2005), Sensoy (2009) and Barber, Huang and Odean (2016). Surprisingly, when we account for heterogeneity of investor's sophistication level, the results change. Our findings indicate that the relation between high (low) sophisticated investor flows and style deviation is negative (positive). For example, a one standard deviation increase in the style deviation index, leads to a $6 \%$ increase in retail fund flows and 3\% reduction in institutional fund flows, which is in contrast with the effect of fund performance on fund flow. ${ }^{24}$ To put the magnitude into context, the effect of style deviation on retail investor fund flows is half the magnitude of the effect of a one standard deviation increase in a fund's prior one-year alpha on fund flows. Moreover, the results are robust for the alternative sophistication proxy, which is broker-sold versus direct-sold funds. For example, the effect of style deviation on the average inflow of broker-sold funds exceeds the inflow of direct-sold funds by more than $14 \%$ per year. We also find that the aggregate result (i.e. the average reaction of all investors to the funds' style deviation) is driven by less-sophisticated fund investors.

Second, by using relatively simple fund performance measures such as benchmarkadjusted return and CAPM alpha and employing more advanced fund performance measures such as factor related returns, we find that style deviation/drift has a positive impact on simple measures and there is no impact on more sophisticated measures. Therefore, less sophisticated investors may interpret style-changing behavior of fund managers as managerial skill. However, sophisticated investors correctly interpret the behavior and leave the style deviated funds.

Third, our results show that there is no relationship between the proportion of less sophisticated investors and the subsequent degree of fund's style deviation/drift.

\footnotetext{
${ }^{24}$ Our results are robust even after considering the convex relationship between fund flow and fund performance.
} 


\section{Chapter 3}

This finding suggests that fund managers do not take advantage of less sophisticated investors by displaying more style changing behavior in the future.

Overall, we argue that a comparison of the fund flow-style changing relationship, by accounting for investor's sophistication level, allows for a more complete picture of an investor's response to the changes in mutual funds' investment style behavior. The remainder of the paper is organized as follows. In section 2, we describe the data that are used in the empirical application. In section 3, we provide a description of the methodology, section 4 represents empirical findings and section 5 includes a robustness check. Finally, section 6 concludes the paper.

\subsection{Data}

To classify the US equity mutual funds in our sample through stated investment objectives, we first review all their prospectuses to determine the principal investment strategy of each fund. ${ }^{25}$ We then employ the Lipper objective codes from the CRSP Survivor-Bias Free database to obtain the historical stated investment style of mutual funds. In the CRSP database only the Lipper objective code is based on a mutual fund's prospectus. ${ }^{26} \mathrm{We}$ also check the historical stated investment style data with the funds' own websites and the official SEC website.

We obtain daily fund return data and monthly/quarterly fund characteristics data including fund expense ratio, Total Net Asset value (TNA), front-end load, backend load and 12b-1 fees at the share-class level. Following Sirri and Tufano (1998), we calculate flows for each share-class $i$ in year $t+1$ as follows:

\footnotetext{
${ }^{25}$ Each fund's prospectus has a specific section which describes what funds invest primarily.

${ }^{26}$ Lipper is also a global leader in providing mutual fund information and its website mentions that: "Lipper's benchmarking and classifications are widely recognized as the industry standard by asset managers, fund companies and financial intermediaries. Our reliable fund data, fund awards designations and ratings information provide valued insight to advisors, media and individual investors."
} 
Investor Clientele and Style Changing Behavior in Mutual Funds

Fund Flow litt+1 $=\left[T N A_{i, t+1}-\left(1+r_{i, t+1}\right) T N A_{i t}\right] / T N A_{i t}$

Where $T N A_{i t}$ is the total net asset value of fund $i$ at the share class-level at the end of year $t$, and $r_{i, t+1}$ is the fund's return over the year $t+1$. All other fund characteristics such as age and turnover are obtained from the CRSP database.

Since the focus of this paper is on actively managed equity funds, we exclude index funds, fixed income funds, as well as balanced and sector funds. Moreover, we remove all funds from the database which have negative weights to exclude short-selling considerations. Also, funds managing less than $\$ 1.5$ million are excluded from our database. We then categorize funds as institutional and retail funds when CRSP designates them as such at the share-class level. ${ }^{27}$ The number of distinct U.S. mutual funds that meet our selection criteria over the sample period from July 2003 through January 2016 is 891 funds with 3,624 different share classes. These funds are classified into three main investment style classes including Growth, Value and Small-cap mutual funds. The data for computing the multi-factor model returns includes the CAPM, the Fama and French (1992) 3factor model and the Carhart (1997) 4-factor model, retrieved from French's website.

Furthermore, as we only consider U.S. equity funds, the relevant style benchmarks are all U.S. indices which are all daily total returns. We include the U.S. value index (S\&P500 Value index), the U.S. growth index (S\&P500 Growth index), the U.S. small cap index (S\&P600 index) and two fixed income classes: cash (30-day Treasury bill rate) and bonds (30-year bonds). The daily indices return data are obtained from FactSet.

27 The CRSP classification of funds into institutional or retail starts from the year 1999, which is why we use this year as the starting point in our investigation. 
Chapter 3

Table 3-1- Descriptive statistics

\begin{tabular}{|c|c|c|c|c|}
\hline & Mean & Std. Dev. & Min & Max \\
\hline \multicolumn{5}{|l|}{ A: Fund characteristics } \\
\hline TNA (\$ million) & 1,576 & 7,281 & 1.5 & 189,188 \\
\hline Turnover Ratio & 0.79 & 0.87 & 0.01 & 13.30 \\
\hline Fund Flow (\%) & 0.06 & 0.45 & -2.16 & 2.98 \\
\hline Fund Age (year) & 13.66 & 10.20 & 1.0 & 78.1 \\
\hline \multicolumn{5}{|l|}{ B: Fund Fees (Annually) } \\
\hline Expense Ratio & 1.26 & 0.49 & 0.04 & 2.15 \\
\hline $12-b$ fee $(\%)$ & 0.59 & 0.35 & 0.00 & 1.00 \\
\hline Front-end Load (\%) & 2.20 & 1.30 & 0.00 & 5.70 \\
\hline Back-end Load (\%) & 0.70 & 0.69 & 0.00 & 2.61 \\
\hline \multicolumn{5}{|l|}{$\begin{array}{l}\text { C: Retail vs. institutional } \\
\text { funds }\end{array}$} \\
\hline $\begin{array}{l}\text { TNA of retail funds ( } \$ \\
\text { million) }\end{array}$ & 1,403 & 5,942 & 0.10 & 112,035 \\
\hline $\begin{array}{l}\text { TNA of institutional funds (\$ } \\
\text { million) }\end{array}$ & 733 & 3,514 & 0.10 & 77,829 \\
\hline $\begin{array}{l}\text { Expense ratio of retail funds } \\
\text { (Annually) }\end{array}$ & 1.42 & 0.49 & 0.01 & 4.82 \\
\hline $\begin{array}{l}\text { Expense ratio of institutional } \\
\text { funds (Annually) }\end{array}$ & 0.97 & 0.36 & 0.4 & 2.99 \\
\hline
\end{tabular}




\subsection{Method}

In this section, we show how we quantify investment style changing behavior of mutual funds which includes (i) deviation from the stated investment objective and (ii) investment style consistency over time. Although the Security and Exchange Commission (SEC) mandates all mutual funds to adhere to their self-claimed investment style, previous studies on mutual funds style analysis show that a substantial number of funds deviate from their investment style mandates. ${ }^{28}$ To measure the style deviation from the stated investment objective we first categorize all funds in our sample in different style classes based on what they claim in their prospectus. To show the difference between actual investment style and stated investment style, we employ the Style Deviation Degree (SDD), which has been introduced by Bams, Otten \& Ramezanifar (2016). Based on this measure, we rank all mutual funds on a continuous scale with respect to the extent of their style deviation.

In addition, we capture style consistency of mutual funds as the second dimension of investment style analysis by using the style drift measure. In particular, we employ the Style Drift Score (SDS) of Idzorek and Bertsch (2004). This measure shows the consistency of the investment style of a fund by calculating the volatility of a fund's investment style over time. The style deviation measure can be different from the style drift measure. For example, if a fund manager of a growth style mutual fund consistently invests in value stocks over time, the style drift would be close to zero but the style deviation will be high and close to one. The SDD and SDS are determined within the framework of Return Based Style Analysis (RBSA) which has been introduced by Sharpe (1992). RBSA is generally expressed as follows:

28 See diBartolomeo \& Wikowski (1997), Brown \& Goetzmann (1997), Kim, Shukla \& Tomas (2000), Kim, White \& Stone (2005), Cremers and Petajisto (2007), Sensoy (2009), Mason et al. (2012) and Bams, Otten \& Ramezanifar (2016) among others. 
Chapter 3

$$
R_{i t}=\sum_{k=1}^{N} \beta_{i k} I_{k t}+u_{i t} \quad t=1, \ldots, T
$$

where $R_{i t}$ denotes the return of mutual fund $i$ at time $t, N$ is the number of style classes, $\beta_{i k}$ is a style parameter that expresses the sensitivity of fund $i$ 's return to the factor-mimicking portfolio return of index $k ; I_{k t}$ denotes the return of index $k$ at time $t$ and $u_{i t}$ is an error term. In our analysis, we employ the strong form of RBSA, in which the style parameters must be positive and sum to 1 .

SDD measures the deviation of a fund from the stated investment style and is defined as one minus the $(1-\alpha)$ quintile of the asymptotic distribution of the investment style exposure: ${ }^{29}$

$S D D=1-\inf \left\{x: \operatorname{Prob}_{P}\{\beta \leq x\} \geq 1-\alpha\right\}$

where $\mathrm{P}$ is the asymptotic distribution of style parameter $\beta ; 0 \leq x \leq 1$ represents possible values for $\beta$ under $\mathrm{P}$. The asymptotic distribution of the style parameters is determined by bootstrapping and is by construction always between zero and one, allowing the measure to be interpreted as a standardized degree. As the SDD gets close to zero, it shows that the fund is highly likely to be a style disciplined fund and clearly, as the SDD gets close to one, it shows that the fund is highly likely to be a style deviated fund.

SDS captures investment style variation of fund over time; the model will be applied using a 'rolling window' technique over an initial time window, which is 36 months using daily observations; subsequently the window will be moved forward by 1 month and new style exposures will be calculated. The SDS is

29 This paper focuses on the Lipper objective codes as a proxy for the stated investment style. Lipper's objective codes are assigned based on the language that the fund uses in its prospectus to describe how it intends to invest. Morningstar is a widely-used source for style analysis but the classification method is not based on the fund's prospectus. 
Investor Clientele and Style Changing Behavior in Mutual Funds calculated as the square root of the sum of the variances of the asset class coefficients:

$S D S=\sqrt{\operatorname{var}\left(\beta_{1 t}\right)+\operatorname{var}\left(\beta_{2 t}\right)+\cdots+\operatorname{var}\left(\beta_{k t}\right)}$

Where $\beta_{1 t}, \beta_{2 t} \ldots \beta_{k t}$ represent the time series of style exposure estimates which have been obtained from the style analysis process (Equation 2); $\mathrm{k}$ is the number of indices. Idzorek and Bertsch (2004) argue that the SDS is an effective, timeefficient way to compare style consistency and eliminates the need to examine rolling window style graphs. A fund with a high SDS will demonstrate greater style inconsistency than a fund with a low SDS. For the cross-sectional analysis, SDS will be used as a measure of style drift as it provides a mean value of the variation in style index coefficients for each fund. SDS is the primary test variable in our analysis.

Table 3-2 reports the value of both measures at the end of each year from 2004 to 2015.

Table 3-2- Style Deviation Degree (SDD) and Style Drift Score (SDS)

\begin{tabular}{ccccccccccccc}
\hline & 2004 & 2005 & 2006 & 2007 & 2008 & 2009 & 2010 & 2011 & 2012 & 2013 & 2014 & 2015 \\
& & & & & & & & & & & & \\
\hline SDD & 0.52 & 0.51 & 0.55 & 0.53 & 0.44 & 0.46 & 0.48 & 0.45 & 0.44 & 0.47 & 0.44 & 0.42 \\
& $(0.30)$ & $(0.2$ & $(0.32)$ & $(0.31)$ & $(0.26)$ & $(0.26)$ & $(0.28)$ & $(0.27)$ & $(0.28)$ & $(0.29)$ & $(0.29)$ & $(0.28)$ \\
& & 8 & & & & & & & & & & \\
SDS & 0.13 & 0.17 & 0.15 & 0.17 & 0.15 & 0.15 & 0.12 & 0.13 & 0.12 & 0.12 & 0.13 & 0.10 \\
& $(0.07)$ & $(0.1$ & $(0.09)$ & $(0.10)$ & $(0.09)$ & $(0.10)$ & $(0.09)$ & $(0.10)$ & $(0.08)$ & $(0.10)$ & $(0.09)$ & $(0.07)$ \\
& & $0)$ & & & & & & & & & & \\
\hline
\end{tabular}

This table reports the mean of the Style Deviation Degree (SDD) and the Style Drift Score (SDS) at the end of each year from 2004 to 2015. Standard deviations are shown within parentheses. 
Chapter 3

\subsection{Results}

In this section, we show the sensitivity of fund investors with differing levels of sophistication to style changing behavior of mutual funds. We believe that highsophisticated investors respond differently to a fund's style-changing behavior than less-sophisticated investors. We next show how style-changing behavior of funds affects different fund performance measures. Finally, we test whether the high proportion of sophisticated fund's participants, in terms of fund activism, can effectively discipline fund managers with respect to style-changing behavior. ${ }^{30}$

\subsubsection{Institutional investors versus retail investors}

Institutional mutual fund investors such as banks, hedge funds, pension funds and insurance companies have more sophisticated systems for monitoring the decisions made by mutual fund managers in comparison with retail investors.

The share classes of mutual funds allow us to split our data into an institutional investor subsample and retail investor subsample. Therefore, we test whether institutional investors and retail investors within the same fund react differently to a change in style. For this, we examine the relationship of investor fund flows at the share-class level to style deviation and style drift of mutual funds. Our tests are based on separate panel data regressions for both subsamples, by considering the fund's degree of style deviation/drift as well as various control variables as follows:

$S T D$ : the volatility of past performance measured as the standard deviation of returns over the performance estimation period; $A G E$ : fund age measured by the natural logarithm of age; SIZE: fund size measured by the natural logarithm of

\footnotetext{
${ }^{30}$ Evans and Fahlenbrach (2012) show that informed investors can effectively discipline fund managers.
} 
Investor Clientele and Style Changing Behavior in Mutual Funds fund TNA in the previous year; FEE: lagged total expense ratio, and FLOW: aggregate flow into each fund category in the preceding year.

We compute the SDD and SDS measures in year $t$ to show the level of style deviation and style drift of mutual funds respectively. The SDD and SDS employ fund's preceding 1-year daily fund returns data. We then establish the panel data regression for institutional investors and retail investors separately as follow:

$$
\begin{gathered}
\text { Flow }_{i, t+1}=a+b_{1} * \text { Alpha }_{i, t}+b_{2} * S D D_{i, t} \\
+ \text { Controls } \varepsilon_{i, t+1} \\
\text { Flow }_{i, t+1}=a+b_{1} * \text { Alpha }_{i, t}+b_{2} * S D S_{i, t} \\
+ \text { Controls } \varepsilon_{i, t+1}
\end{gathered}
$$

Flow $w_{i, t+1}$ is the fund flow at year $\mathrm{t}+1$, Alpha is the fund performance, measured as the Carhart 4-factor alpha for the preceding year $t$. We consider fund fixed effect and time fixed effect in all panel data regressions. 


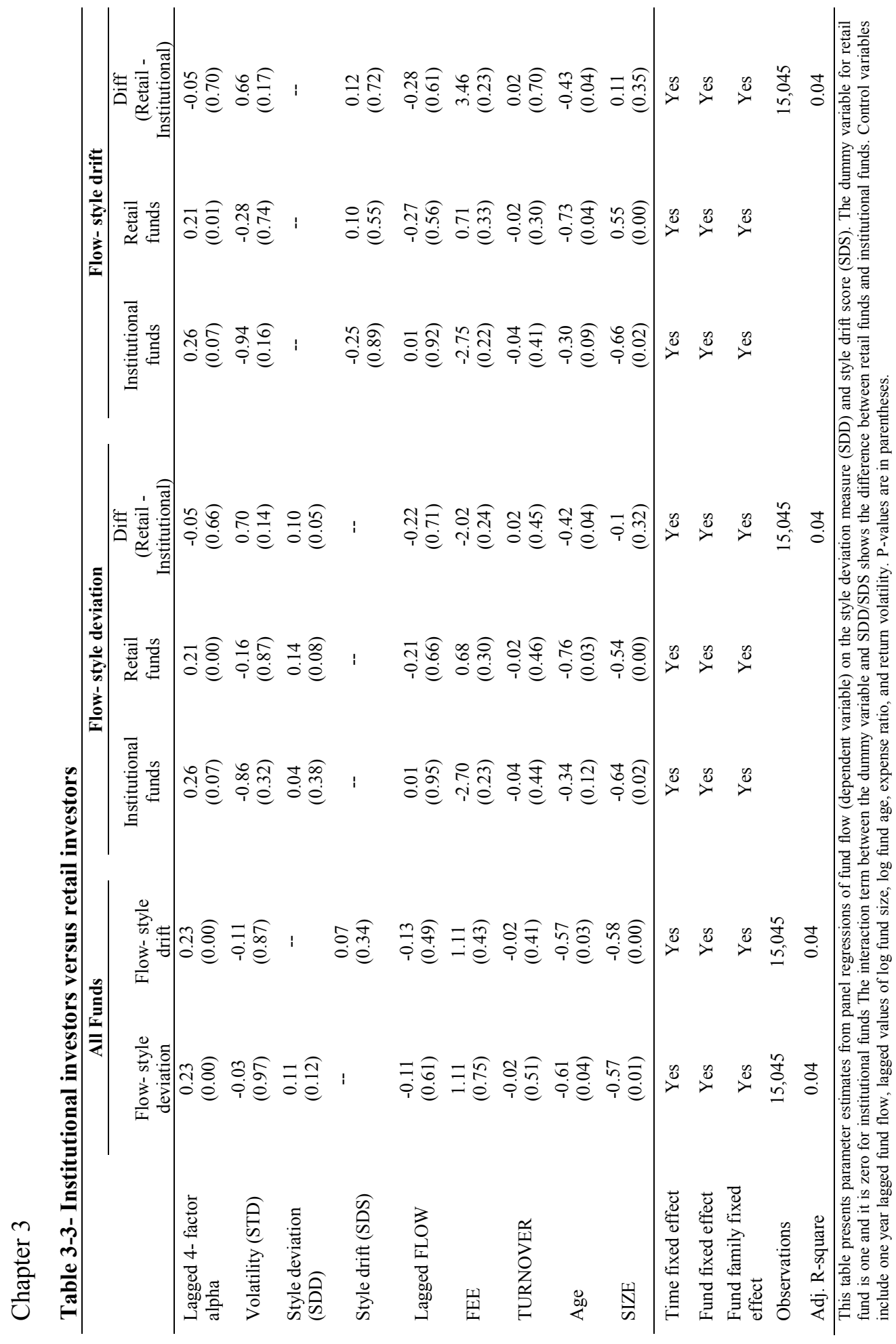


Table 3-3 shows that difference between fund flow of retail funds versus institutional funds with respect to the style deviation is positively significant. This table also reports that fund retail investors positively respond to style-changing behavior and they may interpret this behavior as a skill of the fund manager. However, the institutional investors leave funds when style changing occurs, which hence suggests that highly sophisticated investors have better tools and knowledge to monitor fund manager behavior.

To compare the coefficients with each other, in unreported results we calculate the standardized regression coefficients. We find that with one standard deviation increase in the style deviation degree, there is $6 \%$ increasing in the retail fund flows and $3 \%$ reduction in the institutional fund flows.

\subsubsection{Broker-sold funds versus direct-sold funds}

As a second proxy for investor sophistication level, we divide our sample into two subsamples (i) direct-sold funds and (ii) the broker-sold funds. Following Barber, Huang and Odean (2016), and Evans, and Fahlenbrach (2012), we classify a fund as a broker-sold if $75 \%$ of its TNA meets at least one of the following three criteria: the fund charges a front-end load, a back-end load, or a 12b-1 fee greater than 25 bps. $^{31}$ Alternatively, a fund is direct-sold if $75 \%$ of its TNA charges no front-end load, no back-end load, and no 12b-1 fee. In the average month during our sample period, $41 \%$ of funds are broker-sold, $51 \%$ are direct-sold, and the remaining $8 \%$ have an indeterminate distribution channel.

We then test the hypothesis of heterogeneity of flow-style deviation/drift relations across distribution channels. We use a dummy variable that is one if the fund is

\footnotetext{
${ }^{31}$ Bergstresser, Chalmers, and Tufano (2009) show that broker-sold funds tend to charge front-end loads, back-end loads, or 12b-1 fees as a means to provide compensation to brokers who sell funds to investors.
} 
Chapter 3

broker-sold and zero otherwise and by multiplying the dummy variable with the style deviation/drift measures, we create interaction terms in the regression.

Table 3-4 shows the results in two parts; the first three columns analyze flow styledeviation relations and the second three columns focus on flow style-drift relations. The results are in line with the previous findings of Error! Reference source not $\mathbf{f}$ ound. and show that investors care more about style deviation than style drift. Column 1 and 4 present the coefficient estimates for the direct-sold channel. Column 2 and 5 present the corresponding estimates for the broker-sold channel and Column 3 and 6 present the difference between the direct-sold and broker-sold channel (i.e., the estimated interaction terms).

The results show that deviation from the stated investment style potentially trick the broker-sold fund investors and attract more fund flow which is marginally higher than the flow from direct-sold fund investors. For example, column 3 shows that the effect of style deviation on the average inflow of broker-sold funds exceeds the inflows of direct-sold funds by more than $14 \%$ per year. The same relationship -yet not significant- exists between the broker-sold fund flow and the style drift score. These results are consistent with the notion that investors in the broker-sold channel are less sophisticated in their assessment of fund performance than are investors in the direct-sold channel. 
Investor Clientele and Style Changing Behavior in Mutual Funds

Table 3-4- Broker-sold versus direct-sold mutual funds

\begin{tabular}{|c|c|c|c|c|c|c|}
\hline & \multicolumn{3}{|c|}{ Flow- style deviation } & \multicolumn{3}{|c|}{ Flow- style drift } \\
\hline & Direct & Broker & $\begin{array}{c}\text { Diff } \\
\text { (Broker- } \\
\text { Direct) }\end{array}$ & Direct & Broker & $\begin{array}{c}\text { Diff } \\
\text { (Broker- } \\
\text { Direct) }\end{array}$ \\
\hline $\begin{array}{l}\text { Lagged 4- factor } \\
\text { alpha }\end{array}$ & $\begin{array}{c}0.35 \\
(0.00)\end{array}$ & $\begin{array}{c}0.28 \\
(0.00)\end{array}$ & $\begin{array}{l}-0.07 \\
(0.26)\end{array}$ & $\begin{array}{c}0.35 \\
(0.00)\end{array}$ & $\begin{array}{c}0.29 \\
(0.00)\end{array}$ & $\begin{array}{l}-0.06 \\
(0.29)\end{array}$ \\
\hline Volatility (STD) & $\begin{array}{c}2.26 \\
(0.01)\end{array}$ & $\begin{array}{c}2.31 \\
(0.01)\end{array}$ & $\begin{array}{c}0.04 \\
(0.97)\end{array}$ & $\begin{array}{c}2.21 \\
(0.01)\end{array}$ & $\begin{array}{c}2.15 \\
(0.02)\end{array}$ & $\begin{array}{l}-0.06 \\
(0.91)\end{array}$ \\
\hline $\begin{array}{l}\text { Style deviation } \\
\text { (SDD) }\end{array}$ & $\begin{array}{c}0.10 \\
(0.19)\end{array}$ & $\begin{array}{c}0.24 \\
(0.00)\end{array}$ & $\begin{array}{c}0.14 \\
(0.08)\end{array}$ & -- & -- & -- \\
\hline Style drift (SDS) & -- & -- & -- & $\begin{array}{r}-0.004 \\
(0.98)\end{array}$ & $\begin{array}{c}0.21 \\
(0.10)\end{array}$ & $\begin{array}{c}0.22 \\
(0.30)\end{array}$ \\
\hline Lagged FLOW & $\begin{array}{c}0.11 \\
(0.00)\end{array}$ & $\begin{array}{c}0.15 \\
(0.00)\end{array}$ & $\begin{array}{c}0.05 \\
(0.12)\end{array}$ & $\begin{array}{c}0.11 \\
(0.00)\end{array}$ & $\begin{array}{c}0.16 \\
(0.00)\end{array}$ & $\begin{array}{c}0.05 \\
(0.11)\end{array}$ \\
\hline FEE & $\begin{array}{c}8.43 \\
(0.34)\end{array}$ & $\begin{array}{c}5.93 \\
(0.24)\end{array}$ & $\begin{array}{l}-2.50 \\
(0.80)\end{array}$ & $\begin{array}{c}8.34 \\
(0.93)\end{array}$ & $\begin{array}{c}5.50 \\
(0.27)\end{array}$ & $\begin{array}{c}-2.83 \\
(-0.28)\end{array}$ \\
\hline TURNOVER & $\begin{array}{c}0.05 \\
(0.10)\end{array}$ & $\begin{array}{c}0.002 \\
(0.90)\end{array}$ & $\begin{array}{l}-0.05 \\
(0.20)\end{array}$ & $\begin{array}{c}0.05 \\
(0.08)\end{array}$ & $\begin{array}{c}0.00 \\
(0.90)\end{array}$ & $\begin{array}{l}-0.05 \\
(0.17)\end{array}$ \\
\hline Age & $\begin{array}{l}-0.29 \\
(0.00)\end{array}$ & $\begin{array}{l}-0.18 \\
(0.17)\end{array}$ & $\begin{array}{c}0.17 \\
(0.06)\end{array}$ & $\begin{array}{l}-0.27 \\
(0.00)\end{array}$ & $\begin{array}{l}-0.12 \\
(0.18)\end{array}$ & $\begin{array}{c}0.15 \\
(0.10)\end{array}$ \\
\hline SIZE & $\begin{array}{l}-0.35 \\
(0.00) \\
\end{array}$ & $\begin{array}{l}-0.43 \\
(0.00) \\
\end{array}$ & $\begin{array}{l}-0.08 \\
(0.04) \\
\end{array}$ & $\begin{array}{l}-0.34 \\
(0.00) \\
\end{array}$ & $\begin{array}{l}-0.44 \\
(0.00) \\
\end{array}$ & $\begin{array}{l}-0.09 \\
(0.02) \\
\end{array}$ \\
\hline $\begin{array}{l}\text { Time fixed } \\
\text { effect }\end{array}$ & Yes & Yes & Yes & Yes & Yes & Yes \\
\hline $\begin{array}{l}\text { Fund fixed } \\
\text { effect }\end{array}$ & Yes & Yes & Yes & Yes & Yes & Yes \\
\hline Observations & & 3,866 & & & 3,866 & \\
\hline Adj. R-square & & 0.04 & & & 0.04 & \\
\hline
\end{tabular}

This table presents parameter estimates from panel regressions of fund flow (dependent variable) on the style deviation measure (SDD) and style drift score (SDS). The dummy variable for broker-sold fund is one when $75 \%$ of the underlying assets of the fund is related to share classes that charge front load or rear load or $12 \mathrm{~b}-1$ fee more than 25 basis point. The interaction term between the dummy variable and SDD/SDS shows the difference between direct- sold funds and broker-sold funds. Control variables include one year lagged fund flow, lagged values of log fund size, log fund age, expense ratio, and return volatility. P-values are in parentheses. 
Chapter 3

\subsection{Fund performance and Style deviation/ Style drift}

We now depart from the assumption that an investor in an actively managed fund seeks to identify a fund's alpha. The fund's alpha is estimated after removing any fund return that can be drawn from the fund's exposure to factors such as size, value versus growth and momentum. But less-sophisticated investors due to a lack of financial literacy may not be able to identify these factors and therefore may simply rank funds based on raw returns or benchmark-adjusted returns. Berk and Van Binsbergen (2016) and Barber, Huang and Odean (2016) suggest that the average investor is only concerned about market risk when assessing mutual funds, and a large proportion of investors tends to ignore other factors.

Thus, one potential explanation of heterogeneity between fund flow and style changing behavior of fund can be defined as a different impact of style deviation/drift on various fund performance measures which are used by different types of investors. To test this conjecture, we examine the impact of style deviation/drift behavior of funds across different fund performance measures ranging from relatively simple to advanced such as benchmark-adjusted return, CAPM alpha and Carhart 4-factor model alpha and run a regression as follows:

$$
\begin{aligned}
& \text { Fund performance } \text { Fit, } \\
& \qquad \begin{array}{l}
=a+b_{1} * S D D_{i, t-1}+b_{2} * S D S_{t i,-1}+b_{3} * \text { Alpha }_{t-1} \\
+ \text { Controls }+\varepsilon_{i, t}
\end{array}
\end{aligned}
$$

where Fund performance includes benchmark adjusted-return.

From Table 3-5 it follows that there is a significant positive relationship between the style deviation measure and benchmark adjusted-return as most common measure among naive investors. This relationship also remains positive when using CAPM alpha as a performance measure. However, when we employ the Carhart 4- 
Investor Clientele and Style Changing Behavior in Mutual Funds factor alpha as a proxy for sophisticated fund performance measurement, the sign turns to negative; however, not significant.

Table 3-5- Fund performance and style deviation/drift

\begin{tabular}{|c|c|c|c|c|c|c|}
\hline & $\begin{array}{l}\text { Benchmark } \\
\text { adj. return }\end{array}$ & $\begin{array}{l}\text { Benchmark } \\
\text { adj. return }\end{array}$ & $\begin{array}{l}\text { CAPM } \\
\text { Alpha }\end{array}$ & $\begin{array}{l}\text { CAPM } \\
\text { Alpha }\end{array}$ & $\begin{array}{l}\text { 4-factor } \\
\text { Alpha }\end{array}$ & $\begin{array}{l}\text { 4-factor } \\
\text { Alpha }\end{array}$ \\
\hline $\begin{array}{l}\text { Lagged } \\
\text { benchmark adj. } \\
\text { return }\end{array}$ & $\begin{array}{c}0.02 \\
(0.00)\end{array}$ & $\begin{array}{c}0.02 \\
(0.00)\end{array}$ & -- & -- & -- & -- \\
\hline Lagged CAPM & -- & -- & $\begin{array}{c}0.08 \\
(0.00)\end{array}$ & $\begin{array}{c}0.08 \\
(0.00)\end{array}$ & -- & -- \\
\hline $\begin{array}{l}\text { Lagged 4- factor } \\
\text { alpha }\end{array}$ & -- & -- & -- & -- & $\begin{array}{c}0.09 \\
(0.00)\end{array}$ & $\begin{array}{c}0.09 \\
(0.00)\end{array}$ \\
\hline Volatility (STD) & $\begin{array}{c}0.10 \\
(0.00)\end{array}$ & $\begin{array}{c}0.09 \\
(0.00)\end{array}$ & $\begin{array}{l}-0.00 \\
(0.00)\end{array}$ & $\begin{array}{l}-0.003 \\
(0.64)\end{array}$ & $\begin{array}{l}-0.001 \\
(0.00)\end{array}$ & $\begin{array}{l}-0.001 \\
(0.00)\end{array}$ \\
\hline $\begin{array}{l}\text { Style deviation } \\
\text { (SDD) bps }\end{array}$ & $\begin{array}{c}1.12 \\
(0.00)\end{array}$ & -- & $\begin{array}{c}0.65 \\
(0.71)\end{array}$ & -- & $\begin{array}{l}-0.81 \\
(0.58)\end{array}$ & -- \\
\hline $\begin{array}{l}\text { Style drift (SDS) } \\
\text { bps }\end{array}$ & -- & $\begin{array}{c}1.11 \\
(0.31)\end{array}$ & -- & $\begin{array}{c}0.21 \\
(0.64)\end{array}$ & -- & $\begin{array}{c}0.12 \\
(0.62)\end{array}$ \\
\hline $\begin{array}{l}\text { Lagged FLOW } \\
(\%)\end{array}$ & $\begin{array}{l}-0.20 \\
(0.00)\end{array}$ & $\begin{array}{l}-0.20 \\
(0.00)\end{array}$ & $\begin{array}{c}0.00 \\
(0.29)\end{array}$ & $\begin{array}{c}0.00 \\
(0.30)\end{array}$ & $\begin{array}{c}0.00 \\
(0.19)\end{array}$ & $\begin{array}{c}0.00 \\
(0.18)\end{array}$ \\
\hline FEE & $\begin{array}{l}-0.07 \\
(0.00)\end{array}$ & $\begin{array}{l}-0.07 \\
(0.00)\end{array}$ & $\begin{array}{l}-0.002 \\
(0.00)\end{array}$ & $\begin{array}{l}-0.003 \\
(0.00)\end{array}$ & $\begin{array}{l}-0.003 \\
(0.00)\end{array}$ & $\begin{array}{l}-0.003 \\
(0.00)\end{array}$ \\
\hline TURNOVER & $\begin{array}{c}-3.1 \\
(0.00)\end{array}$ & $\begin{array}{c}-3.1 \\
(0.00)\end{array}$ & $\begin{array}{l}-0.12 \\
(0.00)\end{array}$ & $\begin{array}{l}-0.11 \\
(0.00)\end{array}$ & $\begin{array}{l}-0.11 \\
(0.00)\end{array}$ & $\begin{array}{l}-0.11 \\
(0.00)\end{array}$ \\
\hline Age $(\%)$ & $\begin{array}{c}0.06 \\
(0.05)\end{array}$ & $\begin{array}{c}0.05 \\
(0.09)\end{array}$ & $\begin{array}{c}0.07 \\
(0.58)\end{array}$ & $\begin{array}{c}-0.04 \\
(0.55)\end{array}$ & $\begin{array}{c}0.03 \\
(0.83)\end{array}$ & $\begin{array}{c}0.04 \\
(0.79)\end{array}$ \\
\hline SIZE & $\begin{array}{c}-1.1 \\
(0.28) \\
\end{array}$ & $\begin{array}{c}-1.1 \\
(0.15) \\
\end{array}$ & $\begin{array}{c}0.69 \\
(0.18) \\
\end{array}$ & $\begin{array}{c}0.71 \\
(0.18)\end{array}$ & $\begin{array}{l}-0.59 \\
(0.16) \\
\end{array}$ & $\begin{array}{l}-0.56 \\
(0.18) \\
\end{array}$ \\
\hline $\begin{array}{l}\text { Time fixed } \\
\text { effect }\end{array}$ & Yes & Yes & Yes & Yes & Yes & Yes \\
\hline $\begin{array}{l}\text { Style fixed } \\
\text { effect }\end{array}$ & Yes & Yes & Yes & Yes & Yes & Yes \\
\hline Observations & 5493 & 5493 & 5198 & 5198 & 5473 & 5473 \\
\hline Adj. R-square & 0.23 & 0.23 & 0.14 & 0.14 & 0.13 & 0.13 \\
\hline
\end{tabular}

This table presents parameter estimates from panel regressions of fund performance (dependent variable) on the style deviation measure (SDD), style drift score (SDS), the relative fund performance with one year lag and other control variables. Controls include one year lagged fund flow, lagged values of $\log$ fund size, log fund age, expense ratio, and return volatility. P-values are in parentheses. 
Chapter 3

\subsection{Shareholder composition and fund manager incentive}

Sophisticated fund investors may play the role of shareholder activism in mutual funds and as such they may effectively discipline fund managers with respect to style changing behavior. Thus, the absence of sophisticated investors may create an incentive for a fund manager to employ more strategic behavior like changing the style in the future. To measure the relationship between the proportion of lesssophisticated investors and style-changing behavior, we introduce two different shareholder ratios at the fund's share-class level. The first ratio is the proportion of retail investors in the fund versus institutional investors and the second ratio is high expense funds versus low expense funds.

Based on each ratio, we first split the funds in two parts, sophisticated and unsophisticated investors; we then define the first shareholder ratio as the cumulative TNA of unsophisticated investors divided by the aggregated value of portfolio TNA. The ratio represents the skin of different types of investors in the game. For example, for the first proxy, the ratio is defined as the cumulative TNA of retail investors divided by the aggregated TNA of the portfolio, including TNA of both institutional and retail funds. This ratio varies from 0 to 1 , and if the ratio is close to 1 , it means retail investors are dominant.

The second ratio of fund activism is defined as a proportion of higher-median expense funds versus lower-median expense funds at the fund's share-class level. Low-expense ratio share classes are related to large-scale and more sophisticated investors. Christoffersen and Musto (2002) show that there is heterogeneity among investors regarding sensitivity to fund fees. They show that there is an adverse relation between fees and performance. Gil-Bazo and Ruiz-Verdu (2009) interpret this negative relation as an agency problem in which high-expense funds target less performance-sensitive investors, also referred to as naive investors that are not responsive to expenses. Viewed through this lens, recent studies show signals of agency issues related to style deviation. For example, Bams, Otten and 
Investor Clientele and Style Changing Behavior in Mutual Funds Ramezanifar (2016) show that high style deviation occurs most likely in poorly performing funds with high expense ratios. Frijns, Gilbert, and Zwinkels (2016) report that funds that switch style more aggressively, have on average higher expense ratios. Sensoy (2009) points out that mismatched self-designed funds are more common among high-fee funds. Huang, Sialm \& Zhang (2011) show that funds with higher expense ratios experience more severe performance consequences when they alter the risk profile of the fund. Therefore, we split each fund share class into (i) lower than median and (ii) higher than median expense ratios and refer to them as higher- and lower-sophisticated investors respectively. Thus the second shareholder ratio is defined as the cumulative TNA of uppermedian expense funds divided by the aggregated value of portfolio TNA. To examine the relationship between sophistication level of fund and the fund's style changing behavior, we first rank all funds into five portfolios based on two ratios. We then calculate the average SDD and SDS of funds for the subsequent year.

Fund performance and other control variables in year $t$ may be affected by this relationship. The relevant panel regression equations are defined as follows:

$$
\begin{aligned}
S D D_{i, t+1}=a+ & b_{1} * \text { Alpha }_{i, t}+b_{2} \\
& * \text { Shareholder ratios } \text { Sh }_{i, t}+\text { Controls } \\
& +\varepsilon_{i, t+1} \\
S D S_{i, t+1}=a+ & b_{1} * \text { Alpha }_{i, t}+b_{2} \\
& * \text { Shareholder ratios }_{i, t}+\text { Controls } \\
& +\varepsilon_{i, t+1}
\end{aligned}
$$

where $S D D_{i, t+1}$ and $S D S_{i, t+1}$ represent the style deviation and style drift of fund $i$ in the next period respectively. The Shareholder ratios $i, t$ represent the proportion of unsophisticated fund at the share class-level. We consider time fixed effect and fund fixed effect in the regression. 
Chapter 3

Table 3-6 shows that there is a positive relationship between the proportion of retail investors versus institutional investors and style-deviation of fund managers. Although this relationship is not significant, the positive sign is robust among different style-changing behavior and shareholder ratios. Overall, our findings reject the hypothesis that fund managers take advantage of presence of lesssophisticated investors in the fund. 
Investor Clientele and Style Changing Behavior in Mutual Funds

Table 3-6- Shareholder composition and fund manager incentive

\begin{tabular}{|c|c|c|c|c|}
\hline \multicolumn{5}{|c|}{ One-year future style deviation $\left(\mathrm{SDD}_{\mathrm{t}+1}\right)$ and style drift $\left(\mathrm{SDS}_{\mathrm{t}+1}\right)$} \\
\hline & $\mathrm{SDD}_{\mathrm{t}+1}$ & $\mathrm{SDS}_{\mathrm{t}+1}$ & $\mathrm{SDD}_{\mathrm{t}+1}$ & $\operatorname{SDS}_{\mathrm{t}+1}$ \\
\hline Lagged 4- factor & 0.34 & 0.29 & 0.36 & 0.25 \\
\hline alpha & $(0.00)$ & $(0.00)$ & $(0.00)$ & $(0.00)$ \\
\hline & -0.64 & 0.07 & -0.67 & 0.03 \\
\hline Volatility (STD) & $(0.05)$ & $(0.63)$ & $(0.02)$ & $(0.83)$ \\
\hline Lagged SDS & -- & $\begin{array}{c}0.58 \\
(0.00)\end{array}$ & -- & $\begin{array}{c}0.49 \\
(0.00)\end{array}$ \\
\hline Lagged SDD & $\begin{array}{c}0.71 \\
(0.00)\end{array}$ & -- & $\begin{array}{c}0.74 \\
(0.00)\end{array}$ & -- \\
\hline Shareholder ratio 1 & $\begin{array}{l}0.031 \\
(0.20)\end{array}$ & $\begin{array}{c}0.24 \\
(0.46)\end{array}$ & -- & -- \\
\hline Shareholder ratio 2 & -- & -- & $\begin{array}{c}0.20 \\
(0.75)\end{array}$ & $\begin{array}{c}0.07 \\
(0.84)\end{array}$ \\
\hline Lagged FLOW & $\begin{array}{c}-0.008 \\
(0.14)\end{array}$ & $\begin{array}{l}0.001 \\
(0.49)\end{array}$ & $\begin{array}{c}-0.003 \\
(0.51)\end{array}$ & $\begin{array}{l}0.003 \\
(0.18)\end{array}$ \\
\hline FEE & $\begin{array}{l}-0.22 \\
(0.75)\end{array}$ & $\begin{array}{c}0.94 \\
(0.00)\end{array}$ & $\begin{array}{c}1.21 \\
(0.02)\end{array}$ & $\begin{array}{c}1.54 \\
(0.00)\end{array}$ \\
\hline TURNOVER & $\begin{array}{l}-0.006 \\
(0.21)\end{array}$ & $\begin{array}{l}0.003 \\
(0.16)\end{array}$ & $\begin{array}{c}-0.003 \\
(0.31)\end{array}$ & $\begin{array}{l}-0.002 \\
(0.99)\end{array}$ \\
\hline Age & $\begin{array}{c}-0.041 \\
(0.00)\end{array}$ & $\begin{array}{l}-0.009 \\
(0.05)\end{array}$ & $\begin{array}{c}-0.02 \\
(0.00)\end{array}$ & $\begin{array}{c}-0.008 \\
(0.09)\end{array}$ \\
\hline SIZE & $\begin{array}{c}-0.004 \\
(0.30)\end{array}$ & $\begin{array}{r}-0.001 \\
(0.39)\end{array}$ & $\begin{array}{c}-0.004 \\
(0.26)\end{array}$ & $\begin{array}{l}-0.002 \\
(0.32)\end{array}$ \\
\hline Time fixed effect & Yes & Yes & Yes & Yes \\
\hline Style fixed effect & Yes & Yes & Yes & Yes \\
\hline Observations & 3087 & 3029 & 3087 & 3029 \\
\hline Adj. R-square & 0.69 & 0.42 & 0.68 & 0.42 \\
\hline
\end{tabular}

This table presents parameter estimates from panel regressions of the future style deviation measure (SDD) and future style drift measure (SDS) as dependent variables on the shareholder ratio, which is the total net asset of retail funds divided by the total net asset value of the whole fund. Shareholder ratio 1 is defined as the TNA of retail investors divided by the cumulative TNA of the fund and shareholder ratio 2 is defined as the TNA of higher- median expense funds divided by the cumulative TNA of the fund. We also consider the one-year lag style deviation measure (SDD) and style drift score (SDS) as independent variables. Controls in this regression include one year lagged fund flow, lagged values of the log fund size, the log fund age, expense ratio, and return volatility. Because the variation of return among the styles is considerable, we use style- fixed effect beside the time- fixed effect in this panel. P-values are in parentheses. 
Chapter 3

\subsection{Robustness check}

\subsubsection{Convex relationship between fund flow and fund performance}

Prior studies point out an asymmetric (nonlinear) relationship between mutual fund flows and past performance, in which flows are more strongly related to positive market-adjusted performance than to negative performance. The results in section 3.2 are based on the linear relationship between fund flows and fund performance; we test the robustness of our results by considering the convex relationship between fund flow and style-changing behavior. For this purpose, we follow Huang, Wei and Yan (2007), and rank all mutual funds each year based on their Carhart 4-factor alphas; subsequently we classify them into low-, medium-, and high-performance buckets. Funds in the lowest (highest) performance quintile are in the low (high) group. The medium group includes funds with performance ranked in the middle three quintiles. We employ dummy variables for each bucket and by interacting the dummy variables to the alphas in each bucket, we capture the nonlinear relationship between fund flows and fund performance. The model is given by:

$$
\begin{aligned}
\text { Flow }_{i, t}=a+ & b_{1} * \operatorname{Low}_{i, t-1} * D_{1 i}+b_{2} * D_{1 i}+b_{3} * \operatorname{High}_{i, t-1} * D_{2 i}+b_{4} \\
& * D_{2 i}+b_{5} * D_{2 i} * S D D_{i, t-1}+b_{6} * D_{2 i} * S D S_{i, t-1} \\
& + \text { Controls }+\varepsilon_{i, t}
\end{aligned}
$$

where $L o w_{i, t-1}$ represents the fund performance in the lowest quintile, and $H_{i g h} h_{i, t-1}$ represents the fund performance ranks in the highest quintile. $D_{1}$ is a dummy variable that takes on a value of one for funds in the lowest quintile and $D_{2}$ is a dummy variable that takes on a value of one for funds in the highest quintile. We show the results of this regression in Table 3-7. Consistent with prior studies, 
Investor Clientele and Style Changing Behavior in Mutual Funds there is a nonlinear relationship between fund performance and fund flows. The results show an even a stronger impact of style deviation and style drift measures on fund flows under the nonlinearity assumption in comparison with prior results. 


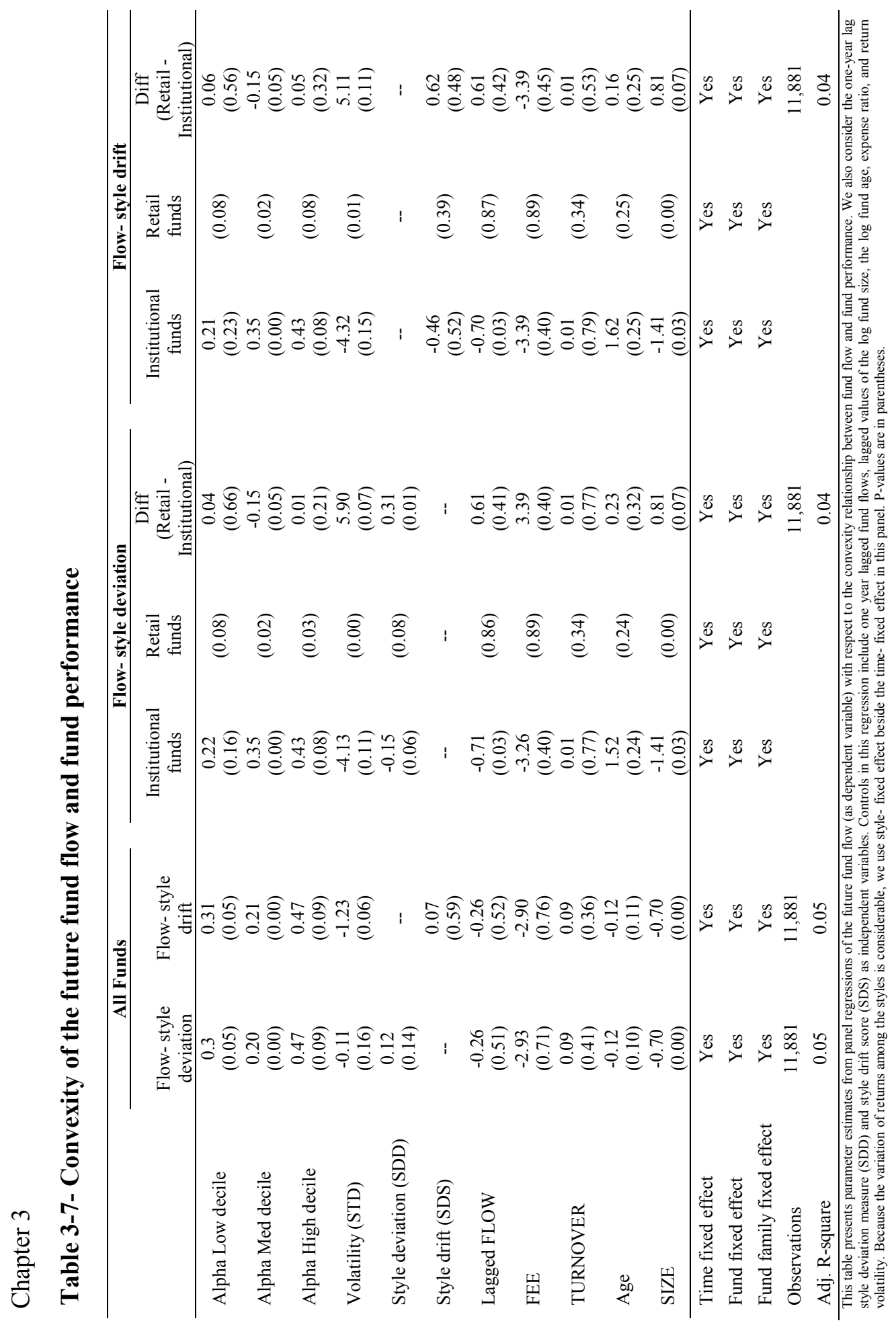


Investor Clientele and Style Changing Behavior in Mutual Funds

\subsection{Conclusion}

While mutual fund investors share some commonality, previous studies show that they are different with respect to their sophistication levels. Given that some investors are better equipped to monitor fund's style-changing behavior, it is natural to ask how different types of investors with various levels of sophistication react to a fund's style changing behavior. We use two different quantitative methods to cover different aspects of style-changing behavior including deviation from the stated investment style and style volatility (drift) over time. We find that fund flows are more sensitive to style deviation than style drift over time and on average investors reward deviation from the stated style. Surprisingly, by explicitly considering the sophistication level of fund investors, we observe that highly sophisticated investors punish this behavior by redemption, while less sophisticated investors appreciate it by investing more money into the style deviated funds. We also demonstrate that the less-sophisticated investors drive aggregate results.

Moreover, because investors with differing sophistication level employ different fund performance tools, one of the explanations of the aforementioned relationship stems from the effect of style-changing behavior on different fund performance measures. By using relevant simple fund performance measures (e.g. benchmarkadjusted return) and more advanced ones (e.g. factor related return), we find that style deviation/drift positively effects simple measures and negatively affects more sophisticated measures. Thus, some investors may, based on their performance measures, interpret style change as a skill of the fund manager and reward it, while other investors may not.

In addition, it is likely that this relationship works in both directions; for example, sophisticated investors may punish funds that display higher levels of style deviation/drift with redemption, and at the same time, fund managers with a larger clientele of sophisticated investors are careful to not let their portfolios deviate too 
Chapter 3

far from their stated style. By introducing the ratio of sophisticated versus unsophisticated investors of funds, we show that there is no relationship between the proportion of less sophisticated investors and the subsequent degree of fund's style deviation/style drift. Overall, our evidence is consistent with sophisticated investors having better abilities to monitor fund managers and extend the conclusions of previous studies which treat all investors as a homogeneous group with regard to the style changing of funds. 
Chapter 4

\section{Pairs Trading Strategy Optimization using the Reinforcement Learning Method: A Cointegration Approach*}

* This chapter is co-authored with Saied Fallahpour (University of Tehran), Hasan Hakimian (University of Tehran) and Khalil Taheri (University of Tehran) and is published in the Soft Computing journal. 
Chapter 4

\subsection{Introduction}

Prior studies have shown a downward trend in the profitability of pairs trading due to its growing popularity. Hence, the use of machine learning to seek more profitable trading opportunities has gained widespread attention among academics and practitioners. This paper applies reinforcement learning, as an area of machine learning, to train a pairs trading agent with the goal of optimizing the parameter values and maximizing the profit. Although the pairs trading strategy has been the subject of extensive research, no prior studies apply reinforcement learning to optimize the performance of this strategy. Therefore, we use reinforcement learning on the econometric paradigm of cointegration to capture the optimal dynamic values of the pairs trading's parameters. The paradigm comprises an estimation window, a trading window, trading thresholds, and stop-loss boundaries. In addition, to exemplify the application of this method, we use the comprehensive intraday data of US equity market from June 2015 to January 2016. Our results are economically and statically higher than the traditional approach of pairs trading with static parameters.

Pairs trading is a market neutral strategy which is appealing in the volatile macroeconomic environment. The profit ultimately depends on the change in the difference between the prices of a pair of stocks. This strategy exploits the statistical arbitrage opportunities that arise from the temporary fluctuations in the price of two assets which are in long-term equilibrium (Gatev, 2006). When these prices temporarily deviate from the equilibrium, the strategy opens a long position on the asset which is overpriced and a short position on the asset which is underpriced. Therefore, when the prices converge to the long-term equilibrium, the positions change and a profit occurs. In general, there are four different approaches to implement pairs trading which include the distance approach, combine forecasts approach, stochastic approach, and cointegration approach. In this study, we focus on the cointegration approach by using the machine learning method. 
The first step in implementing this strategy is to select a proper pair of assets which have a long-run statistical relation. This relation during the trading period is the necessary condition for conducting trades on a pair of assets. After choosing a pair of assets by examining the cointegration relation, we then estimate the parameters. The pairs trading platform is always associated with a quantity called the "spread." This quantity is computed by using the prices of the two assets. The spread value fluctuates on both sides of its mean value due to the mean reversion characteristics and the long-run equilibrium relations.

The spread thresholds and the quantity of stop-loss are specified as two boundaries on both sides of the spread's mean value. The distance of the boundaries from the mean value specifies the profit of each trade. Overall, selecting the appropriate parameters for the pairs trading plays an important role in the profitability of this strategy. After creating a portfolio of two assets, we use the Sortino ratio as an objective function to evaluate the overall performance of the strategy. Therefore, we attempt to maximize the objective function by applying a series of nonlinear limitations to obtain an optimal model. To achieve that, we apply reinforcement learning to optimize the parameters of the pairs trading.

The reinforcement learning as an area of machine learning is based on the penaltyreward strategy and includes two main components called the "agent" and "environment." The agent lives in the environment and updates his or her experiences based on the feedback from the environment. In this study, we apply reinforcement learning to optimally determine the pairs trading parameters of the estimation window, executive time windows, trading thresholds, and the stop-loss boundary to maximize the Sortino ratio as an objective function. We use the n-arm bandit to model the trading strategy. The $n$-arm bandit is a game device with an $n$ arm, or a lever. The player pulls the lever and is rewarded with a score from the device. Each player can only pull a limited number of levers. The goal of players is 


\section{Chapter 4}

to maximize the summation of the acquired scores from the game device in the limited iterations (i.e., pulling the arms). We use the n-arm bandit to design a knowledge-acquisitive agent. Based on pulling an arm in each iteration of the narm bandit model, as long as the portfolio is open, the agent starts learning from exploration of the environment and selects values for different desired parameters. The goal of the agent is to maximize the Sortino ratio which means receiving a score from the environment based on the selected parameters. The results indicate the superiority of this algorithm for improving the return and reducing the downside risks as compared with the basic model.

The remainder of the paper is organized as follows. In Section 2, we show the relevant studies. Section 3 contains an explanation of the data, and Section 4 presents the method and the concepts of cointegration, pairs trading, and reinforcement learning. In Section 5, we discuss the results, and Section 6 describe the conclusion.

\subsection{Literature Review}

Optimization of the pairs trading parameters and strategies has gotten a lot of attention in the literature. For example, Moura, Pizzinga and Zubelli (2016) propose a pairs trading strategy entirely based on linear state space models, which are designed to formulate the spread. Once an adequate state space model for the spread is estimated, they use the Kalman filter to compute the spread value. They evaluate the approach based on the data on the daily stock price of two assets: Exxon Mobil Corporation and Southwest Airlines Co. The main difference between their work and our study is that we use a cointegration approach instead of the state space model.

Furthermore, using the stochastic control approach, Tourin and Yan (2013) propose a model of pairs trading strategies with the goal to maximize the cumulative profit for a fixed time horizon and the expected terminal utility of 
wealth. Moreover, they evaluate their approach on the data of two stocks: Goldman Sachs Group and J.P. Morgan Chase. They show that the approach maximizes the cumulative profit and minimizes the loss function. The major concern about their study is related to the uncertainty of the stochastic control approaches for optimizing the cumulative profit.

Moreover, Puspaningrum, Lin and Gulati (2010) study the pre-set boundaries of pairs trading parameters which are selected in the opening positions of a pair. They develop a numerical algorithm to estimate the average duration of a trade, the average inter-trade interval, and the average number of trades. They then use these values to find the optimal pre-set boundaries that maximize the total profit for the Error Cointegration Model. Moreover, they use the seven pairs of stocks from the Australian Stock Exchange to examine their algorithm. The numerical result shows one trade, either a U-trade or an L-trade, per 15.70 days. Bertram (2010) also indicates that the optimal boundaries which are symmetrically placed around the mean for both the return maximization per each time interval and the maximization of the Sharpe ratio. He then uses the combination on the dual-listed securities for ANZ Banking Group (ANZ.AX, ANZ.NZ). These securities are traded on the Australian and New Zealand stock exchanges simultaneously, and the security price in his study follows an Ornstein-Uhlenbeck process. Furthermore, based on the impact of selecting a range of boundaries on the return and period of each trade, Zeng and Lee (2014) discuss the optimal boundaries with a function of trading costs and parameters of an OU process to maximize the average profit expected in the long run. They then implement this method on the daily stock price data of Coca Cola and Pepsi.

Using the classical mean-variance portfolio selection criteria, Chiu and Wong (2015) introduce an optimal dynamic trading of cointegrated assets. The optimal strategy is acquired over a set of time-consistent policies to ensure rational 
Chapter 4

economic decisions. From a nonlinear Hamilton-Jacobi-Bellman partial differential equation, they solve the optimal dynamic trading strategy in a closedform explicit solution. The main drawback of their approach is that the results in the long term are not stable.

It is worth noting that all of the aforementioned articles choose static values for the parameters in the estimation windows, trading thresholds, and stop-losses. In this paper, we extend the literature by using a dynamic approach to find the optimum values for the parameters with the goal of maximizing the objective function. For this purpose, we use the reinforcement learning approach.

Reinforcement learning is an unsupervised artificial intelligence method which understands, learns, and makes decisions automatically from environmental inspiration toward its objective. Reinforcement learning is stated as the third category of learning algorithms. In this type of learning, it clarifies how different positions are mapped to different actions in order to maximize the profit. The agent is designed with the reinforcement learning and it tries to obtain the expected action which maximizes the profit through experience. While making decisions, the agent can consider different policies to select the desired actions. An example of common policies for selecting the action is the $\epsilon$-greedy policy in which the agent selects the action in $\epsilon$ with the highest value in terms of the agent, and then selects the actions randomly and independently of their value in $1-\epsilon$ (Sutton and Barto 1998).

Based on the learning power, the reinforcement learning algorithm can mathematically formulate a set of variables in which there is no knowledge or predefinition pertaining to their environment and structure. In financial analyses and problems in which uncertainty and dynamics are essential components, this algorithm can be useful (Sutton and Barto 1998). 
Gao and Chan (2000) use the absolute return and relative risk-adjusted return (Sharpe ratio) as a performance function and propose the Q-learning algorithms for portfolio trades. But, the major concern of this approach is that there is no guarantee that the Q-leaning approach can converge to any particular value. Lee and Hong (2007) also propose a Q-learning framework with a stock trading multiagent to improve the performance of the systems based on reinforcement learning. They use stock trading by defining the necessary roles to make selective decisions and price the stocks simultaneously. They check their test results by implementing their trading framework on the Korean Stock Exchange and show a better performance in comparison to other similar approaches. Lee (2001) also uses reinforcement learning to model and to learn different types of interactions in real situations for the problem of predicting a stock price. He considers the problem of predicting the stock price as a Markov's process which can be optimized on the basis of the reinforcement learning algorithm. Lee (2001) uses stock price trends and consecutive price changes to describe the state of reinforcement learning. Although the assumption of Markov's process should simplify the problem, it can lose some information. Tan, Quek and Cheng (2011) use the Adaptive Network Fuzzy Inference System (ANFIS) accompanied by reinforcement learning to propose a non-arbitrage, high-frequency trading system. They examine the approach with data on several industries over the period from 1994 to 2005 and show that their approach can perform more efficiently than the previous work. It should be noted that the ANFIS network can be over fitted. Moody and Saffell (2001) introduce a method for optimizing the portfolio and trading systems based on direct reinforcement learning to discover investment policies. Their method is an adaptive algorithm called Recurrent Reinforcement Learning (RRL). They evaluate their approach on intraday currency prices and the S\&P 500 Stock Index and T-Bills. The primitive results show that the approach can perform efficiently. 
Chapter 4

As they used Q-learning and TD-learning approaches for reinforcement learning, their method has the same drawbacks as the above studies.

The main contribution of our study is that the reinforcement learning agent can find the optimum dynamic values for the parameters rather than using the static values in order to maximize the objective function, that is, the Sortino ratio. Our approach can model the fluctuation of stocks as a dynamic behaviour of the environment and therefore can show the optimum values for the model parameters with respect to changes in anenvironment.

\subsection{Data}

We use the intraday price of the US stock data to implement our pairs trading strategy. The data is obtained from FactSet Research Systems, Inc. and comprise the intraday prices of the following stocks: Facebook (FB), Google (GOOG), Amazon (AMZN), Twitter (TWTR), Alibaba (BABA), General Motors (GM), Ford Motor Company (F), Center Point Energy (CNP), NextEra Energy (NEE), Dow Chemical (DOW), LyondellBasell (LYB), Adobe Systems Inc (ADBE), Autodesk Inc (ADSK), Amphenol Corp A (APH), Boeing Company (BA), Johnson \& Johnson (JNJ), Medtronic plc (MDT), Bank of America Corp (BAC), The Bank of New York Mellon Corp (BK), Helmerich \& Payne (HP), Hess Corporation (HES), The Hershey Company (HSY), Tyson Foods (TSN), Tegna (TGNA), and Twenty-First Century Fox Class A (FOXA). All the pairs are jointly from the same industry, and they are highly liquid in the market.

In this study, we focus on seven months of data from June 2015 to January 2016. Table 4-1 shows the summary statistics for the entire sample. 
Pairs Trading Strategy Optimization using the Reinforcement Learning Method: A Cointegration Approach

Table 4-1- Summary statistics

\begin{tabular}{|c|c|c|c|c|c|}
\hline & Mean & Std. Dev. & Min & Max & Observation \\
\hline Facebook & 97.12 & 7.04 & 74.10 & 115.68 & 61,298 \\
\hline Google & 664.08 & 71.84 & 515.35 & 779.71 & 61,862 \\
\hline Amazon & 611.58 & 58.17 & 474.47 & 722.25 & 65,536 \\
\hline Twitter & 20.63 & 5.29 & 13.77 & 31.84 & 65,536 \\
\hline Alibaba & 75.56 & 7.82 & 57.35 & 87.71 & 61,350 \\
\hline General motors & 32.38 & 2.44 & 25 & 36.87 & 61,345 \\
\hline Ford motors & 14.17 & 0.905 & 11.23 & 15.83 & 61,337 \\
\hline Center Point Energy & 18.25 & 0.909 & 16.07 & 20.09 & 63,949 \\
\hline Next Era Energy & 101.80 & 3.63 & 94.09 & 113.42 & 64,194 \\
\hline Dow Chemical & 48.12 & 4.08 & 36.38 & 57.08 & 63,797 \\
\hline Lyondell Basell & 90.32 & 7.89 & 69.12 & 106.49 & 63,774 \\
\hline Adobe Systems Inc & 85.32 & 5.11 & 71.64 & 96.4 & 64,081 \\
\hline Autodesk Inc & 53.68 & 5.80 & 42.09 & 65.74 & 63,811 \\
\hline Amphenol Corp A & 53.25 & 2.87 & 45.11 & 58.63 & 63,933 \\
\hline Boeing Company & 139.51 & 7.52 & 115.09 & 150.54 & 63,885 \\
\hline Johnson \& Johnson & 98.69 & 3.34 & 83.08 & 105.48 & 63,687 \\
\hline Medtronic plc & 74.65 & 2.87 & 61.15 & 78.90 & 63,798 \\
\hline Bank of America Corp & 16.63 & 1.16 & 12.94 & 18.47 & 63,777 \\
\hline The Bank of New & 39.92 & 0.58 & 39 & 41.42 & 36,685 \\
\hline \multicolumn{6}{|l|}{ York Mellon Corp } \\
\hline Helmerich \& Payne & 56.53 & 7.36 & 40.02 & 75.21 & 63,892 \\
\hline Hess Corporation & 56.6 & 8.02 & 32.44 & 70.6 & 63,586 \\
\hline The Hershey Company & 89.74 & 3.22 & 82.46 & 97.4 & 63,912 \\
\hline Tyson Foods & 46.09 & 4.23 & 39.19 & 54.57 & 63,859 \\
\hline Tegna & 27.06 & 3.95 & 21.35 & 38.47 & 64,017 \\
\hline Twenty-First Century & 29.39 & 2.62 & 24.84 & 34.68 & 64,336 \\
\hline Fox Class A & & & & & \\
\hline
\end{tabular}

This table shows the summary statistic of 25 stocks from June 2015 to January 2016. The mean, standard deviation, minum, maximum and number of observations are reported in this table. 
Chapter 4

\subsection{Method}

\subsubsection{Cointegration and Error Correction Model}

Granger (1981) was the first to introduce cointegration as a standard statistical method to analyse economic problems. To be more precise, cointegration is a general concept for describing a stationary relation between two variables. For example, if two or more time series are non-stationary, the results from their linear combination might also be non-stationary. For example, if $x_{t}$ and $y_{t}$ are a nonstationary time series, then:

$$
x_{t} \sim I(d), \quad y_{t} \sim I(e), \quad z_{t}=\alpha x_{t}+\beta y_{t} .
$$

Hence if $\mathrm{e}>\mathrm{d}$, then $z_{t} \sim I(e)$. After subtracting $z_{t}$ from itself $e$ times, the stationary time series is as follows:

$$
\Delta^{e} z_{t}=\alpha \Delta^{e} x_{t}+\beta \Delta^{e} y_{t}
$$

Now consider the linear combination of $\mathrm{x}_{\mathrm{t}}$ and $\mathrm{y}_{\mathrm{t}}$ as follows:

$$
y_{t}=u_{t}+\beta x_{t} \text {. }
$$

Again if we assume that $x_{t} \sim I(1), y_{t} \sim I(1)$, then the disturbance term is equal to $u_{t}=y_{t}-\beta x_{t}$, which is non-stationary, and I(1). If there is a value for $\beta$ to make $y_{t}-\beta x_{t}$ stationary, then $x_{t}$ and $y_{t}$ are cointegrated. Cointegration means that while the variables are non-stationary, a linear combination of them that uses a specific value of $\beta$ is stationary. Additionally, if $u_{t}$ is stationary, then the equation is cointegrated; and they do not diverge from each other in a long-run equilibrium relation.

The explanation for a dynamic in cointegration is defined by the concept in the Error Correction Model (ECM). Such a relation is clarified through Granger's 
representation theorem in which a set of economic variables are in a long-run equilibrium according to the following relation:

$$
\beta_{1} x_{1 t}+\beta_{2} x_{2 t}+\cdots+\beta_{n} x_{n t}=0
$$

where $\beta$ and $x_{t}$ indicate the vectors of $\left(\beta_{1}, \beta_{2}, \ldots \beta_{n}\right)$ and $\left(x_{1 t}, x_{2 t}, \ldots x_{n t}\right)^{\prime}$, respectively. The above system is in equilibrium if $\beta x_{t}=0$.

Therefore, the deviation from the long-run equilibrium is $e_{t}$. It is also called an equilibrium error as follows:

$$
\mathrm{e}_{t}=\beta x_{t}
$$

where vector $\beta$ is called the cointegration vector.

One of the main characteristics of a cointegrated vector is a temporal trend which is influenced by the deviation in two series from their long-run equilibrium. Hence, a system reverts to the long-run equilibrium if the minimal changes in some variables are in the reverse direction of imbalance. This behaviour can not be captured unless a dynamic model is used, which is the error correction process. In an ECM, short-run changes in the system variables occur based on the deviation in the system from the long-run equilibrium.

For example, consider the following vector auto regressive (VAR) equations:

$$
y_{t}=\mathrm{a}_{11} y_{t-1}+\mathrm{a}_{12} z_{t-1}+\varepsilon_{y t}
$$

and 
Chapter 4

$$
z_{t}=\mathrm{a}_{21} y_{t-1}+\mathrm{a}_{12} z_{t-1}+\varepsilon_{z t}
$$

In these equations $\varepsilon_{y t}$ and $\varepsilon_{z t}$ are white noise disturbance terms which can be correlated with one another. For the sake of simplicity, we assume that the models do not have static components. Therefore, the equations are written as follows:

$$
\left(1-\mathrm{a}_{11} L\right) y_{t}-\mathrm{a}_{12} L z_{t}=\varepsilon_{y t}
$$

and

$$
-\mathrm{a}_{21} L y_{t}+\left(1-\mathrm{a}_{22} L\right) z_{t}=\varepsilon_{z t} .
$$

This system is rewritten in a matrix form to calculate the values of $y_{t}$ and $z_{t}$ from the above equations as follows:

$$
\left[\begin{array}{cc}
\left(1-\mathrm{a}_{11} L\right) & -\mathrm{a}_{12} L \\
-\mathrm{a}_{21} L & \left(1-\mathrm{a}_{22} L\right)
\end{array}\right]\left[\begin{array}{l}
y_{t} \\
z_{t}
\end{array}\right]=\left[\begin{array}{l}
\varepsilon_{y t} \\
\varepsilon_{z t}
\end{array}\right]
$$

According to Cramer's rule, the answers to $y_{t}$ and $z_{t}$ are as follows:

$$
y_{t}=\frac{\left(1-\mathrm{a}_{22} L\right) \varepsilon_{y t}+\mathrm{a}_{12} L \varepsilon_{z t}}{\left(1-\mathrm{a}_{11} L\right)\left(1-\mathrm{a}_{22} L\right)-\mathrm{a}_{12} \mathrm{a}_{21} L^{2}}
$$

and

$$
z_{t}=\frac{\mathrm{a}_{21} L \varepsilon_{y t}+\left(1-\mathrm{a}_{11} L\right) \varepsilon_{z t}}{\left(1-\mathrm{a}_{11} L\right)\left(1-\mathrm{a}_{22} L\right)-\mathrm{a}_{12} \mathrm{a}_{21} L^{2}}
$$

Further, the characteristic roots of both equations are the same and equal to $\left(1-\mathrm{a}_{11} L\right)\left(1-\mathrm{a}_{22} L\right)-\mathrm{a}_{12} \mathrm{a}_{21} L^{2}$. 
If the value of this characteristic root goes to zero, the roots of the reverse characteristic equation are based on the interrupting operand (L). Therefore, the parameter $\lambda$ defined as $1 / \mathrm{L}$, and the characteristic equation is written as follows:

$$
\lambda^{2}-\left(\mathrm{a}_{11}+\mathrm{a}_{22}\right) \lambda+\left(\mathrm{a}_{11} \mathrm{a}_{22}-\mathrm{a}_{12} \mathrm{a}_{21}\right)=0 .
$$

Since both variables have the same characteristic roots, the roots of the equation indicate the characteristic of a temporal trend in both variables.

It is necessary for one of two characteristic roots, which are $\left(\lambda_{1}, \lambda_{2}\right)$, to be equal to one, and the absolute value of the other one should be less than one. Therefore, $\left\{y_{t}\right\}$ and $\left\{z_{t}\right\}$ will be convergent or equaled to $\mathrm{CI}(1,1)$. Under these conditions, the variables have the same random trends, and their first subtraction is stationary. After that we continue the computational process and normalize the parameters based on $y_{t}$. If $\lambda_{1}=1$ and $\left|\lambda_{2}\right|<1$, then the ECM is as follows:

$$
\Delta y_{t}=\mathrm{a}_{y}\left(y_{t-1}-\beta z_{t-1}\right)+\varepsilon y t
$$

and

$$
\Delta z_{t}=\mathrm{a}_{z}\left(y_{t-1}-\beta z_{t-1}\right)+\varepsilon_{z t} .
$$

The term $\left(y_{t-1}-\beta z_{t-1}\right)$ is representative of the deviation from the long-run equilibrium, and $\beta$ is the coefficient of cointegration. If $\left(y_{t-1}-\beta z_{t-1}\right)$ is stationary, then $y_{t}$ and $z_{t}$ are cointegrated. This cointegration requires that $\beta \neq 0$ and that at least one of the speed equilibrium parameters $a_{y}$ or $a_{z}$ must be nonzero. 


\section{Chapter 4}

Generally, if the necessary condition for the relation $\mathrm{CI}(1,1)$ among the variables is reached, then it is possible to define an error correction equation for these variables. Therefore, an ECM among the I(1) variables demonstrates a cointegration relationship.

\subsubsection{Cointegration Test}

There are several methods to conduct the cointegration test such as EngleGranger's method (1987) and Johansen's method (1988). In this paper, we use the Johansen's test among stocks to identify the pair of stocks which have cointegration relationship. Johansen's method (1988) is the generalization of Dickey Fuller test to the multi-variable version which uses the one-step method based on the relationship between the matrix and its characteristic roots to check cointegration. The advantage of this method is having fewer errors in comparison with the two-step method of Engle-Granger (1987). Moreover, Engle-Granger's method is highly dependent on the type and the number of variables. However, these drawbacks are all resolved in Johansen's method which estimates the cointegration relationships in the form of VECM using the maximum likelihood method under the assumptions about the trend, parameters, and the number of vectors is indicated with $r$. Conducting the trace-statistic test for vector $r$, this method investigates the number of cointegration vectors for $r=0,1, \ldots, k-1$. Based on the $\log$-likelihood ratio $\ln [\operatorname{Lmax}(\mathrm{r}) / \operatorname{Lmax}(\mathrm{k})]$, this test investigates the trace of a diagonal matrix including normalized Eigenvalues. It also compares the null hypothesis (with cointegration order $r$ ) to an alternative hypothesis (with cointegration order $k$ ). Considering trace-statistic and p-values, the existence of cointegration we investigate between the pair of assets. Finally, Johansen's test generates the values of normalized cointegration coefficients to adopt trading strategies. 


\subsection{Pairs Trading Strategy: A Cointegration Approach}

A estimate and analyse a long-run economic relation among the assets in the cointegration framework. The main idea of the cointegration analysis is that while many economic time series are non-stationary with an ascending or descending random trend, a linear combination of these variables might be approach.

\subsubsection{Pairs selection}

There are $\frac{n \times(n-1)}{2}$ possibilities to select a pair of stocks among $n$ stocks. It is not a proper option to check and run cointegration tests on all possible states. For this reason, we apply the pre-selection criteria in accordance with the basic analyses to choose the most appropriate stocks for implementing our trading strategy. Since the probability of a cointegration relation between two stocks from the same industry is higher, we select the stock candidates from the same industry by considering criteria such as liquidity, turnover rates, and the size of deals. The result is 14 appropriate pairs of stocks to test the performance of the pairs trading strategies.

\subsubsection{Estimating Parameters through VECM}

After selecting the stock candidates, we estimate the error correction equations to predict the parameters and the spread value. According to Granger's theorem, there might be a short-run relation for any long-run economic relation in the form of the ECM to achieve a long-run equilibrium. Thus, if there is no mechanism to converge the variables into a long-run equilibrium relation, the ECM will not hold among the variables. Therefore, the cointegration relation requires the ECM. One of the main characteristics of cointegration vectors is that deviations caused by a long-run equilibrium influence their temporal trend. Therefore, a system returns to 
Chapter 4

a long-run equilibrium if the minimal changes in some variables act in the opposite direction of the imbalances.

The long-run equilibrium relations for two variables (assets or stocks) A and B are as follows:

$$
\Delta A_{t}=\alpha_{A}\left(A_{t-1}-\beta A_{t-1}+\rho_{A}\right)+\cdots+\varepsilon_{A t}
$$

and

$$
\Delta B_{t}=\alpha_{B}\left(B_{t-1}-\beta B_{t-1}+\rho_{B}\right)+\cdots+\varepsilon_{B t}
$$

The expressions inside the parentheses refer to the long-run equilibrium relations, which are called the spread. It can be rewritten as a mean $(\mu)$ and a white noise expression $\left(\varepsilon_{t}\right)$ as follows:

$$
A_{t-1}-\beta B_{t-1}+\rho=\mu+\varepsilon_{t}
$$

Now, in terms of the cointegration characteristics, the spread has a static mean during the period. Therefore, the standardized value of the spread can be defined as follows:

$$
\text { indicator }=\frac{\text { spread }- \text { mean }(\text { spread })}{S T D(\text { spread })} .
$$

Therefore, the trading positions can be adopted based on the standardized value of the spread.

\subsubsection{Designing and Implementing Pairs Trading Strategies}

One of the most important parts of a pairs trading strategy is the parameters. For this reason, we first summarize the parameters of our strategy here: 
1- The time horizon for the estimation window: we select the proper time interval to run the cointegration tests, to estimate the cointegration parameters and coefficients, and to re-estimate the spread equation for each iteration.

2- Trading window: If there is cointegration; the coefficients, parameters, and spread equation will be corrected throughout the trading window period.

3- Trading thresholds $(\Delta)$ : Delta thresholds above and below the mean spread generate trading signals and take a position in the portfolio.

4- Stop-loss: These are thresholds on two sides of the mean spread and are wider than the delta thresholds. It is used to close the portfolio positions at the time of loss to prevent further losses. Since one of the risks of pairs trading strategies is that the spread is driven away from the long-run mean over time, the stop-loss can reduce this type of risk.

However, previous studies only use the static values for the pairs trading parameters; but by using the reinforcement learning in this paper, we compute the optimum dynamic values for the parameters to maximize the objective function. Because of the reinforcement learning method, we can allocate static values for each trading parameter, and we can apply the experiences from pre-processes to select the optimal parameter values.

When the spread reaches one of the high or low delta thresholds over time, the portfolio opens the trading positions. When the spread returns to the mean or reaches the stop-loss, the trading position closes. Then the information and value function of the algorithm are updated again, and the algorithm initializes four parameters. The Sortino ratio as the objective function is used to evaluate the algorithm's performance with respect to the returns and risks of the strategies. 


\subsection{Reinforcement Learning (Modeling based on the N-Arm Bandit Problem)}

The main two components of reinforcement learning are the agent and the environment. The agent lives in the environment and updates his or her experiences by receiving feedback from the environment. For example, If the agent is in the state of $s$ for each moment by selecting an action $(a)$ out of his or her action space, then the agent moves to the next state $\left(s^{\prime}\right)$ and receives the reward $(r)$ from the environment. After that, based on the acquired reward, the agent updates the experience of being in state $s$ and doing action "a". To update the agent's experience, we estimate the value of the desired state and the action which has been done in that state (estimating the value of the state-action). The following relation is used to estimate the value of the state-action:

\section{Acquired Reward $\times$ Learning Rate + Previous Estimation $\longrightarrow$ New Estimation}

The learning rate, $\alpha \in[0,1]$, decreases as time passes. In the beginning of the agent's life, the value of $\alpha$ is close to one because the agent does not have any experience at that time. As time passes, the agent receives feedback from the environment and can consider the estimated value of the state-action to decrease the effect of feedback from the environment for updating the new estimations. When the learning rate is zero, the agent selects the best action in each state only through estimating the value of the state-action. Therefore, the agent can identify a behaviour in the environment and make the best decision to maximize the reward in different states.

Each action is taken by the agent in accordance with a learning policy in each state. The learning policy specifies the way that an agent behaves through time. Given the objective of the agent and the environmental assumptions, different policies can be used. In this paper, we use the $\epsilon$-greedy policy. In this policy, an agent behaves 
greedily as much as $\epsilon$ and behaves randomly as much as $1-\epsilon$. In other words, $\epsilon$ is selected out of the practical decisions which have the highest value to the agent. On the other hand, $1-\epsilon$ is selected out of the decision cases in which an action is selected by the agent at random and independent of the value. As the agent's knowledge increases, the value of $\epsilon$ can gradually decrease and drive the agent toward the selection of more promising actions which can be selected through the experience of living in the environment. The algorithm of a reinforcement learning agent who lives by the $\epsilon$-greedy policy is presented as follows.

\section{Algorithm 1: The agent behaves in RLM based on the $\epsilon$-greedy policy.}

Initialize $Q(s, a), \forall s \in \mathcal{S}, a \in \mathcal{A}(s)$, arbitrarily, and $Q($ terminal - state,.$)=0$ Repeat (for each episode):

Initialize $S$

Choose $A$ from $S$ using policy derived from $Q(e . g ., \epsilon-$ greedy $)$

Repeat (for each step of episode):

Act $A$, observe $R, S^{\prime}$

greedy)

Choose $A^{\prime}$ from $S^{\prime}$ using policy derived from $Q(e . g ., \epsilon-$

$$
\begin{aligned}
& Q(S, A) \leftarrow Q(S, A)+\alpha\left[R+\gamma Q\left(S^{\prime}, A^{\prime}\right)-Q(S, A)\right] \\
& S \leftarrow S^{\prime} ; A \leftarrow A^{\prime} ;
\end{aligned}
$$

Algorithm 1- The pseudo code of a reinforcement leaning agent who behaves by the $\epsilon$ greedy policy.

One of the well-known frameworks to train the agent in reinforcement learning is the n-arm bandit. When a random arm is pulled, the device generates a score as a reward for the player. Each player can pull a limited number of arms and receive 


\section{Chapter 4}

the rewards. This method is used in reinforcement learning to design an acquisitive agent. In each state, the agent decides to pull an arm and receive his or her reward from the device. The state space includes only one state in this method, and the action space comprises all of the arms. After selecting and pulling an arm in the state and receiving the score, the agent returns to the state to select another arm to pull. Since the scores from pulling each arm follow an unknown distribution, the agent tries to select an arm which gives a higher average score after discovering the environment. The learning rate decreases as the frequency increases, and the importance of selecting an arm which has the highest estimation value increases.

The paradigm of the n-arm bandit gives an idea as to how an agent can maximize the profit obtained in pairs trading through reinforcement learning. Since the price changes of two stocks are influenced by many factors over time, modelling these factors as a simple noise is not efficient. Therefore, we need to design a reinforcement learning agent that formulates different uncertain factors more efficiently than the traditional methods. (Sutton and Barto 1998)

The values of all pairs trading parameters only work in a limited interval. The parameters of the estimation and trading windows use discrete values with a 1minute time interval. But the parameters of delta and stop-loss are continuous values. If we make the values of the delta and stop-loss parameters discrete, then we can consider the framework of pairs trading as like the framework of the n-arm bandit. Therefore, we can design an agent which is able to find an appropriate value for the parameters after the cointegration test.

After closing the portfolio, the agent takes the Sortino ratio as a reward. Therefore, the state of the agent is the opening time of the portfolios. Moreover, the agent's action space has four parameters. The agent then selects a value for each of these parameters by estimating the value of the state-action at the time of opening the portfolio. Using the acquired Sortino ratio, the agent updates the estimation of the 
values of the state-action. In other words, like the framework of the n-arm bandit, the agent should select a value for each of these parameters when the portfolio is open, and the Sortino ratio acquired from this selection is updated when the portfolio is closed. Therefore, the agent returns to the initial state and waits for another portfolio to open so that he or she can select another four values. The values of the estimation and trading windows are discrete, whereas the values of the trading threshold and stop-loss parameters are continuous. Since the action state is discrete in the platform of the n-arm bandit, the quantity of delta and stoploss parameters can be made discrete by considering a small interval (for instance 0.5 of a unit). Now, the values of all parameters are discrete. Each permutation of the parameters is an action whereas each of them represents an arm in the problem of the n-arm bandit. To model the problem of pairs trading like the problem of the $\mathrm{n}$-arm bandit, we need to design and simulate the agent. As pointed out before, the agent must adopt a policy to select the optimal action in each decision. Because the action space is discrete, the $\epsilon$-greedy policy is used as a decision-making policy. The algorithm of our proposed method is as follows.

\section{Algorithm 2: RLM framework for the Pairs Trading}

Input: Stock $A$, Stock $B$

1. Initialization:

2. actionspace $_{n \times 4} \leftarrow$ $\left[\delta_{n \times 1}\right.$, stoplos $_{n \times 1}$, estimation window $_{n \times 1}$, tradingwindow $_{n \times 1}$ ] numofiteration $\leftarrow$ maxnumberofiteration

3. For episode $\leftarrow 1$ to numofiteration

4. $\quad$ action $\leftarrow$ choose action based on epsilon greedy policy

5. $\quad$ reward $\leftarrow$ perform action (action, $A, B$ )

6. action update (action, reward)

7. end

8. return sortino ratio. 
Chapter 4

The algorithm starts with initialized values, and the space comprises four parameters: the estimation window, trading window, trading thresholds $(\Delta)$, and the stop-loss value. Then, for each iteration, an agent selects enough iterations to train him or herself and select one value out of the four parameters as an action in accordance with the $\epsilon$-greedy policy. The value of the Sortino ratio is calculated as the reward by using a perform action function, and the result returns to the agent from the environment as feedback. Using the action update function and the value of the reward acquired in the previous step, the agent can update the state-action value for each of the four parameters. Finally, the overall Sortino ratio is acquired after evaluating all the input data.

\subsection{Numerical results}

This section emphasizes the testing of the performance of our method. We then compare our results with the results from the static parameters method. More specifically, we first show the simulation parameters and then present the test cases. 


\subsubsection{Simulation parameters}

In our simulation, the Sortino ratio is considered a reward function. Our simulations are done with Matlab 2013a on a machine with Corei5 2.4Ghz and 4GB RAM. The values of the four parameters are as follows:

- Estimation window varies from 60 to 600 over a 5-minute time interval.

- Trading window varies from 5 to 120 over a 5 -minute time interval.

- Trading thresholds vary from 0 to 3 with a precision of 0.5 units.

- Stop-loss varies between 0 and 5 with a precision of 0.5 units.

We select $75 \%$ of data as in-sample for the training phase and the rest of it as outof-sample data for the testing phase. The training phase iterates to 100 times with $\alpha=1, \epsilon=1$. For each iteration of the training phase, a value is chosen for each of the four parameters based on the $\epsilon-$ greedy policy, and the value of the stateaction is updated. In the testing phase, the agent chooses parameters for pairs trading, and considers $\alpha=0.3, \epsilon=0.3$.

\subsubsection{Test case}

We retrieve 28 intraday observations from June 2015 to January 2016 for FBGOOG, BABA-AMZN, FB-TWTR, GM-F, AMZN-GOOG, CNP-NEE, DOWLYB, ADBE-ADSK, APH-BA, JNJ-MDT, BAC-BK, HP-HES, HSY-TSN, and TGNA-FOXA. Figure 4-1 shows the trend in Amazon-Google's intraday prices, where time $=0$ indicates 9 June2015. 
Chapter 4

Figure 4-1- Intraday prices of Amazon and Google

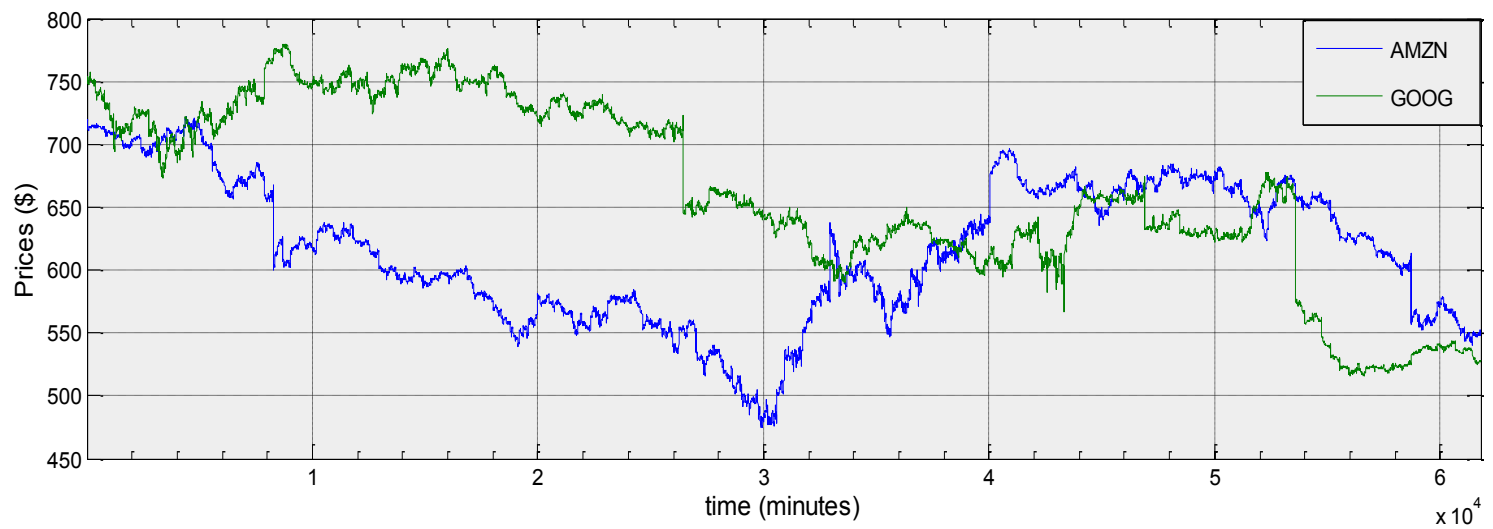

\subsubsection{Simulations results}

We initially choose a 420-minute time interval for the estimation window and a 30 minute time interval for the trading window. Then, we run a grid search algorithm on both windows with 5 and 20 minutes as the steps for the trading window and the test and estimation window respectively.

The results of the initial, best, and worst window sizes with respect to the return are presented in Table 4-2.

Table 4-2- Optimum size of windows

Initial Best Worst

Test and estimation window size (minutes)

$\begin{array}{ccc}420 & 380 & 240 \\ 30 & 80 & 20 \\ 9.50 & 31.6 & -83.55 \\ 0.55 & 0.64 & 0.85 \\ 0.13 & 0.15 & -1.47 \\ 390 & 265 & 563\end{array}$

Trading window size (minutes)

Return (\%)

This able shows the initial, the best and worst values for the SPM strategy to choose the

Standard deviation

Sortino ratio

Number of trades length of the estimation window, trading window, return, standard deviation, Sortino ratio and number of trades. 
Based on the results of the Table 4-2, we choose the best parameters, that is, the "Best" column, for the static parameter model (SPM).

Here we show the results of the Amazon-Google pairs in the in-sample data, we use the following parameters: estimation window as 420 minutes, trading window as 60 minutes, trading thresholds as 2 , and stop-loss as 3 . The dynamic parameters are shown in Figure 4-2. Further, we use $R_{f}=0.02$ as the risk-free rate for the numerator of the Sortino ratio that is calculated in each iteration of the algorithm. Also, Figure 4-2 and Figure 4-3 display the results for the out-of-sample data.

Now, we use reinforcement learning to consider the dynamic parameters of the estimation window, trading window, trading thresholds, and stop-loss. In each interval, we vary the parameters in order to maximize the Sortino ratio. The summary of the results for in-sample and out of sample are shown in Figure 4-5 and Figure 4-4. 
Chapter 4

Figure 4-2- indicator and positions on the in-sample data of Amazon-Google pair which is calculated by the RLM method

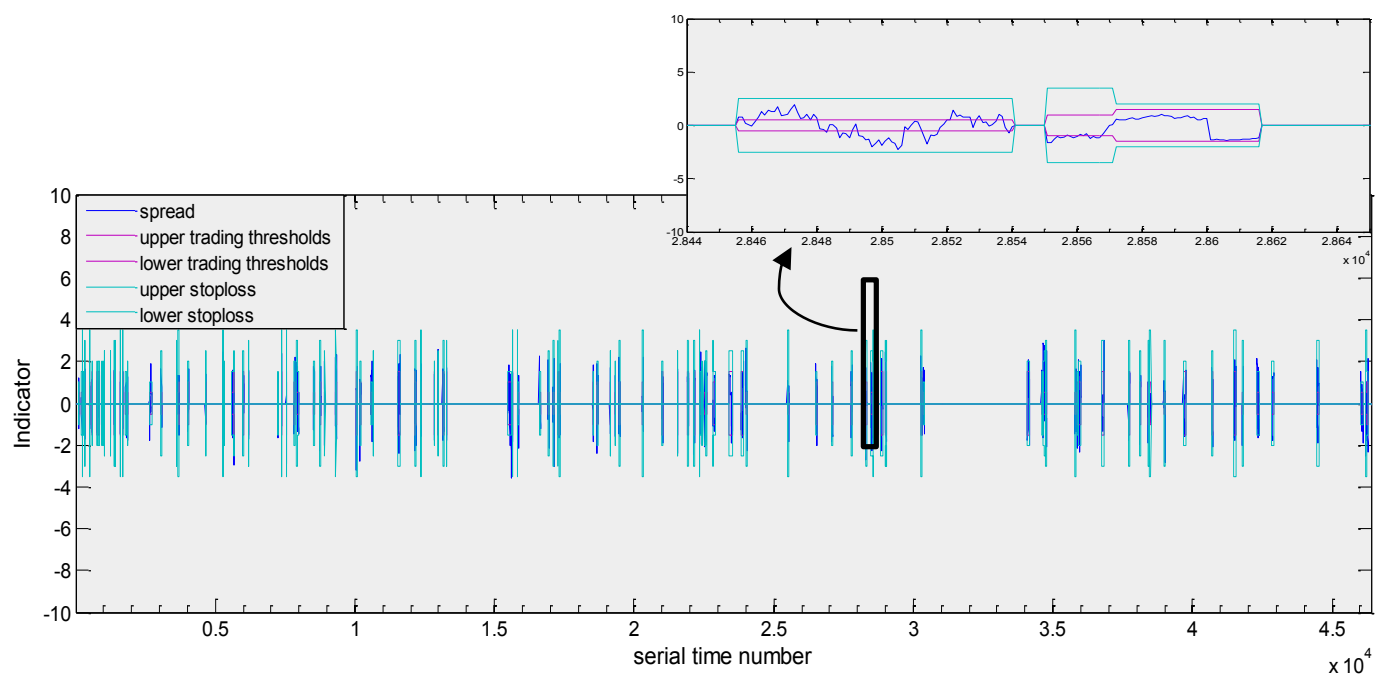

Figure 4-3- indicator and positions on the in sample data of Amazon-Google pair which is calculated by the static parameters method (SPM)

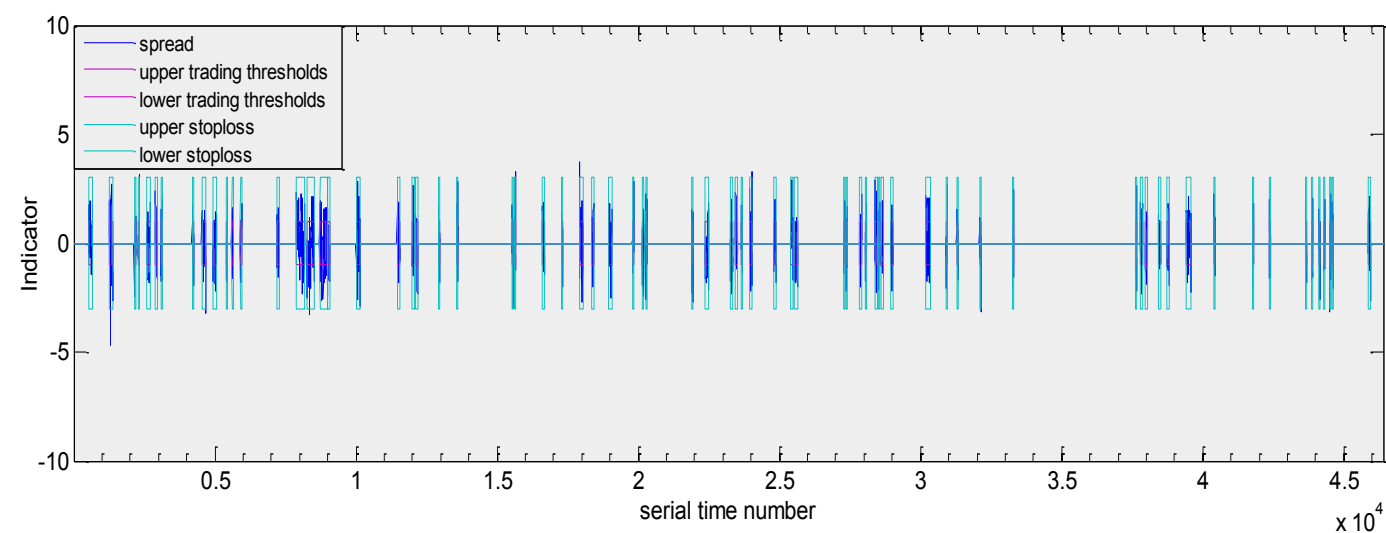


Pairs Trading Strategy Optimization using the Reinforcement Learning Method: A

Cointegration Approach

Figure 4-5- indicator and positions on the out of sample data of Amazon-Google pair which has been calculated by the proposed method (RLM)

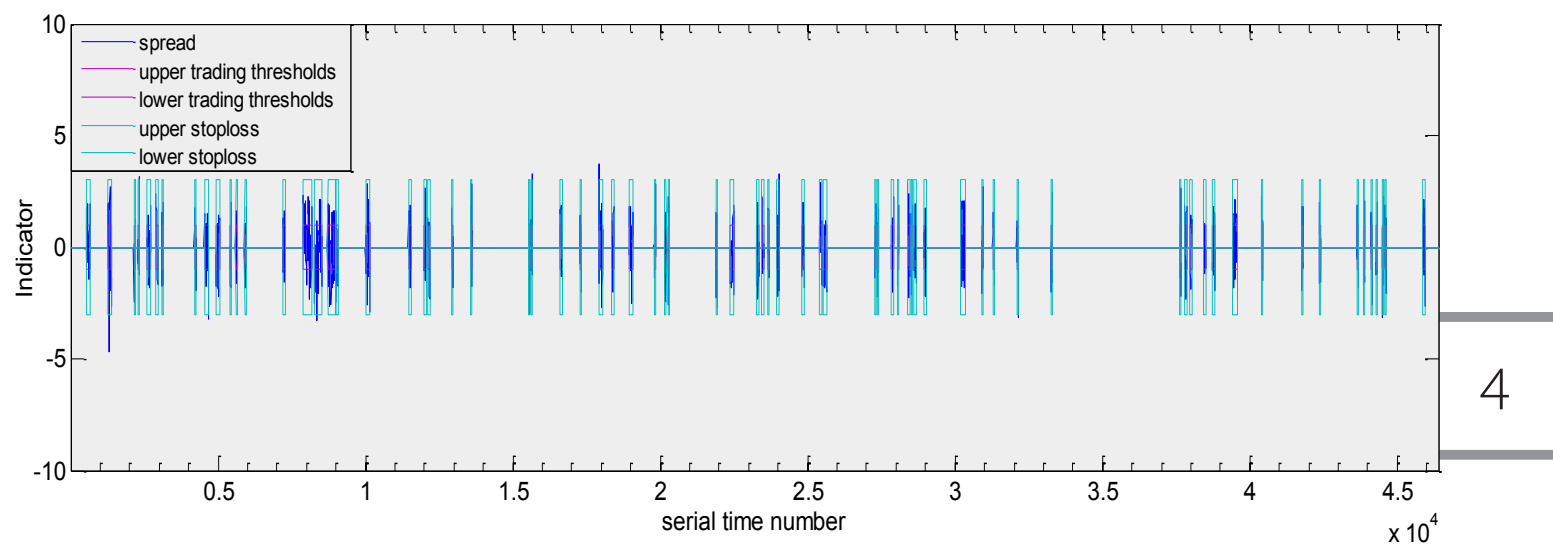

Figure 4-4- indicator and positions on the out of sample data of Amazon-Google pair which has been calculated by the static parameters method (SPM)

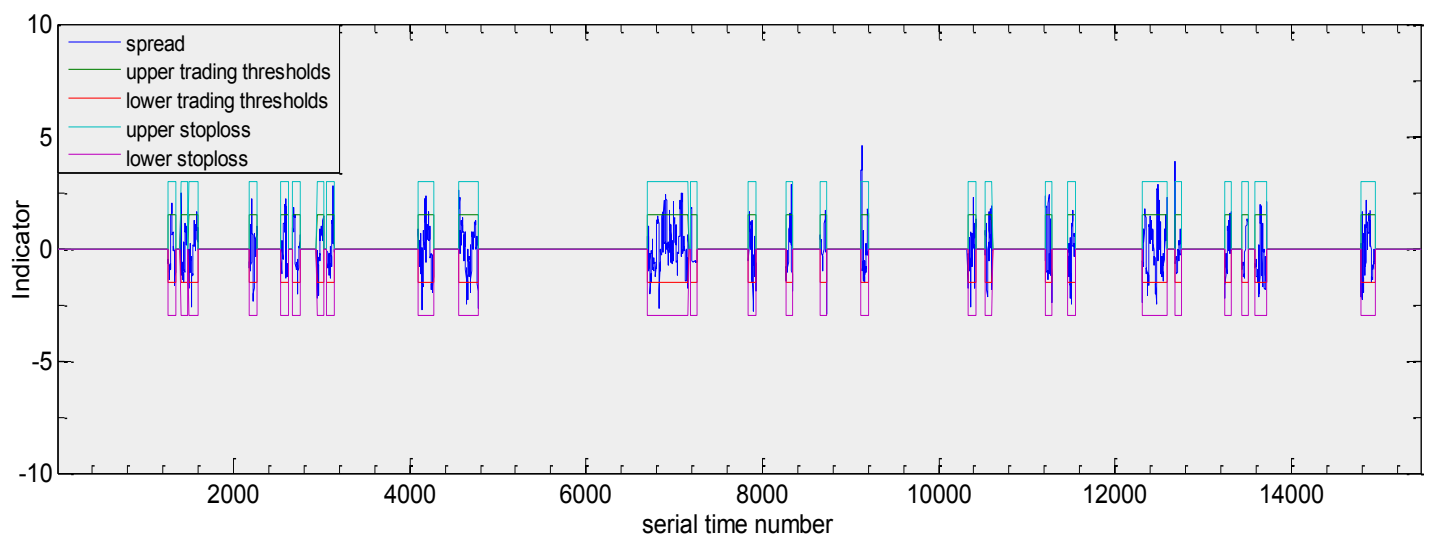


Chapter 4

Table 4-3- simulation results on Amazon-Google pair in the in sample and out of sample data

\begin{tabular}{|c|c|c|c|c|}
\hline & SPM & & RLM & \\
\hline Test and estimation window size (minutes) & 380 & \multicolumn{3}{|c|}{ Dynamic $[60,600]$} \\
\hline Trading window size (minutes) & 80 & \multicolumn{3}{|c|}{ Dynamic $[5,120]$} \\
\hline$($ standard deviation $) \Delta$ & 1.5 & \multicolumn{3}{|c|}{ Dynamic $[0.5,3]$} \\
\hline Stop-loss (standard deviation) & 3 & \multicolumn{3}{|c|}{ Dynamic $[1,5]$} \\
\hline & In sample & $\begin{array}{l}\text { Out of } \\
\text { sample }\end{array}$ & In sample & $\begin{array}{l}\text { Out of } \\
\text { sample }\end{array}$ \\
\hline Return $(\%)$ & 15.8 & 11.3 & 91.5 & 46.6 \\
\hline Downside volatility & 0.51 & 0.18 & 0.61 & 0.12 \\
\hline Annualized return $(\%)$ & 31.6 & 67.8 & 183 & 279.6 \\
\hline Sortino ratio & 0.27 & 0.52 & 1.46 & 3.72 \\
\hline Number of trades & 265 & 180 & 586 & 388 \\
\hline Average return per trade $(\%)$ & 0.06 & 0.06 & 0.16 & 0.12 \\
\hline Average time per trade (minutes) & 185.4 & 91 & 83.8 & 42.2 \\
\hline
\end{tabular}

Table shows the simulation results on Amazon-Google pair in sample and out of sample for both method RLM and SPM

Table 4-3 shows that the reinforcement learning method has higher performance than the static parameters method in which the in-sample and out-of-sample data on the returns of the pairs trading are higher. The Sortino ratio is also 1.46 for the 
reinforcement learning method and 0.27 for the static parameters method. The outof-sample data shows the Sortino ratio is 3.72 for the reinforcement learning method and 0.52 for the static parameters method.

On the other hand, the average return per trade form the reinforcement learning method and the SPM are $0.12 \%$ and $0.06 \%$, respectively. Since the agent can explore the environment and learn from past experiences, he or she can select the optimum parameters to maximize the Sortino ratio. Consequently, the reinforcement learning method uses less average time per trade than the SPM.

Note that the reinforcement learning method is iterated up to 100 times in the training phase which means the agent experiences only 100 states from 100,000 possible states. Increasing the number of iterations allows the agent to experience higher possible states, which leads to better training.

\subsection{Robustness check}

The robustness check shows to what extent the system can generate an optimal output in the case of different inputs and conditions. Furthermore, the goal of the robustness test is to develop test cases to examine the robustness of the system. To achieve this goal, we consider five appropriate pairs to compare our method with the SPM approach. Table 4-4, Table 4-5, and Table 4-6 show the results. 


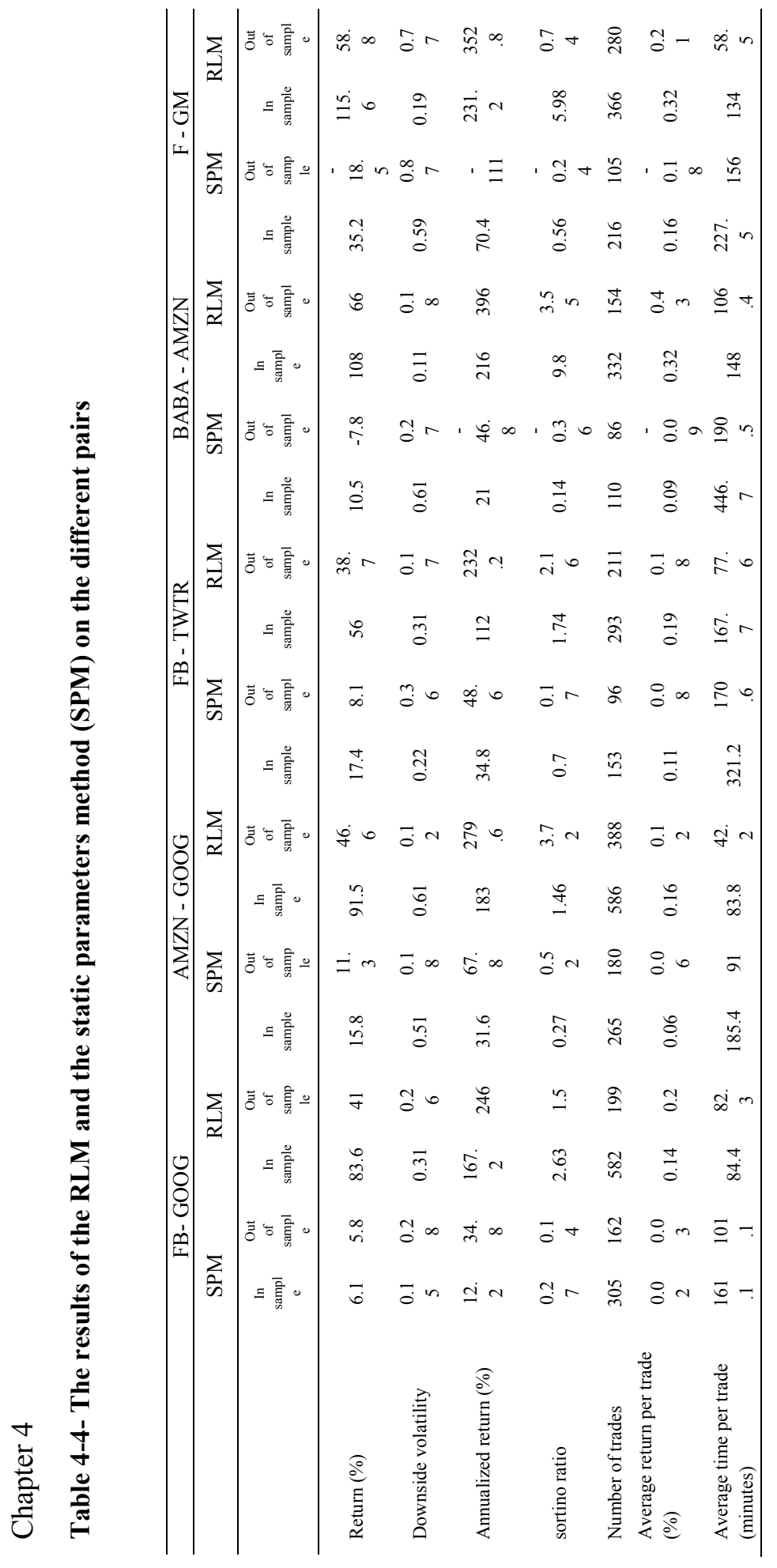




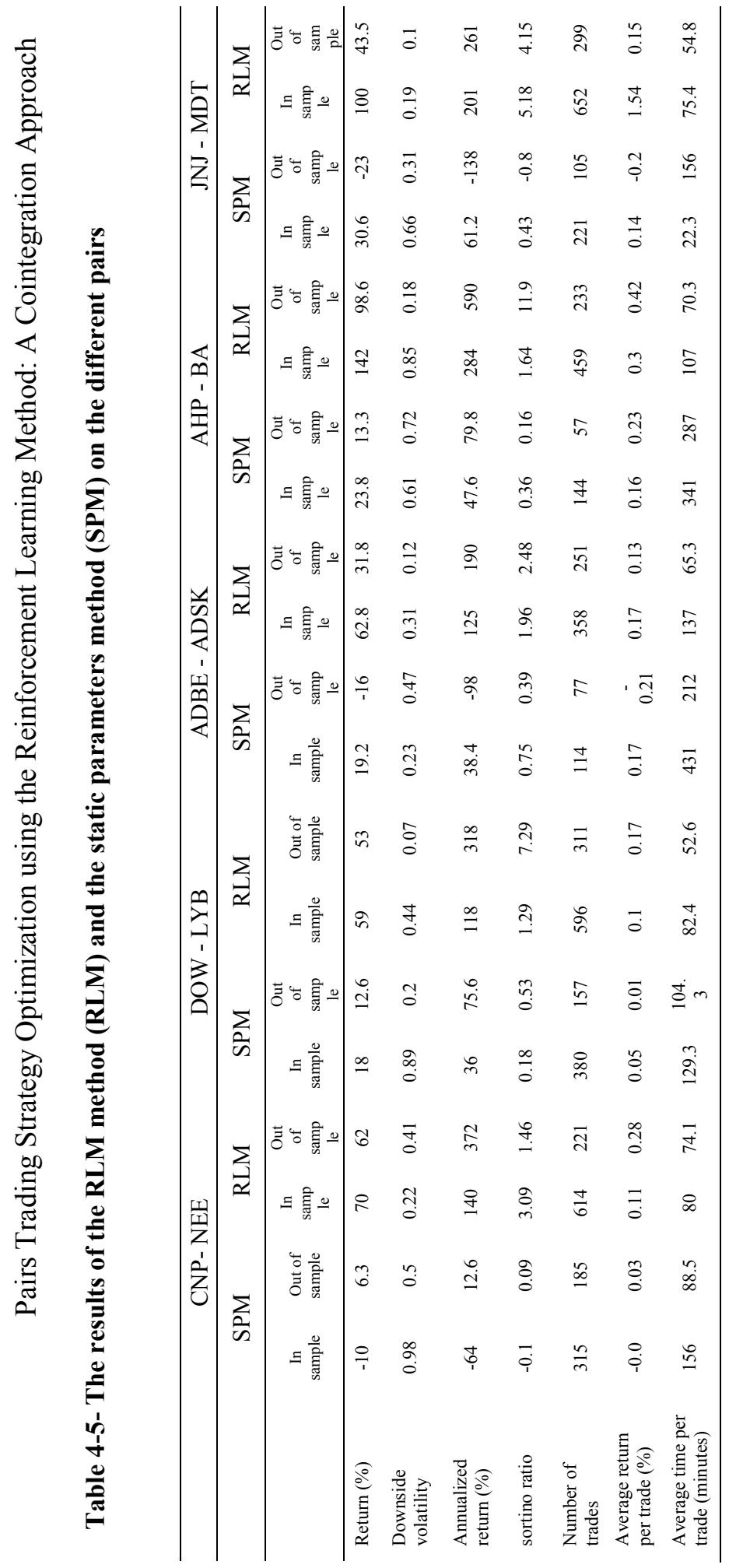




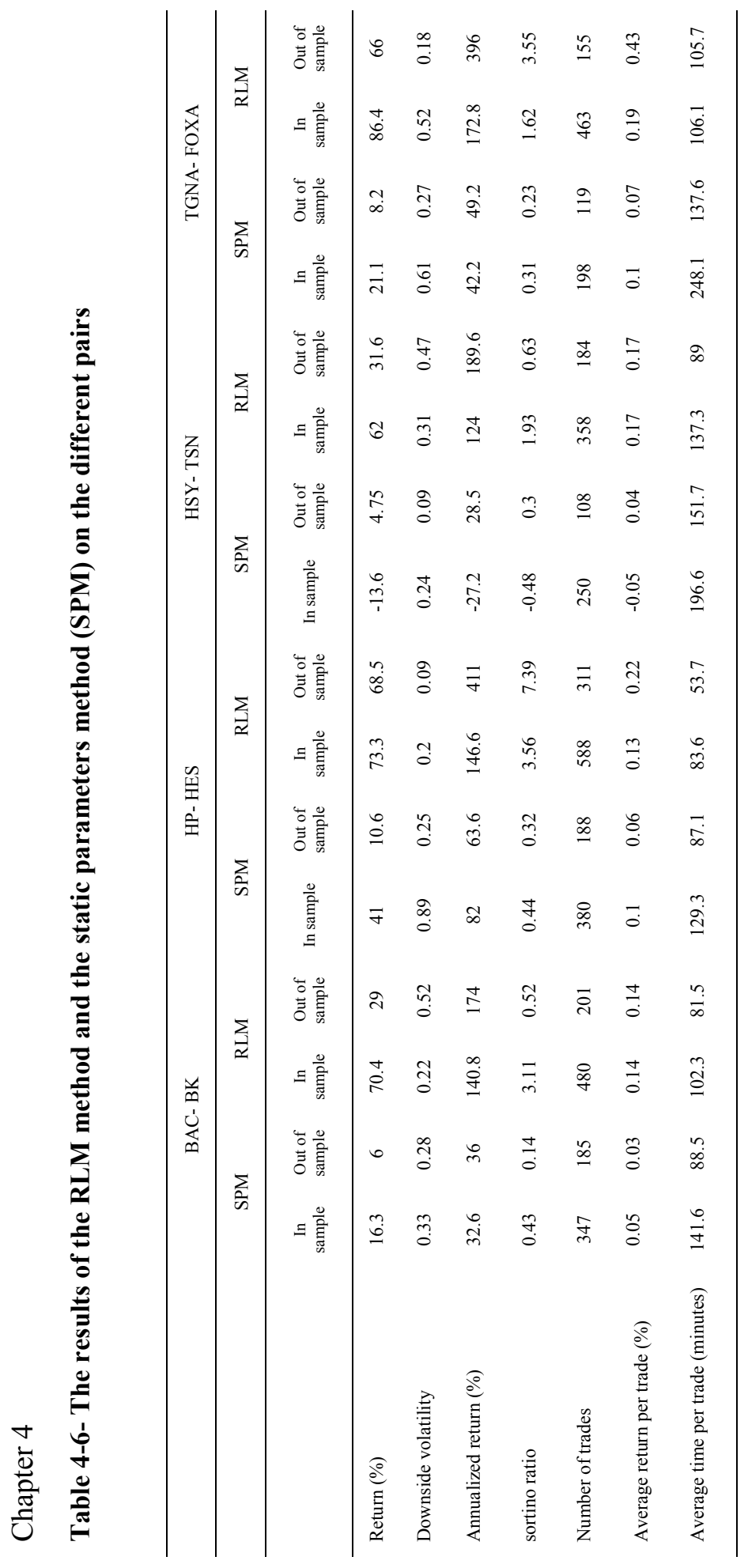


Moreover, to compare the reinforcement learning to the SPM, we use the t-test on the return series of the two methods. The return of the SPM method is static in each run of the model. The results of the t-test for the out-of-sample data come from 15 iterations and are summarized in Table 4-7.

Table 4-7 shows that our method achieves significantly higher results than the method of static parameters with a confidence level of $95 \%$.

Table 4-7- Copmaring the results of five-pair stocks from two methods

\begin{tabular}{lccc}
\hline & SPM return (\%) & Average return for RLM (\%) & $\begin{array}{c}\text { Mean difference } \\
(\%)(\text { RLM-SPM })\end{array}$ \\
\hline FB- GOOG & 5.8 & 35.71 & $29.91^{* * *}$ \\
AMZN - GOOG & 11.3 & 33.73 & $22.43^{* * *}$ \\
FB - TWTR & 8.1 & 27.26 & $19.16^{* * *}$ \\
BABA - AMZN & -7.8 & 40.84 & $48.64^{* *}$ \\
F - GM & -18.5 & 26.1 & $44.6^{* * *}$ \\
CNP- NEE & 6.3 & 36.6 & $30.3^{* * *}$ \\
DOW - LYB & 12.6 & 29 & $16.4^{* * *}$ \\
ADBE - ADSK & -16.4 & 22.64 & $39.04^{* * *}$ \\
AHP - BA & 13.3 & 45.57 & $32.27^{* *}$ \\
JNJ - MDT & -23 & 26.99 & $49.99^{* * *}$ \\
BAC- BK & 6.2 & 20.33 & $14.33^{* * *}$ \\
HP- HES & 10.6 & 28.77 & $18.17^{* * *}$ \\
HSY- TSN & 4.75 & 25.15 & $20.4 * *$ \\
TGNA- FOXA & 6.65 & $31.45^{* * *}$ \\
\hline
\end{tabular}

This table presents the results of five-pair stocks from the RLM method and from the SPM approach in columns 2 and 3 respectively. Column 4 shows the differences between two methods. We indicate significance at the $10 \%$, $5 \%$ and $1 \%$ level, by $*, * *$, and $* * *$, respectively. 
Chapter 4

\subsection{Conclusion}

The prior studies consider static parameters for pairs trading including estimation window, trading window, trading thresholds and stop-loss boundries. In this paper, we propose applying reinforcement learning to a pairs trading strategy to determine the value of all parameters dynamically. The combination of reinforcement learning and the cointegration paradigm allow a trader to experience the long-run relations between two prices and find the optimum values for the parameters to maximize the objective function. The results of our simulations on 14 pairs of stocks show that this method performs significantly better than the method with the static parameters. Furthermore, we do a robustness check and compare the mean difference between the SPM and reinforcement learning methods with respect to the average return and the Sortino ratio. Our results show that our method is robust and performs significantly better than the method with static parameters. 


\section{Chapter 5}

Conclusion 


\subsection{Summary of findings}

The US financial market includes various types of players who have important roles to play and have an incredible influence on the market and subsequently on all investors' welfare. This dissertation focuses on two main players in the US financial market including the mutual fund industry and the automated investment industry to contribute to a better understanding of their functioning and their performance.

At the end of 2016, assets under management of US mutual funds rose 16 times from the 1990s. As more and more investors invest their money into mutual funds, it is becoming more and more important to evaluate fund managers correctly and understand the way in which they function. On the other hand, from the early 2000 s, the nature of market players has shifted from traditional traders to algorithmic traders. The volumes of algorithmic trading in the US financial market have risen significantly over the last decade and it now comprises approximately half of the total trading volume. Algorithmic trading contributes to the efficiency of markets by exploiting arbitrages and reducing frictions. Therefore, any improvement in the algorithmic trading can contribute significantly to the whole market and welfare of market participants.

In brief, Chapter 2 focuses on the US mutual fund industry and develops a novel measure that allows for a more granular investigation of the investment style deviation among mutual funds. Chapter 3 in line with Chapter 2 test whether all different types of investors react to style deviation in an equal manner. Finally, Chapter 4 looks at the automated investment industry and shows how Machine Learning helps algorithmic trading to improve. The result of this study should be of interest to retail and institutional investors, regulators and academics.

More specially, in Chapter 2, we re-examine investment style deviation of US mutual funds through 2003-2016. Although the US Securities and Exchange 


\section{Chapter 5}

Commission (SEC) mandates all mutual fund managers to adhere to their stated investment style, prior studies show that many mutual fund managers drift or even change their investment style over time. This chapter starts with the introduction of a novel and more granular measure of style analysis to figure out style deviation degree with a certain confidence level. Based on this measure, we first document that $14 \%$ of US equity mutual funds in our sample are significantly misclassified. We also point out that the degree of style deviation matters to the actively managed fund performance based on the stock selection criteria. For instance, we show that misclassified funds significantly underperform well-classified funds by $-0.92 \%$ annually based on a Carhart four-factor alpha; We then address the question what type of mutual funds are more likely to deviate from the stated investment style. We find that misclassified funds appear to be younger, are smaller and charge higher expense ratios. Our results suggest that maintaining a consistent investment style is a crucial ingredient for achieving solid long-term fund performance. The results also call for diligent monitoring of style consistency by investors.

Chapter 3 investigates the relationship between fund flows and investment style changing behavior among US mutual funds. As human beings are not all equal, mutual fund investors are also different. Previous studies show that investors vary in their sophistication level and show that more sophisticated investors use more sophisticated tools to monitor and evaluate fund managers. However, prior research on the impact of style changing behavior on fund flow has treated all investors as a homogenous group. We extend this literature by explicitly taking account of the heterogeneity among investors. We expect different types of investors to differently understand and consequently react to investment style deviation. The empirical approach that we apply to several proxies of investors' sophistication level indicates that less sophisticated investors reward stylechanging behavior by an increase in fund flow, while more sophisticated investors punish this behavior by redemption. We also show that style-changing behavior 
has a different impact on various types of fund performance measures. More specifically, style deviation has a strong positive impact on the 'simple' fund performance measures, which are used by less-sophisticated investors, while it has no impact on more advanced fund performance measures. Overall, we argue that a comparison of the fund flow-style changing relationship, by accounting for investor's sophistication level, allows for a more complete picture of an investor's response to the changes in mutual funds' investment style behavior.

Finally, Chapter 4 provides more insight about algorithmic trading by using machine learning. Previous studies show that in 2012 half of the trade volume in the US financial market was related to algorithmic trading. Hence, any improvement in an algorithmic trading platform may have a phenomenal impact on the financial market with respect to liquidity and market efficiency. Recent studies show that the growing popularity of some algorithmic trading strategies such as pairs trading may pose a problem as the opportunities to trade become much smaller. Using machine-learning technique, we examine the optimal level of pairs trading specifications over time. More specifically, this chapter employs Reinforcement Learning as one of the machine learning methods to capture the optimal level of pairs trading's parameters including an estimation window, a trading window, trading thresholds and stop-loss boundaries. Our results are economically and statistically higher than the traditional approach of pairs trading with static parameters. 
Valorization 


\section{Valorization}

The studies presented in this dissertation contribute to our understanding of investment management and algorithmic trading which in turn results into smarter investment decision making and increases the aggregate utility of investors. The two research projects offer a distinct contribution for investors in the financial market. Chapters two and three focus on the investment style analysis of US mutual funds as the largest segment of the asset management business in the world, whereas chapter four examines an investment strategy by employing artificial intelligence.

The mutual fund industry has experienced tremendous growth in the last thirty-five years. According to Investment Company Institute (2017), the share of household financial assets held in the US investment companies rose from 3\% in 1980 to more than $22 \%$ at year-end 2016 . The growth of individual pension plans partially explains the increased household reliance on investment companies. Today there are more than 9,500 mutual funds with various investment objectives in the US financial market. With increased competition in the mutual fund industry, fund managers attempt to provide evidence of superior performance to attract more investors. Since the actual risks of these funds are unobservable, some funds may be tempted to deviate from their stated objectives and take higher risks to earn higher returns and consequently a higher performance rank in their stated objective group. This behavior can change the type and level of risks of what investors are supposed to be exposed to. Chapter two and chapter three critically investigate this behavior.

Chapter two introduces a more granular approach of the investment style analysis, which allows investors to measure the gap between actual investment style and stated investment style in a single statistic with a certain confidence level. The novel results of this chapter show that: (1) mutual funds differ substantially in their commitments to the stated investment style, (2) the most misclassified funds significantly underperform well-classified funds by $1.73 \%$ per year based on 
Carhart alpha of gross return, and (3) misclassified funds appear to be younger, smaller in size and charge higher expense ratios. This insight might serve a motivation for mutual funds not to deviate from their stated investment style, thereby limiting the extent to which investors are exposed to risks they have not been informed of.

Chapter three critically examines different clienteles' reactions to investment style deviation behaviour. Not only do more than 95 million households invest in the US mutual funds, but also various business and institutional investors are involved in this industry. Previous studies show that investors vary with regards to sophistication level, and better-informed investors like institutional investors use more sophisticated tools to monitor fund managers. Hence, this chapter tests how investors with different levels of sophistication respond to the style changing behaviour of mutual fund managers. The novel findings of this chapter show that heterogeneity in investors' sophistication levels strongly relates to heterogeneity in responses to style changing behaviour. The empirical approach that we apply to several proxies of investors' sophistication level indicates that less sophisticated investors reward style-changing behaviour by an increase in fund flow, while more sophisticated investors punish this behaviour by redemption. The results extend the conclusions of previous studies, which treat all investors as a homogeneous group with respect to the style changing of mutual funds.

Technological change has reshaped the way financial assets are traded and has potential to make asset prices more efficient. Algorithmic trading is an example of the technological changes. Previous articles show that due to the growing popularity of algorithmic trading, there is a downward trend in their profitability. Hence, the optimization of algorithmic trading features has gained widespread attention among traders specifically using new machine learning methods. Chapter four employs Reinforcement Learning (RL), which is a branch of machine learning, in a platform of pairs trading strategy. The results show improvement in 
Valorization

finding of trading opportunities and indicate that our method is robust and performs significantly better than the method with static parameters.

Taken together, the studies presented in this dissertation provide answers to a variety of questions in the field of investment management and financial market. The findings in chapter two and three are of special interest to mutual fund investors and policy makers. The focus of chapter four is on the algorithmic trading with combination of artificial intelligence, which is of interest to high frequency traders in the financial market. 


\section{Bibliography}


Amihud, Y., \& Goyenko, R. (2013). Mutual fund's R 2 as predictor of performance. The Review of Financial Studies, 26(3), 667-694.

Andrade, S., Di Pietro, V., \& Seasholes, M. (2005). Understanding the profitability of pairs trading. Unpublished working paper, UC Berkeley, Northwestern University.

Annaert, J., \& Van Campenhout, G. (2007). Time variation in mutual fund style exposures. Review of Finance, 11(4), 633-661.

Annaert, J., \& Van Campenhout, G. (2007). Time variation in mutual fund style exposures. Review of Finance, 11(4), 633-661.

Bams, D., Otten, R., \& Ramezanifar, E. (2016). Investment Style Misclassification and Mutual Fund Performance.

Barber, B. M., Huang, X., \& Odean, T. (2016). Which factors matter to investors? Evidence from mutual fund flows. The Review of Financial Studies, 29(10), 26002642.

Barberis, N., \& Shleifer, A. (2003). Style investing. Journal of financial Economics, 68(2), 161-199.

Bergstresser, D., Chalmers, J. M., \& Tufano, P. (2009). Assessing the costs and benefits of brokers in the mutual fund industry. The Review of Financial Studies, 22(10), 4129-4156.

Berk, J. B., \& Green, R. C. (2004). Mutual fund flows and performance in rational markets. Journal of political economy, 112(6), 1269-1295.

Berk, J. B., \& Van Binsbergen, J. H. (2016). Assessing asset pricing models using revealed preference. Journal of Financial Economics, 119(1), 1-23.

Berk, J. B., \& Walden, J. (2013). Limited capital market participation and human capital risk. The Review of Asset Pricing Studies, 3(1), 1-37.

Bertram, W. K. (2010). Analytic solutions for optimal statistical arbitrage trading. Physica A: Statistical Mechanics and its Applications, 389(11), 2234-2243.

Bogomolov, T. (2010). Pairs trading in the land down under.

Brown, K. C., Harlow, W. V., \& Starks, L. T. (1996). Of tournaments and temptations: An analysis of managerial incentives in the mutual fund industry. The Journal of Finance, 51(1), 85-110. 
Bibliography

Brown, S. J., \& Goetzmann, W. N. (1997). Mutual fund styles. Journal of financial Economics, 43(3), 373-399.

Brown, K. C., Harlow, W., \& Zhang, H. (2011). Investment style volatility and mutual fund performance. Working Paper, University of Texas (Austin) and Nanyang Technological University.

Brown, S. J., \& Goetzmann, W. N. (1997). Mutual fund styles. Journal of financial Economics, 43(3), 373-399.

Budiono, D., \& Martens, M. (2009). Mutual fund style timing skills and alpha.

Cao, C., lliev, P., \& Velthuis, R. (2017). Style drift: Evidence from small-cap mutual funds. Journal of Banking \& Finance, 78, 42-57.

Carhart, M. M. (1997). On persistence in mutual fund performance. The Journal of finance, 52(1), 57-82.

Chalmers, J., \& Reuter, J. (2010). What is the Impact of Financial Advisors on Retirement Portfolio Choices \& Outcomes? (No. orrc10-05). National Bureau of Economic Research.

Chan, L. K., Chen, H. L., \& Lakonishok, J. (2002). On mutual fund investment styles. The Review of Financial Studies, 15(5), 1407-1437.

Chen, J., Hong, H., Huang, M., \& Kubik, J. D. (2004). Does fund size erode mutual fund performance? The role of liquidity and organization. The American Economic Review, 94(5), 1276-1302.

Chevalier, J., \& Ellison, G. (1997). Risk taking by mutual funds as a response to incentives. Journal of Political Economy, 105(6), 1167-1200.

Chiu, M. C., \& Wong, H. Y. (2015). Dynamic cointegrated pairs trading: meanvariance time-consistent strategies. Journal of Computational and Applied Mathematics, 290, 516-534.

Christoffersen, S. E., \& Musto, D. K. (2002). Demand curves and the pricing of money management. The Review of Financial Studies, 15(5), 1499-1524.

Christoffersen, S. E., Evans, R., \& Musto, D. K. (2013). What do consumers' fund flows maximize? Evidence from their brokers' incentives. The Journal of Finance, 68(1), 201-235. 
Clifford, J. (2013). Returns. Harvard University Press.

Cooper, M. J., Gulen, H., \& Rau, P. R. (2005). Changing names with style: Mutual fund name changes and their effects on fund flows. The Journal of Finance, 60(6), 2825-2858.

Cremers, K. M., \& Petajisto, A. (2009). How active is your fund manager? A new measure that predicts performance. The Review of Financial Studies, 22(9), 33293365 .

Del Guercio, D., \& Tkac, P. A. (2002). The determinants of the flow of funds of managed portfolios: Mutual funds vs. pension funds. Journal of Financial and Quantitative Analysis, 37(4), 523-557.

de Moura, C. E., Pizzinga, A., \& Zubelli, J. (2016). A pairs trading strategy based on linear state space models and the Kalman filter. Quantitative Finance, 16(10), 1559-1573.

DiBartolomeo, D., \& Witkowski, E. (1997). Mutual fund misclassification: Evidence based on style analysis. Financial Analysts Journal, 53(5), 32-43.

Elton, E. J., Gruber, M. J., \& Blake, C. R. (2001). A first look at the accuracy of the CRSP mutual fund database and a comparison of the CRSP and Morningstar mutual fund databases. The Journal of Finance, 56(6), 2415-2430.

Egan, M., Matvos, G., \& Seru, A. (2016). The market for financial adviser misconduct (No. w22050). National Bureau of Economic Research.

Evans, R. B., \& Fahlenbrach, R. (2012). Institutional investors and mutual fund governance: Evidence from retail-institutional fund twins. The Review of Financial Studies, 25(12), 3530-3571.

Engle, R. F., \& Granger, C. W. (1987). Co-integration and error correction: representation, estimation, and testing. Econometrica: journal of the Econometric Society, 251-276.

Fama, E. F., \& French, K. R. (1992). The cross-section of expected stock returns. the Journal of Finance, 47(2), 427-465.

Fama, E. F., \& French, K. R. (1993). Common risk factors in the returns on stocks and bonds. Journal of financial economics, 33(1), 3-56. 
Fama, Eugene F., and James D. MacBeth. "Risk, return, and equilibrium: Empirical tests." The Journal of Political Economy (1973): 607-636.

Frijns, B., Gilbert, A., \& Zwinkels, R. C. (2016). On the Style-Based Feedback Trading of Mutual Fund Managers. Journal of Financial and Quantitative Analysis, 51(3), 771-800.

Froot, K., \& Teo, M. (2008). Style investing and institutional investors. Journal of Financial and Quantitative Analysis, 43(4), 883-906.

Gao, X., \& Chan, L. (2000). An algorithm for trading and portfolio management using Q-learning and sharpe ratio maximization. In Proceedings of the international conference on neural information processing (pp. 832-837).

Gatev, E., Goetzmann, W. N., \& Rouwenhorst, K. G. (2006). Pairs trading: Performance of a relative-value arbitrage rule. The Review of Financial Studies, 19(3), 797-827.

Gil-Bazo, J., \& Ruiz-Verdú, P. A. B. L. O. (2009). The relation between price and performance in the mutual fund industry. The Journal of Finance, 64(5), 21532183.

Glantz, M., \& Kissell, R. (2013). Multi-asset risk modeling: techniques for a global economy in an electronic and algorithmic trading era. Academic Press.

Goyal, A., \& Wahal, S. (2008). The selection and termination of investment management firms by plan sponsors. The Journal of Finance, 63(4), 1805-1847.

Grinold, R. C. (1999). Mean-variance and scenario-based approaches to portfolio selection. The Journal of Portfolio Management, 25(2), 10-22.

Gruber, M. J. (1996). Another puzzle: The growth in actively managed mutual funds. The journal of finance, 51(3), 783-810.

Guercio, D. D., \& Reuter, J. (2014). Mutual fund performance and the incentive to generate alpha. The Journal of Finance, 69(4), 1673-1704.

Granger, C. W. (1981). Some properties of time series data and their use in econometric model specification. Journal of econometrics, 16(1), 121-130.

Granger, C. W. (1981). Some properties of time series data and their use in econometric model specification. Journal of econometrics, 16(1), 121-130. 
Hendershott, T., Jones, C. M., \& Menkveld, A. J. (2011). Does algorithmic trading improve liquidity? The Journal of Finance, 66(1), 1-33.

Holm, S. (1979). A simple sequentially rejective multiple test procedure. Scandinavian journal of statistics, 65-70.

Holmes, K. A., \& Faff, R. W. (2007). Style drift, fund flow and fund performance: new cross-sectional evidence. Financial Services Review, 16(1), 55.

Huang, C. F., Hsu, C. J., Chen, C. C., Chang, B. R., \& Li, C. A. (2015). An intelligent model for pairs trading using genetic algorithms. Computational intelligence and neuroscience, 2015, 16.

Huang, J., Sialm, C., \& Zhang, H. (2011). Risk shifting and mutual fund performance. The Review of Financial Studies, 24(8), 2575-2616.

Huang, J., Wei, K. D., \& Yan, H. (2007). Participation costs and the sensitivity of fund flows to past performance. The Journal of Finance, 62(3), 1273-1311.

Huck, N., \& Afawubo, K. (2015). Pairs trading and selection methods: is cointegration superior?. Applied Economics, 47(6), 599-613.

Indro, D. C., Jiang, C. X., Hu, M. Y., \& Lee, W. Y. (1998). Mutual fund performance: a question of style. The Journal of Investing, 7(2), 46-53.

Idzorek, T. M., \& Bertsch, F. (2004). The style drift score. The Journal of Portfolio Management, 31(1), 76-83.

Ippolito, R. A. (1992). Consumer reaction to measures of poor quality: Evidence from the mutual fund industry. The Journal of Law and Economics, 35(1), 45-70.

James, C., \& Karceski, J. (2006). Investor monitoring and differences in mutual fund performance. Journal of Banking \& Finance, 30(10), 2787-2808.

Johansen, S. (1988). Statistical analysis of cointegration vectors. Journal of economic dynamics and control, 12(2-3), 231-254.

Kacperczyk, M., Sialm, C., \& Zheng, L. (2005). On the industry concentration of actively managed equity mutual funds. The Journal of Finance, 60(4), 1983-2011.

Kacperczyk, M., Sialm, C., \& Zheng, L. (2006). Unobserved actions of mutual funds. The Review of Financial Studies, 21(6), 2379-2416. 
Kacperczyk, M., \& Schnabl, P. (2013). How safe are money market funds?. The Quarterly Journal of Economics, 128(3), 1073-1122.

Kawasaki, Y., Tachiki, S., Udaka, H., \& Hirano, T. (2003, March). A characterization of long-short trading strategies based on cointegration. In Computational Intelligence for Financial Engineering, 2003. Proceedings. 2003 IEEE International Conference on (pp. 411-416). IEEE.

Kempf, E., Manconi, A., \& Spalt, O. G. (2016). Learning by doing: The value of experience and the origins of skill for mutual fund managers.

Keswani, A., \& Stolin, D. (2008). Which money is smart? Mutual fund buys and sells of individual and institutional investors. The Journal of Finance, 63(1), 85-118.

Khorana, A. (2001). Performance changes following top management turnover: Evidence from open-end mutual funds. Journal of Financial and Quantitative Analysis, 36(3), 371-393.

Kim, M., Shukla, R., \& Tomas, M. (2000). Mutual fund objective misclassification. Journal of Economics and Business, 52(4), 309-323.

Kim, T. H., White, H., \& Stone, D. (2005). Asymptotic and Bayesian confidence intervals for Sharpe-style weights. Journal of Financial Econometrics, 3(3), 315343.

Lee, J. W. (2001). Stock price prediction using reinforcement learning. In Industrial Electronics, 2001. Proceedings. ISIE 2001. IEEE International Symposium on (Vol. 1, pp. 690-695). IEEE.

Lee, J. W., Park, J., Jangmin, O., Lee, J., \& Hong, E. (2007). A Multiagent Approach to \$Q \$-Learning for Daily Stock Trading. IEEE Transactions on Systems, Man, and Cybernetics-Part A: Systems and Humans, 37(6), 864-877.

Lobosco, A., \& DiBartolomeo, D. (1997). Approximating the confidence intervals for Sharpe style weights. Financial Analysts Journal, 53(4), 80-85.

Lynch, A. W., \& Musto, D. K. (2003). How investors interpret past fund returns. The Journal of Finance, 58(5), 2033-2058.

Mason, A., McGroarty, F., \& Thomas, S. (2012). Style analysis for diversified US equity funds. Journal of Asset Management, 13(3), 170-185. 
Moody, J., \& Saffell, M. (2001). Learning to trade via direct reinforcement. IEEE transactions on neural Networks, 12(4), 875-889.

Muslumov, A., Yuksel, A., \& Yuksel, S. A. (2009). The profitability of pairs trading in an emerging market setting: evidence from the Istanbul stock exchange.

Nanda, V. K., Wang, Z. J., \& Zheng, L. (2009). The ABCs of mutual funds: On the introduction of multiple share classes. Journal of Financial Intermediation, 18(3), 329-361.

Nanda, V. K., Wang, Z. J., \& Zheng, L. (2009). The ABCs of mutual funds: On the introduction of multiple share classes. Journal of Financial Intermediation, 18(3), 329-361.

Pástor, L., Stambaugh, R. F., \& Taylor, L. A. (2015). Scale and skill in active management. Journal of Financial Economics, 116(1), 23-45.

Parida, S., \& Teo, T. (2018). The impact of more frequent portfolio disclosure on mutual fund performance. Journal of Banking \& Finance, 87, 427-445.

Petajisto, A. (2013). Active share and mutual fund performance. Financial Analysts Journal, 69(4), 73-93.

Perlin, M. S. (2009). Evaluation of pairs-trading strategy at the Brazilian financial market. Journal of Derivatives \& Hedge Funds, 15(2), 122-136.

Puspaningrum, H., Lin, Y. X., \& Gulati, C. M. (2010). Finding the optimal pre-set boundaries for pairs trading strategy based on cointegration technique. Journal of Statistical Theory and Practice, 4(3), 391-419.

Puspaningrum, H., Lin, Y. X., \& Gulati, C. M. (2010). Finding the optimal pre-set boundaries for pairs trading strategy based on cointegration technique. Journal of Statistical Theory and Practice, 4(3), 391-419.

Sensoy, B. A. (2009). Performance evaluation and self-designated benchmark indexes in the mutual fund industry. Journal of Financial Economics, 92(1), 25-39.

Sharpe, W. F. (1988). Determining a fund's effective asset mix. Investment management review, 2(6), 59-69.

"Asset allocation: Management style and performance measurement." The Journal of Portfolio Management 18.2 (1992): 7-19. 
Bibliography

Sirri, E. R., \& Tufano, P. (1998). Costly search and mutual fund flows. The journal of finance, 53(5), 1589-1622.

Sutton, R. S., \& Barto, A. G. (1998). Reinforcement learning: An introduction (Vol. 1, No. 1). Cambridge: MIT press.

Swinkels, L., \& Tjong-A-Tjoe, L. (2007). Can mutual funds time investment styles? Journal of Asset Management, 8(2), 123-132.

Swinkels, L., \& Van Der Sluis, P. J. (2006). Return-based style analysis with timevarying exposures. The European Journal of Finance, 12(6-7), 529-552.

Tan, Z., Quek, C., \& Cheng, P. Y. (2011). Stock trading with cycles: A financial application of ANFIS and reinforcement learning. Expert Systems with Applications, 38(5), 4741-4755.

ter Horst, J. R., Nijman, T. E., \& de Roon, F. A. (2004). Evaluating style analysis. Journal of Empirical Finance, 11(1), 29-53.

Tourin, A., \& Yan, R. (2013). Dynamic pairs trading using the stochastic control approach. Journal of Economic Dynamics and Control, 37(10), 1972-1981.

Wermers, R. (2001). The potential effects of more frequent portfolio disclosure on mutual fund performance. Perspective, 7(3), 1-11.

Wermers, R. (2012). Matter of style: The causes and consequences of style drift in institutional portfolios.

Zeng, Z., \& Lee, C. G. (2014). Pairs trading: optimal thresholds and profitability. Quantitative Finance, 14(11), 1881-1893.

Zhang, Q. (2001). Stock trading: An optimal selling rule. SIAM Journal on Control and Optimization, 40(1), 64-87. 
Curriculum Vitae 
Ehsan Ramezanifar was born on $22^{\text {nd }}$ of March 1987 in Mashhad, Iran. In 2010, he obtained a BSc in Industrial Engineering from Ferdowsi University of Mashhad (Mashhad, Iran). During his bachelor's studies, Ehsan managed to publish two scientific papers and obtained the top student award of Industrial Engineering department. After his bachelor program, he started teaching at a university and working for some industrial companies for one year. He then continued his studies by joining the master program in Financial Engineering at Tehran University. In 2014 he successfully defended his master thesis under the title of "Fractional cointegration approach" and obtained his MSc. During his master's program, Ehsan joined AAICCO, financial consulting company (Tehran, Iran) as a junior financial analyst. One year later, he was promoted to a senior financial analyst and after a few months he became the head of the financial engineering department.

In September 2014, he started his PhD in Finance in the School of Business and Economics at Maastricht University. Ehsan's field of research is asset management and risk management, and his academic papers have been presented in various conferences such as the annual meeting of the American Finance Association (Philadelphia 2018 and Chicago 2017), the annual meeting of the Financial Management Association (Boston 2017), French Finance Association conference (Liege 2016), Australian Finance and Banking conference (Sydney 2015), Auckland Finance Meeting (Auckland 2015). In fall 2016, he visited the finance department of University of California, San-Diego (UCSD) for six-month. During the visit, his research was substantially inspired by Harry Markowitz and Allan Timmermann.

Beside his $\mathrm{PhD}$, he collaborated with various international investment companies as a financial consultant. Finally, as of September 2017, Ehsan has joined the School of Economics at Utrecht University and also the Finance Department of Open University (Heerlen, the Netherlands) as an assistant professor of finance. 

